\title{
2 Wheat
}

Rajeev K. Varshney ${ }^{1}$, Harindra S. Balyan ${ }^{2}$, and Peter Langridge ${ }^{3}$

${ }^{1}$ International Crops Research Institute for the Semi-Arid Tropics (ICRISAT), Patancheru-502, 324 (A.P.), India, e-mail: r.k.varshney@cgiar.org

2 Molecular Biology Laboratory, Department of Genetics and Plant Breeding, Ch. Charan Singh University, Meerut-250, 004 U.P. India

${ }^{3}$ Australian Centre for Plant Functional Genomics (ACPFG), University of Adelaide, Waite Campus, PMB 1 Glen Osmond, SA 5064, Australia

\section{1}

\section{Introduction}

The wheats (Triticum spp.) belong to the Poaceae, the largest family within the monocotyledonous plants. Bread wheat (Triticum aestivum L. em. Thell) is one of the most important cereal grain crops of the world and is cultivated over a wide range of climatic conditions. Global production of bread wheat in 2003 was $557 \mathrm{Mt}$, with an average yield of $2.68 \mathrm{t} / \mathrm{ha}$ (http://apps.fao.org/). The world's major bread wheatproducing areas are in northern China, northern India, northern USA and adjoining areas in Canada, northern and central Europe, western Russia, southern Australia, southern Latin America and South Africa. Worldwide, wheat provides nearly $55 \%$ of the carbohydrate and $20 \%$ of the food calories consumed globally (Breiman and Graur 1995).

Wheat is one of the most extensively studied crop species, particularly in the area of cytogenetics. An extensive catalogue of genetic and cytogenetic stocks was developed in the years following the groundbreaking isolation of aneuploid lines by Sears (1954). This work led to the concept of chromosome engineering, which takes advantage of the effect of the $\mathrm{Ph}$ genes. These genes restrict pairing and recombination to homologous chromosomes (Riley and Chapman 1958). Wheat provides a model system for the study of polyploid cytogenetics because of the ease of chromosome manipulation. The pioneering cytogenetic work by Kihara, Sakamura, Sax, Sears, Riley and others (Riley and Chapman 1958; Riley 1965) showed that the species of the genus Triticum form a polyploid series, with a basic number of $x=7$. Thus there are the diploid $(2 n=2 x=14)$, tetraploid $(2 n=4 x=28)$ and hexaploid $(2 n=6 x=42)$ species. Most modern cultivated wheat varieties are hexaploid (T. aestivum), described as 'common' or 'bread' wheat and valued for bread making. Bread wheat is a segmental allopolyploid containing the three distinct but genetically related (homoeologous) genomes A, B and D. It also has a very large genome $\left(1.8 \times 10^{10} \mathrm{bp}\right)$, making an average wheat chromosome about 25 -fold larger in terms of DNA content than the average rice chromosome (Moore et al. 1995b). Thus three wheat chromosomes carry the same DNA content of the entire haploid maize genome, and half of an average wheat chromosome is equivalent to the haploid rice genome (Gill and Gill 1994). The large genome size of bread wheat is due to extensive regions of retrotransposon-type elements such that over $80 \%$ of the genome consists of repetitive DNA sequence (Schulman et al. 2004). In contrast to the suitability of bread wheat for cytogenetic studies, the application of molecular techniques has been slow (Lagudah et al. 2001; Langridge et al. 2001). Many molecular markers are unable to detect an adequate and useful polymorphism for the construction of molecular maps, and consequently applications of marker-assisted selection (MAS) applications have been limited. However, despite these problems, some success has been achieved in recent years, and molecular genetic as well as physical maps have become available for the chromosomes of all homoeologous groups (Gupta et al. 1999; Varshney et al. 2004a). Molecular markers are increasingly being used to tag genes or QTLs (quantitative trait loci) of agronomic importance, offering the possibility of their use in marker-assisted selection (MAS) for wheat breeding (Gupta et al. 1999; Jahoor et al. 2004). In addition to their use in MAS, molecular markers have begun to be used to isolate genes via map-based cloning (Stein and Graner 2004). Some molecular markers detect homoeoloci; that is, the same sequence is present 
on all three members of a homoeologous group. Such homoeoloci have helped in the construction of comparative maps in different cereals, and these sometimes demonstrate the presence of major translocations thought to have occurred during speciation. In this article, we review recent progress related to the generation of genetic and physical maps in wheat and their applications for a variety of purposes including gene tagging for MAS, map-based cloning, diversity studies and comparative mapping in cereals. The impact of functional genomics and other recent approaches such as association mapping and genetical genomics on wheat breeding in the near future is also discussed.

\section{2 \\ Molecular Markers - Types and Availability}

Recent advances in molecular techniques have led to the development of assays based on variation in DNA sequence, broadly referred to as DNA (or molecular) markers (Langridge and Chalmers 2004). DNA markers provide good resolutio because, unlike most non-DNA-based markers (morphological, biochemical or physiological), they are (1) unlimited in number, (2) independent of environment, developmental stage and complex genetic interactions, (3) frequently free of dominant and recessive effects and (4) easy to score, analyse and interpret. The DNA markers that have been used for the construction of molecular maps are broadly classified into three groups: the first-generation markers, RFLPs (restriction fragment length polymorphisms) and RAPDs (randomly amplified polymorphic DNAs); the second-generation markers, SSRs (simple sequence repeats or microsatellites) and AFLPs (amplified fragment length polymorphisms); and the third-generation markers, SNPs (single nucleotide polymorphisms) and InDels (insertion-deletions) (for details see Gupta et al. 2002b; Varshney et al. 2004a; Mohler and Schwarz 2004). In addition, an array of marker types have been developed amongst which are STSs (sequence tagged sites), SCARs (sequence characterized amplified regions), ISSRs (intersimple sequence repeats), and SAMPL (selective amplification of microsatellite polymorphic loci). More recently, EST (expressed sequence tag)based markers (EST-SSRs and EST-SNPs) have been developed in wheat (Varshney et al. 2004a).
Retrotransposon sequences (which are present in high-copy numbers), both alone or in combination with microsatellites or AFLPs, have been exploited to generate IRAPs (interretrotransposon amplified polymorphisms), REMAPs (retrotransposonmicrosatellite amplified polymorphisms) and SSAPs (sequence-specific amplified polymorphisms) (Schulman et al. 2004). Each marker system has particular advantages and disadvantages (Gupta et al. 2002b) and user choice is best based on objective, convenience and cost. All these marker types, except the SNPs, have been incorporated into current molecular maps, and efforts are currently under way to construct SNP maps of wheat (Varshney et al. 2004a).

The accepted nomenclature for DNA marker loci and alleles in wheat and related species is published every 4 years in the Proceedings of the International Wheat Genetics Symposium (for the most recent edition see Proc of the 10th Int Wheat Genet Symp, Paestum, Italy, 2003), and an annual supplement is published in the Annual Wheat Newsletter (http://wheat.pw.usda.gov/ggpages/awn/). The catalogue lists all Triticum genes, RFLPs, SSRs, STSs, AFLPs, etc. that have been localized to a chromosome or chromosome arm, all known alleles of Triticum genes and prototype strains for each allele, the chromosomal locations of genetic markers, the linkage position of mapped genes, literature citations and other relevant information.

\section{3}

\section{Construction of Molecular Maps}

Early genetic maps were based entirely on morphological and biochemical markers. However, these maps had poor resolution, as marker number was limited and allelic variants were frequently restricted to exotic germplasm, precluding their usefulness in breeding programmes. Molecular markers detect both sequence (for example SNPs, resulting in RFLPs, RAPDs, AFLPs, etc.) and length polymorphisms (polymorphisms due to length variation of a sequence, as in SSRs and sometimes also in RFLPs). These loci usually segregate in a Mendelian manner, so that the conventional basis of linkage and recombination can be used for constructing these maps. A major advantage of molecular mapping is the possibility of analysing a large number of markers in a single mapping population. Therefore, DNA-based markers have been used 
for the construction of maps with a high marker density in almost all major crops including cereals (Varshney et al. 2004a). These maps have found application for gene tagging, QTL identification, and for the characterization of germplasm collections (Gupta et al. 1999; Langridge and Chalmers 2004). The aneuploid and deletion stocks in the type variety Chinese Spring have allowed the alignment of physical and genetic maps, and this has provided an insight into the physical and genetic organization of the wheat genome.

\subsection{1}

\section{Genetic Maps}

RFLPs were developed for mapping in the human genome (Botstein et al. 1980). Subsequently, they were adapted for use in mapping plant genomes (Bernatzky and Tanksley 1986; Weber and Helentjaris 1989) including bread wheat (Chao et al. 1989; Liu and Tsunewaki 1991). Disappointingly, RFLPs have only been able to detect a low level of polymorphism in wheat. This has been attributed variously to its polyploid nature, its high proportion of repetitive DNA, its large genome size and its recent origin (ca. 10,000 years ago). Thus in an effort to maximize the diversity between the parents of mapping populations, a standard hexaploid variety was crossed with a synthesized hexaploid (a chromosome-doubled hybrid of the wide cross tetraploid T. turgidum x diploid Aegilops tauschii) to produce a reference mapping population known as the ITMI population (Langridge et al. 2001). Alternatively, the three constituent genomes have been analysed at the diploid level. This involves generation of populations from specimen diploids $A e$. tauschii (D genome) (Boyko et al. 1999, 2002) and T. monococcum (A genome) (Dubcovsky et al. 1996). Mapping populations have included $\mathrm{F}_{2}$ populations, $\mathrm{F}_{3}$ families, bulked $\mathrm{F}_{4}$ families and recombinant inbred line (RIL) populations, and, in some cases, doubled haploids (DHs) and recombinant substitution lines (RSLs). RSLs, DHs and RILs have the particular advantage of being immortal, while $\mathrm{F}_{2}$ populations, $\mathrm{F}_{3}$ families and bulked $\mathrm{F}_{4}$ families are easier to produce.

Using various mapping populations, a number of RFLP-based maps have been constructed both for individual chromosomes and for the entire wheat genome (Table 1). RFLP genotyping is time consuming and labour intensive and is therefore unsuitable for the rapid evaluation of large segregating populations typically encountered in commercial breeding programmes (Gale et al. 1995). The first replacement PCR-based technology was RAPDs, and these have been used for mapping many species including Arabidopsis (Reiter et al. 1992), barley (Giese et al. 1994) and rye (Masojć et al. 2001). In wheat, RAPDs have been of limited use, partly because of the low level of polymorphism that they uncover, but also because of poor reproducibility. Critically, RAPD alleles are usually dominant, and therefore a heterozygous genotype cannot be distinguished from one of the related homozygotes. A more profound disadvantage of the system is that a given pair of similarly sized RAPD products amplified from two genotypes may not represent homologous sequences (Devos and Gale 1992). As with RAPDs, AFLPs are commonly dominant markers. However, AFLP is a superior platform, due both to its greater robustness, and to its delivery of a far higher multiplex ratio (the number of distinct loci analysed per primer pair and per gel lane) (Ma and Lapitan 1998). AFLP has found its greatest application in fingerprinting studies (see later), but also to some extent in mapping. A number of genetic maps have incorporated AFLP loci, but usually associated with an RFLP and/or SSR backbone (Table 1). More recently, microsatellites (SSRs) have become the favoured markers. Their advantages include multi-allelism, codominant inheritance, relative abundance and extensive genome coverage (Gupta and Varshney 2000). Microsatellite markers for wheat have been generated from a number of sources, including the John Innes Centre (JIC), Norwich, UK (Stephenson et al. 1998), IPK, Gatersleben, Germany (Röder et al. 1998b), the Wheat Microsatellite Consortium (WMC; Varshney et al. 2000a; Gupta et al. 2002a), Beltsville Agricultural Research Centre (BARC; Song et al. 2002a,b) and the Genoplante/INRA Wheat SSR Club (http://wheat.pw.usda.gov/ggpages/SSRclub/; Guyomarc'h et al. 2002; Nicot et al. 2004). To date the densest microsatellite-based map of wheat contains 1,238 loci covering $2,569 \mathrm{cM}$ with an average interval distance of $2.2 \mathrm{cM}$ (Somers et al. 2004). In addition, wheat ESTs have also been exploited to generate the microsatellite (EST-SSR) markers in wheat (see later). A detailed account on development and application of microsatellite markers in wheat is available in a recent review by Röder et al. (2004).

Emphasis in marker research is now beginning to shift to the development of SNP markers, which are biallelic and are extremely abundant. SNPs have the potential to deliver very high throughput and 
Table 1. A list of some important genetic maps constructed in wheats ${ }^{\mathrm{a}}$

\begin{tabular}{|c|c|c|c|c|}
\hline Map type & Population used for mapping & $\begin{array}{l}\text { Number of } \\
\text { loci mapped }\end{array}$ & $\begin{array}{l}\text { Genetic map } \\
\text { length }(\mathrm{cM})\end{array}$ & Reference \\
\hline \multicolumn{5}{|l|}{ RFLP maps } \\
\hline Wheat (Group 1) & ITMI RILs (W7984 × Opata85) & 98 & 146 to 344 & Van Deynze et al. (1995a) \\
\hline Wheat (Group 2) & $\begin{array}{l}\text { F2/F3s (Chinese Spring } \times \\
\text { SyntheticTimgalen) }\end{array}$ & 114 & - & Devos et al. (1993b) \\
\hline Wheat (Group 2) & ITMI RILs (W7984 × Opata85) & 173 & $\sim 600$ & Nelson et al. (1995b) \\
\hline Wheat (Group 3) & $\begin{array}{l}\text { F2/F3s (Chinese Spring } \times \\
\text { SyntheticTimgalen) }\end{array}$ & $\sim 60$ & - & $\begin{array}{l}\text { Devos et al. (1992) } \\
\text { Devos and Gale (1993) }\end{array}$ \\
\hline Wheat (Group 3) & ITMI RILs (W7984 × Opata85) & 160 & $\sim 660$ & Nelson et al. (1995c) \\
\hline Wheat (Group 4) & ITMI RILs (W7984 × Opata85) & 98 & - & Nelson et al. (1995a) \\
\hline Wheat (Group 5) & $\begin{array}{l}\text { F2/F3s (Chinese Spring } \times \\
\text { SyntheticTimgalen) }\end{array}$ & $\sim 50$ & - & Xie et al. (1993) \\
\hline Wheat (Group 5) & ITMI RILs (W7984 × Opata85) & 118 & - & Nelson et al. (1995a) \\
\hline Wheat (Group 6) & ITMI RILs (W7984 × Opata85) & 154 & 516 & Marino et al. (1996) \\
\hline Wheat (Group 6) & F2/F3s (Chinese Spring $\times$ Synthetic) & 62 & 317 & Jia et al. (1996) \\
\hline Wheat (Group 7) & ITMI RILs (W7984 × Opata85) & 109 & - & Nelson et al. (1995a) \\
\hline Wheat & $\begin{array}{l}\text { F2s (T. aestivum var. Chinese Spring } \times \\
\text { T. spelta var. Duha) }\end{array}$ & 197 & - & Liu and Tsunewaki (1991) \\
\hline Wheat & DHs (Chinese Spring $\times$ Courtot) & 264 & 1,772 & Cadalen et al. (1997) \\
\hline Wheat & $\begin{array}{l}\text { RILs (T. aestivum cv. Chinese Spring } \times \\
\text { T. spelta var. duhamelianum K19-1) }\end{array}$ & 320 & 3,451 & $\begin{array}{l}\text { Sasakuma and Shindo } \\
(2003)\end{array}$ \\
\hline Wheat-durum & $\begin{array}{l}\text { RILs ( T. durum var. Messapia } \times \\
\text { T. turgidium var. MG4343) }\end{array}$ & 245 & - & Blanco et al. (1998) \\
\hline Wheat-diploid & $\begin{array}{l}\text { F2s (T.monococcum KT3-5 } \times \\
\text { T. Boeoticum KT1-1) }\end{array}$ & 115 & 1,250 & $\begin{array}{l}\text { Sasakuma and Shindo } \\
\text { (2003) }\end{array}$ \\
\hline \multicolumn{5}{|l|}{ SSR maps } \\
\hline Wheat & ITMI RILs (W7984 × Opata85) & 279 & - & Roder et al. (1998b) \\
\hline Wheat & F2s (Chinese Spring $\times$ Synthetic) & 53 & & Stephenson et al. (1998) \\
\hline Wheat & ITMI RILs (W7984 × Opata85) & 65 & & Pestsova et al. (2000) \\
\hline Wheat & DHs & 172 & - & Harker et al. (2001) \\
\hline Wheat & ITMI RILs (W7984 × Opata85) & 65 & - & Gupta et al. (2002a) \\
\hline Wheat & $\begin{array}{l}4 \text { mapping populations }(\text { W7984 } \times \\
\text { Opata85, Courtot } \times \text { Chinese Spring, } \\
\text { Eureka } \times \text { Renan; Arche } \times \text { Recital })\end{array}$ & 533 & - & Gandon et al. (2002) \\
\hline Wheat & RIL (Courtot $\times$ Chinese Spring) & 84 & - & Guyomarc'h et al. (2002) \\
\hline Wheat & ITMI RILs (W7984 × Opata85) & 168 & - & Song et al. $(2002 a, b)$ \\
\hline Wheat & F2:3s (ND3338 x F390) & 247 & 3,067 & Liu et al. (2003) \\
\hline Wheat & $\begin{array}{l}3 \text { DHs (RL4452 } \times \text { AC Domain, Wuhan } \times \\
\text { Maringa, Superb } \times \text { BW278) and ITMI } \\
\text { RILs (W7984 } \times \text { Opata85) }\end{array}$ & 1,235 & 2,569 & Somers et al. (2004) \\
\hline Wheat & ITMI RILs (W7984 × Opata85) & 825 & - & Nicot et al. (2003a) \\
\hline Wheat & ITMI RILs (W7984 × Opata85) & 61 (eSSRs) & - & Nicot et al. (2003b) \\
\hline Wheat & ITMI RILs (W7984 × Opata85) & 126 (eSSRs) & - & Nicot et al. (2004) \\
\hline Wheat & ITMI RILs (W7984 × Opata85) & 101 (eSSRs) & - & Gao et al. (2004) \\
\hline Wheat & ITMI RILs (W7984 × Opata85) & 149 (eSSRs) & - & Yu et al. (2004b) \\
\hline Wheat & ITMI RILs (W7984 × Opata85) & 876 (eSSRs) & - & Peng et al. (2004a) \\
\hline Wheat & ITMI RILs (W7984 × Opata85) & 638 & - & Röder et al. (2004b) \\
\hline Wheat-durum & $\begin{array}{l}\text { RILs (T. Durum var. Messapia } \times \\
\text { T. Turgidium var. MG4343) }\end{array}$ & 79 & - & Korzun et al. (1999) \\
\hline Wheat-durum & RILs (T.turgidum subsp. Durum) & 112 & - & Jurman et al. (2003) \\
\hline
\end{tabular}


Table 1. (continued)

\begin{tabular}{|c|c|c|c|c|}
\hline Map type & Population used for mapping & $\begin{array}{l}\text { Number of } \\
\text { loci mapped }\end{array}$ & $\begin{array}{l}\text { Genetic map } \\
\text { length }(\mathrm{cM})\end{array}$ & Reference \\
\hline \multicolumn{5}{|l|}{ AFLP maps } \\
\hline Wheat & DHs (Garnet $\times$ Saunders) & 426 & - & Penner et al. (1998) \\
\hline Wheat & ITMI RILs (W7984 × Opata85) & 140 & - & Hazen et al. (2002) \\
\hline \multicolumn{5}{|l|}{ Composite maps } \\
\hline Aegilops tauschii & $\begin{array}{l}\text { F2s [Ae. tauschii var meyeri (TA1691) } \times \\
\text { Ae. tauschii var typical (TA1704)] }\end{array}$ & 732 & - & Boyko et al. 2002 \\
\hline Wheat-einkorn & $\begin{array}{l}\text { F2s }(T . \text { monococcum } \times \text { T. boeoticum } \\
\text { ssp. boeoticum })\end{array}$ & $\begin{array}{c}81 \\
\text { (RFLPs, RAPDs, } \\
\text { ISSRs) }\end{array}$ & - & Kojima et al. (1998) \\
\hline Wheat-einkorn & $\begin{array}{l}\text { F2s/ F3s (T. monococcum ssp. } \\
\text { monococcum DV } 92 \times \text { T. monococcum ssp. } \\
\text { Aegilopoides C3116) }\end{array}$ & $\begin{array}{c}335 \\
\text { (mainly RFLPs) }\end{array}$ & 714 & Dubcovsky et al. (1996) \\
\hline Wheat-durum & $\begin{array}{l}\text { RILs [T. durum (Messapia) } \times \\
\text { T. turgidium (MG4343)] }\end{array}$ & $\begin{array}{c}88 \\
\text { (AFLPs, RFLPs) }\end{array}$ & 2,063 (total) & Lotti et al. (2000) \\
\hline Wheat-durum & $\begin{array}{l}\text { F2s (T. dicoccoides acc. Hermon } \mathrm{H} 52 \times \\
\text { T. durum cultivar Langdon (Ldn) }\end{array}$ & $\begin{array}{c}545 \\
\text { (AFLPs, RAPDs, } \\
\text { SSRs) }\end{array}$ & $3,169-3,180$ & Peng et al. (2000b) \\
\hline Wheat-durum & RILs (Jennah Khetifa $\times$ Cham 1 ) & $\begin{array}{l}306 \\
\text { (RFLPs, SSRs } \\
\text {, AFLPs) }\end{array}$ & 3,598 & Nachit et al. (2001) \\
\hline Wheat-durum & $\begin{array}{l}\text { RILs }(\text { Omrabi5 } \times \text { T.dioccoides } 600545 \times \\
\text { Ombrabi 5) }\end{array}$ & $\begin{array}{c}279 \\
(\mathrm{RFLP}, \mathrm{SSR}, \mathrm{SSP})\end{array}$ & 2,289 & Elouafi and Nachit (2004) \\
\hline Wheat-emmer & RILs & $\begin{array}{l}549 \\
\text { (SSRs, AFLPs, } \\
\text { RAPDs) }\end{array}$ & & Nevo (2001) \\
\hline Wheat & DHs (Schomburgk $\times$ Yarralinka) & $\begin{array}{l}147 \\
\text { (RFLPs, SSRs, } \\
\text { AFLPs) }\end{array}$ & - & Parker et al. (1998) \\
\hline Wheat & $\begin{array}{l}\text { RILs (T. aestivum L. var. Forno } \times \\
\text { T. spelta L. var. Oberkulmer) }\end{array}$ & $\begin{array}{c}230 \\
\text { (RFLPs, SSRs) }\end{array}$ & 2,469 & Messmer et al. (1999) \\
\hline Wheat & $\begin{array}{l}\text { DHs (Cranbook } \times \text { Halbred, CD } 87 \times \\
\text { Katepwa, Sunco } \times \text { Tasman })\end{array}$ & $\begin{array}{l}355 \text { to } 902 \\
\text { (RFLPs, SSRs, } \\
\text { AFLPs) }\end{array}$ & - & Chalmers et al. (2001) \\
\hline Wheat & DHs (Courtot $\times$ Chinese Spring) & $\begin{array}{l}380 \\
\text { (RFLP, SSRs, } \\
\text { AFLPs) }\end{array}$ & 2,900 & Sourdille et al. (2000b) \\
\hline Wheat & DHs (Courtot $\times$ Chinese Spring) & $\begin{array}{l}659 \\
\text { (RFLP, SSRs, } \\
\text { AFLPs) }\end{array}$ & 3,685 & Sourdille et al. (2003) \\
\hline Wheat & F5s $($ Arina $\times$ Forno $)$ & $\begin{array}{c}396 \\
\text { (RFLPs, SSRs) }\end{array}$ & 3,086 & Paillard et al. (2003) \\
\hline Wheat & DHs (Beaver x Soissons) & $\begin{array}{c}241 \\
\text { (AFLPs, SSRs) }\end{array}$ & 2,290 & Verma et al. (2004) \\
\hline
\end{tabular}

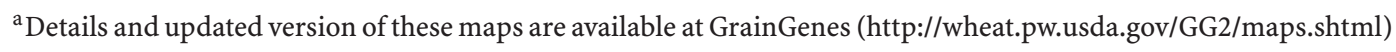


automation. In the human genome, 1.8 million SNPs have been documented (http://snp.cshl.org/). In an international consortium, an attempt has been made to mine for SNPs from the massive amounts of wheat EST sequence available on public databases (http://wheat.pw.usda.gov/ ITMI/2002/WheatSNP.html). Using this approach, Somers et al. (2003b) estimated SNP frequency as 1 every $540 \mathrm{bp}$, and efforts are under way to develop SNP markers in wheat (Mochida et al. 2003; Ogihara 2003).

Integrated (or 'composite') maps including more than one type of molecular marker (particularly RFLPs, SSRs and AFLPs) have also been prepared (Table 1). These maps typically have higher resolution than those based on a single marker type because they exploit a larger number of loci.

Comparisons between specific chromosomal regions across related species usually show that locus order (but not map distance) is highly conserved. Consequently, the construction of 'consensus maps' has become possible, where common markers are used as anchors and the position of other loci mapping in interstitial positions is extrapolated (for example, in barley, see Varshney et al. 2004b). In this way, 4,000 loci from 16 independent maps have been integrated into a single map (Appels 2003). This consensus map has been aligned with physical maps (see later) and has recently been put forward as the backbone for a long-range wheat genomic sequencing proposal. More rigorous consensus maps that use the linkage data from multiple populations can also be constructed using computer packages such as JoinMap (Stam and Van Ooijen 1995), but this method has not yet been used to develop a consensus map of wheat.

\subsection{2}

\section{Transcript Genetic Maps or Functional Maps}

A large amount of EST data has been generated in wheat, and 587,088 sequences are currently available in the public domain (http://www.ncbi.nlm.nih.gov/ dbEST/dbEST_summary.html; 12 November 2004). From these, 44,630 TCs (tentative consensi) and 79,008 EST singletons have been identified (Sect. 3.5.1 $\mathrm{Ts}^{1}$ ). The integration of these loci into genetic maps would generate a "stranscript map"/'gene map' or 'functional map' (Schuler et al. 1996). To achieve this, each EST has to be converted into an effective marker as- say. This could be in the form of RFLP, STS, CAPS (cleaved amplified polymorphic sequences), SSR or SNP. For instance, a given EST could be amplified from genomic DNA and the PCR product obtained used as an RFLP probe in a Southern hybridization (Smilde et al. 2001); or it could be tested directly for length or sequence polymorphism between the parents of a mapping population (Gilpin et al. 1997). Sequence variation between homologous PCR products can be detected directly by sequencing, indirectly by digestion with restriction enzymes (CAPS), or by heteroduplex analysis. Many ESTs contain microsatellites, which can be targeted by conventional SSR technology (Kantety et al. 2002; Varshney et al. 2002, 2004c, 2005a). Software search programmes have been developed to identify such situations, for example MISA (Thiel et al. 2003; available at http://pgrc.ipkgatersleben.de/misa). The frequency of SSRs in wheat ESTs has been variously reported to be as high as 1 in $1.33 \mathrm{~kb}$ (Morgante et al. 2002) to as low as 1 in $17.42 \mathrm{~kb}$ (Gao et al. 2003). Discrepancies in the estimates of frequency and distribution of SSRs across different studies are probably an artefact of varying identification criteria and data quantity (Varshney et al. 2005a). Some ESTs via SSR assay (EST-SSRs) have been placed in genetic maps (Gao et al. 2004; Nicot et al. 2004; Peng et al. 2004a; Yu et al. 2004b), but they have not been integrated, to any great extent, in wheat in the way that has been done in rice (Harushima et al. 1998) and maize (Davis et al. 1999). An important feature of EST-SSR markers is their applicability across species (Holton et al. 2002; Gupta et al. 2003; Yu et al. 2004a; Varshney et al. 2005b), which makes them valuable for comparative mapping.

\subsection{3}

\section{Physical Maps}

Physical maps are based on the actual separation between markers, in terms of base pairs (or linear length, measured cytologically on metaphase mitotic chromosomes). This is in contrast with genetic distances, which are based on recombintaional frequencies. At the chromosome level, a physical map can be generated by hybridizing a labelled DNA in situ to a cytological preparation. Sites of hybridization can then be directly visualized microscopically (Schwarzacher 2003; Jiang and Gill 1994). A comparison has been made between physical and genetic distances between adjacent markers in hexaploid wheat using in situ 
hybridization (ISH) with 21 RFLP probes from linkage groups 5 and 6 (Zhang et al. 2000). Although the linear order and linkage relationships between DNA probes on these physical maps were generally conserved, a significant difference between the genetic and the physical distances was observed. However, this technique is laborious and not practicable on a genome-wide scale (Varshney et al. 2004a). An alternative strategy to physically mapping single and low-copy sequences is to generate and characterize chromosomal deletion stocks (Endo and Gill 1996). Chromosomal segments defined by these deletions have been labeled 'bins', and a large number of molecular markers including functional markers have been assigned to these bins (Table 2). In the USA a National Science Foundation-funded consortium has assigned 16,099 EST loci to 159 bins (http://wheat.pw.usda.gov/ NSF/progress_mapping.html, Qi et al. 2003, 2004). This 'transcriptome map' has an average of 766 loci per chromosome and an expected average of 95 loci per chromosome bin or $1 \mathrm{EST}$ locus per $1 \mathrm{Mb}$ of wheat DNA (Gill et al. 2003; Qi et al. 2004).

Comparing across wheat homoeologues, synteny appeared to decrease with the distance of a chromosome region from the centromere and with an increase in recombination rates along the average chromosome arm (Akhunov et al. 2003a). Furthermore, 31 paralogous sets of loci were observed with perturbed synteny. In a separate study, the physical mapping data were also used to assess organizational and evolutionary aspects of the wheat genome. It was found that recombination has played a central role in the evolution of wheat genome structure. The gradients of recombination rates along chromosome arms promoted more rapid rates of genome evolution in distal, high-recombination regions (hot spots of recombination) than in the low recombination proximal regions (Akhunov et al. 2003b; Dvorák et al. 2003).

In another project in France, a total of $725 \mathrm{mi}-$ crosatellite loci were assigned to 94 breakpoints in a homozygous (88 terminal deletions, 6 interstitial) and 5 in a heterozygous state representing 159 deletion bins with an average of $4.97 \mathrm{SSR} / \mathrm{bin}$ (Sourdille et al. 2004). Assignment of ESTs and genetically mapped SSRs to deletion bins in the above studies will be useful not only for verification of deletion stocks but also for allocating associated QTLs to deletion bins.

Physical mapping of wheat genomes using deletion lines suggests a non-random distribution of cDNA markers and ESTs (Gill et al. 1996a,b; Faris et al. 2000; Qi et al. 2003, 2004). The lower number or com- plete absence of cDNA markers in the centromeric region parallels the absence of recombination in these regions and suggests the presence of $85 \%$ of wheat genes in less than $10 \%$ of the genome. The small generich regions are thought to be interspersed by large blocks of repetitive DNA (Gill et al. 1996a,b; Sandhu and Gill 2002a; Sandhu et al. 2003; Sidhu et al. 2003). It is believed that about three to four major and four to five minor gene-rich regions are present in each wheat chromosome (Sandhu and Gill 2002b). The gene-poor regions, in contrast, mainly contain retrotransposonlike repetitive sequences (Feuillet and Keller 1999; Schulman et al. 2004). Interestingly, physical location, structural organization and gene densities of the generich regions are similar across the three genomes of hexaploid wheat (Gill et al. 1996a; for a review see Gill 2004). The resolution of this physical localization was, however, low due to a limited number of deletion lines and should improve in future with the availability of more deletion lines.

The availability of genome-wide BAC-contigs has been a prerequisite for sequencing the model genomes of Arabidopsis and rice (TAGI 2000, Sasaki and Burr 2000). Similar efforts are currently under way to prepare contig maps of the genomes of sorghum (Klein et al. 2000) and maize (Gardiner et al. 2004; http://www.maizemap.org/iMapDB/ iMap.html). As a resource for contig construction, several large insert DNA libraries have been constructed for wheat (Stein and Graner 2004). However, the large size of the wheat genome presents serious problems for the development of a full genome contig map. Nevertheless, efforts are under way to prepare a contig map of the $\mathrm{D}$ genome of wheat to produce a detailed picture of gene distribution in the wheat $\mathrm{D}$ genome and enhance our understanding of the evolution of large genomes (http://wheat.pw.usda.gov/ PhysicalMapping/). To date a total of 215,645 genomic fragments, cloned in BAC and BiBAC vectors, of an Ae. tauschii line (the $\mathrm{D}$-genome progenitor of wheat) have been fingerprinted (Luo et al. 2003). As a result, 10,035 contigs were obtained at a Sulston score of $1 \times 10^{-30}$ and a tolerance of $0.4 \mathrm{bp}$, corresponding to about 3,200 Mb (http://wheatdb.ucdavis.edu:8080/ wheatdb/). Recent developments on construction of chromosome specific BAC library would facilitate preparation of individual physical maps of wheat in the near future (Safar et al. 2004).

As an alternative to the resource-intense development of contig maps, subgenomic physical maps of wheat can also be developed using radiation hybrid 
Table 2. Some physical maps of wheat prepared after using the deletion lines

\begin{tabular}{|c|c|c|c|}
\hline Genome & Marker loci mapped & $\begin{array}{l}\text { Cytogenetic } \\
\text { stocks used }\end{array}$ & Reference \\
\hline Wheat (homoeologous group 1) & 19 RFLP & $18 \mathrm{DLs}^{\mathrm{a}}$ & Kota et al. (1993) \\
\hline Wheat (homoeologous group 1) & 50 RFLPs & 56 DLs & Gill et al. (1996a) \\
\hline Wheat (homoeologous group 1) & 2,212 loci (944 ESTs) & $101 \mathrm{DLs}$ & Peng et al. $(2003,2004 a)$ \\
\hline Wheat (homoeologous group 2) & 30 RFLPs & $21 \mathrm{DLs}$ & Delaney et al. (1995a) \\
\hline Wheat (homoeologous group 2) & 43 SSRs & $25 \mathrm{DLs}$ & Röder et al. (1998a) \\
\hline Wheat (homoeologous group 2) & 2,600 loci (1,110 ESTs) & $101 \mathrm{DLs}$ & Conley et al. (2004) \\
\hline Wheat (homoeologous group 3) & 29 RFLPs & 25 DLs & Delaney et al. (1995b) \\
\hline Wheat (homoeologous group 3) & 2,266 loci (996 ESTs) & $101 \mathrm{DLs}$ & Munkvold et al. (2004) \\
\hline Wheat (homoeologous group 4) & 40 RFLPs & 39 DLs & Mickelson-Young et al. (1995) \\
\hline Wheat (homoeologous group 4) & 1,918 loci (938 ESTs) & $101 \mathrm{DLs}$ & Miftahudin et al. (2004) \\
\hline Wheat (homoeologous group 5) & 155 RFLPs & 65 DLs & Gill et al. (1996b) \\
\hline Wheat (homoeologous group 5) & 245 RFLPs, 3 SSRs & 36 DLs & Faris et al. (2000) \\
\hline Wheat (homoeologous group 5) & 2,338 loci (1,052 ESTs) & 102 DLs & Linkiewicz et al. $(2003,2004)$ \\
\hline Wheat (homoeologous group 5S) & 100 RFLPs & 17 DLs & Qi and Gill (2001) \\
\hline Wheat (chromosome 5A) & 22 RFLPs & 19 DLs & Ogihara et al. (1994) \\
\hline Wheat (homoeologous group 6) & 24 RFLPs & 26 DLs & Gill et al. (1993) \\
\hline Wheat (homoeologous group 6) & 210 RFLPs & 45 DLs & Weng et al. (2000) \\
\hline Wheat (homoeologous group 6) & 5,154 loci (7,965 ESTs) & $101 \mathrm{DLs}$ & Randhawa et al. (2004) \\
\hline Wheat (homoeologous group 6S) & 82 RFLPs & 14 DLs & Weng and Lazar (2002a) \\
\hline Wheat (homoeologous group 7) & 16 RFLPs & 41 DLs & Werner et al. (1992) \\
\hline Wheat (homoeologous group 7) & 91 RFLPs, 6 RAPDs & 54 DLs & Hohmann et al. (1995) \\
\hline Wheat (homoeologous group 7) & 2,148 loci (919 ESTs) & $101 \mathrm{DLs}$ & Hossain et al. (2004a) \\
\hline Wheat (chromosomes 6B, 2D and 7D) & 16 SSRs & 13 DLs & Varshney et al. (2001) \\
\hline Wheat (chromosome 1D) & 32 SSRs & 11 DLs & Huang and Röder (2003) \\
\hline Wheat (chromosome arm 1BS) & 24 AFLPs & $8 \mathrm{DLs}$ & Zhang et al. (2000) \\
\hline Wheat (chromosome arm 4DL) & 61 AFLPs, 2 SSRs, 2 RFLPs & $8 \mathrm{DLs}$ & Milla and Gustafson (2001) \\
\hline Wheat (chromosome arm 1BS) & 22 expressed sequences & DLs & Sandhu et al. (2002) Ts' \\
\hline Wheat (chromosome arm 6BL) & 32 AFLPs & - & Dieguez et al. (2003) \\
\hline Wheat (whole genome) & $\begin{array}{l}121 \text { expresses candidate } \\
\text { resistance genes }\end{array}$ & 339 DLs & Dilbirligi and Gill (2003) \\
\hline Wheat (whole genome) & $\begin{array}{l}94 \text { loci for genes involved } \\
\text { in } \mathrm{N} \text {-uptake, bread making } \\
\text { quality or disease } \\
\text { resistance }\end{array}$ & 97 DLs & Benard et al. (2003) \\
\hline Wheat (whole genome) & $\begin{array}{l}59 \text { loci for } 14 \text { candidate } \\
\text { ESTs for FHB }\end{array}$ & 91 DLs & Han et al. (2003) \\
\hline Wheat (whole genome) & 16,099 loci (7,104 ESTs) & $101 \mathrm{DLs}$ & $\begin{array}{l}\text { Gill et al. }(2003) \\
\text { Qi et al. }(2003,2004)\end{array}$ \\
\hline Wheat (whole genome) & 725 SSRs & 159 DLs & Sourdille et al. (2004) \\
\hline
\end{tabular}

${ }^{\mathrm{a}}$ DLs $=$ deletion lines

(RH) populations (Cox et al. 1990) or by the so-called HAPPY (haploid genome; polymerase chain reaction) mapping procedure (Dear and Cook 1989). Neither method relies on the availability of BAC-contigs or cloned DNA fragments and may be suitable for the high-throughput mapping of PCR-based markers independent of the presence of polymorphism (Waugh et al. 2002; Thangavelu et al. 2003; Wardrop et al. 2002). RH mapping of one $s c s^{a e}$ (species cytoplasm specific) gene in durum wheat is already in progress (http://cropandsoil.oregonstate.edu/ $\mathrm{cgb} /$ projects.html). $\mathrm{RH}$ mapping permitted the 
localization of the $s c s^{a e}$ gene on the long arm of chromosome 1D along with eight linked markers (Kianian et al. 2003; Hossain et al. 2004b).

\section{4 \\ Application of Molecular Markers in Wheat Genetics and Breeding}

In the last decade the generation of molecular markers and their mapping has offered new opportunities for plant breeding and has become a key component of what is now popularly termed molecular breeding. These resources allow the tracking of specific loci and alleles through the identification of markers linked to major genes, analysis of quantitative trait loci (QTLs), positional cloning of genes and characterization of genetic variation in germplasm. In addition, mapped markers can often be used in related species to analyse syntenic relationships.

\subsection{1}

\section{Gene Tagging and QTL Analysis for MAS}

The potential value of genetic markers, linkage groups and their association with agronomic traits has been known for more than 80 years. The usefulness of marker-assisted selection (MAS) was recognized as early as 1923 when Sax demonstrated in beans an association between seed size and seed coat pigmentation. The first molecular-marker based (RFLP) map in plants was made in tomato and consisted of 57 loci (Bernatzky and Tanksley 1986). Since then, maps have been constructed for nearly all crop plants (summarized by Philips and Vasil 2001), allowing, in principle, the application of MAS in plant breeding, as originally proposed by Sax (1923) and Thoday (1961). The concept of selection based on genotype rather than phenotype created strong interest among plant breeders (Tanksley et al. 1989; Paterson et al. 1994). The rationale relies on the discovery of phenotype/genotype associations between genome regions (as assayed by molecular markers) and traits in segregating populations (such as $\mathrm{F}_{2}$ s, RILs, DHs, etc.). These are derived by analysis of segregation of simply inherited traits and by QTL analysis for complex traits (Lee 1995). The identification of markers sufficiently tightly linked to target genes/QTLs and their conversion, if necessary, to a PCR platform has made MAS feasible in some plant breeding programmes (Langridge and Chalmers 2004). MAS can increase the efficiency and accuracy of selection, especially for traits that are difficult to phenotype or are recessive. The time-lag between the advent of DNA-marker technologies and their practical application for MAS has been, and remains, attributable to the high unit cost in the context of a relatively low value end product (Koebner et al. 2001).

In wheat, a significant number of major genes and QTLs for different traits have been tagged. Markers for more than 36 traits were already developed by 1999 (Gupta et al. 1999). Recent progress and significant achievements in the area of mapping disease resistance genes and the identification of QTLs and major genes for some agronomically important traits are summarized in Tables 3 and 4, respectively. A variety of molecular markers (RFLP, RAPD, AFLP, SSR) have been used for gene tagging and QTL analysis, but the consensus is that SSRs are best suited for this purpose (Gupta et al. 2002b). RFLP is not readily adapted to high sample throughput and RAPD assays are not sufficiently reproducible or transferable between laboratories. While both SSRs and AFLPs are efficient in identifying polymorphisms, SSRs are more readily automated (Shariflou et al. 2003). While RFLPs and AFLPs can in principle be converted into a simple PCR assay (STS), AFLP conversion is complicated by the observation that in large genome templates, individual bands are generally composed of multiple fragments (Shan et al. 1999; Carter et al. 2003). The inclusion of many microsatellite markers on genetic maps (Röder et al. 1998b; Gandon et al. 2002; Somers et al. 2004; Peng et al. 2004a) will ease their use for tagging for marker-assisted wheat breeding.

\section{Status of MAS in Wheat Breeding}

Prior to their use in plant breeding, the markers need to be validated, a process where functionality is tested in a range of genetic backgrounds (Langridge and Chalmers 1998; Gupta et al. 1999). For instance, marker validation studies were conduced for QTL for grain protein content by using NILs (Singh et al.2001), for $\operatorname{Lr} 10$ by using 16 wheat cultivars (Blazkova et al. 2002), for QTL for Fusarium head blight (FHB) resistance by using the progeny of crosses between the FHB-resistant spring wheat line and five European wheat varieties (Angerer et al. 2003; Liu and Anderson 2003a) or NILs from existing breeding populations (Pumphrey and Anderson 2003) and in germplam 
Table 3. Some examples of gene tagging or QTL identification for resisiatnce to important diseases of wheat

\begin{tabular}{|c|c|c|c|c|}
\hline Disease & Gene/QTLs & Chromosome & Marker type & Reference \\
\hline \multicolumn{5}{|l|}{ I. Fungal resistances } \\
\hline Black (stem) rust/ & Stb1 & $5 \mathrm{BL}$ & AFLP, RAPD & Adhikari et al. (2004b) \\
\hline \multirow[t]{17}{*}{ Septoria trici bloch (STB) } & Stb2 & 3BS & SSR & Adhikari et al. (2004c) \\
\hline & Stb3 & $6 \mathrm{DS}$ & SSR & Adhikari et al. (2004c) \\
\hline & Stb4 & 7DS & AFLP, SSR & Adhikari et al. (2004a) \\
\hline & Stb5 & 7DS & SSR & Arraiano et al. (2001) \\
\hline & Stb6 & $3 \mathrm{AS}$ & SSR & Brading et al. (2002) \\
\hline & Stb7 & $4 \mathrm{AL}$ & SSR & McCartney et al. (2003) \\
\hline & Stb8 & $7 \mathrm{BL}$ & SSR & Adhikari et al. (2003) \\
\hline & QStb.risø-2B & $2 \mathrm{BL}$ & SSR & Eriksen et al. (2003a) \\
\hline & QStb.risø-3A.1, & $3 \mathrm{AS}$ & SSR & Eriksen et al. (2003a) \\
\hline & QStb.risø-3A.2 & & & \\
\hline & QStb.risø-3B & $3 B \mathrm{BL}$ & AFLP & Eriksen et al. (2003a) \\
\hline & QStb.risø-6B.1, & $6 \mathrm{~B}$ & AFLP & Eriksen et al. (2003a) \\
\hline & QStb.risø-6B.2 & & & \\
\hline & QStb.risø-7B & $7 \mathrm{~B}$ & AFLP & Eriksen et al. (2003a) \\
\hline & $Q S t b$ & $1 \mathrm{DS}$ & RFLP/SSR & Börner et al. (2003) \\
\hline & $Q S t b$ & 6BS & RFLP/SSR & Börner et al. (2003) \\
\hline & $Q S t b$ & $7 \mathrm{BL}$ & RFLP/SSR & Börner et al. (2003) \\
\hline \multirow[t]{29}{*}{ Powdery mildew } & $P m 1$ & $7 \mathrm{AL}$ & RFLP & Ma et al. (1994) \\
\hline & & & & Hartl et al. (1995) \\
\hline & & $7 \mathrm{AL}$ & STS & Hu et al. (1997) \\
\hline & $P m 1 c$ & $7 \mathrm{AL}$ & AFLP & Hartl et al. (1999) \\
\hline & $\begin{array}{l}\text { Pm1e } \\
\text { (formerly Pm22) }\end{array}$ & $7 \mathrm{AL}$ & SSR & Singrün et al. (2003) \\
\hline & $P m 2$ & 5DS & RFLP & $\begin{array}{l}\text { Ma et al. (1994), } \\
\text { Hartl et al. (1995) }\end{array}$ \\
\hline & $\operatorname{Pm} 3 a, b, c$ & $1 \mathrm{AS}$ & RFLP & Hartl et al. (1993) \\
\hline & $P m 3 b$ & $1 \mathrm{AS}$ & RFLP & Ma et al. (1994) \\
\hline & Pm3g (Mlar) & $1 \mathrm{AS}$ & Gliadin & Sourdille et al. (1999) \\
\hline & $P m 3$ & $1 \mathrm{AS}$ & SSR & Bougot et al. (2002) \\
\hline & $P m 4 a$ & $2 \mathrm{AL}$ & RFLP & Ma et al. (1994) \\
\hline & & $2 \mathrm{AL}$ & AFLP & Hartl et al. (1999) \\
\hline & & $2 \mathrm{AL}$ & STS & Ma et al. (2003) \\
\hline & Pm5e & $7 \mathrm{BL}$ & SSR & Huang et al. (2003c) \\
\hline & Pm6 & $2 \mathrm{BL}$ & RFLP & Tao et al. (2000) \\
\hline & $\mathrm{Pm} 8 / \mathrm{Pm} 17$ & 1BL/1RS; & STS & Mohler et al. (2001) \\
\hline & (allelic) & $1 \mathrm{AL} / 1 \mathrm{RS}$ & & \\
\hline & $P m 13$ & 3DS & STS & Cenci et al. (1999) \\
\hline & $\operatorname{Pm} 18$ & $7 \mathrm{~A}$ & RFLP & Hartl et al. (1995) \\
\hline & $\operatorname{Pm} 21$ & 6AL/6VS & RAPD & Qi et al. (1996) \\
\hline & & 6AL/6VS & SCAR & Liu et al. (1999a) \\
\hline & $\operatorname{Pm} 24$ & $1 \mathrm{DS}$ & SSR, AFLP & Huang et al. (2000) \\
\hline & $P m 25$ & $1 \mathrm{~A}$ & RAPD & Shi et al. (1998) \\
\hline & $\operatorname{Pm} 26$ & 2BS & RFLP & Rong et al. (2000) \\
\hline & $\operatorname{Pm} 27$ & $6 \mathrm{~B}-6 \mathrm{G}$ & SSR & Järve et al. (2000) \\
\hline & $\operatorname{Pm} 29$ & $7 \mathrm{DL}$ & RFLP & Zeller et al. (2002) \\
\hline & $P m 30$ & $5 \mathrm{BS}$ & SSR & Liu et al. (2002b) \\
\hline & $Q p m \cdot v t-1 B$ & $1 \mathrm{~B}$ & SSR, RFLP & Liu et al. (2001a) \\
\hline & Qpm.vt-2A & $2 \mathrm{~A}$ & SSR & Liu et al. (2001a) \\
\hline
\end{tabular}


Table 3. (continued)

\begin{tabular}{|c|c|c|c|c|}
\hline Disease & Gene/QTLs & Chromosome & Marker type & Reference \\
\hline & Qpm.vt-2B & $2 \mathrm{~B}$ & RFLP, SSR & Liu et al. (2001a) \\
\hline & QTL & $5 \mathrm{~A}$ & RFLP & Keller et al. (1999b) \\
\hline & QTL & 7B & RFLP & Keller et al. (1999b) \\
\hline \multirow[t]{35}{*}{ Yellow (stripe) rust } & Yr5 & $2 \mathrm{BL}$ & RGAP/CAPS & Yan et al. (2003a), \\
\hline & & & & Chen et al. (2003) \\
\hline & Yr7 & $2 \mathrm{BL}$ & AFLP & Bariana et al. (2001) \\
\hline & Yr9 & 1BL/1RS & RGAP & Shi et al. (2001) \\
\hline & & 1BL/1RS & SCAR & Mago et al. (2002) \\
\hline & Yr10/ Yr10vav & $1 \mathrm{BS}$ & SSR & Wang et al. (2002), \\
\hline & & & & Bariana et al. (2002) \\
\hline & $\operatorname{Yr} 10$ & $1 \mathrm{BS}$ & SCAR & Shao et al. (2001) \\
\hline & Yr15 & $1 \mathrm{BS}$ & RFLP & Sun et al. $(1997,2002)$ \\
\hline & & $1 \mathrm{BS}$ & SSR & Chagué et al. (1999), \\
\hline & & & & Peng et al. (2000a) \\
\hline & Yr17 & $2 \mathrm{AS}$ & SCAR & Robert et al. (1999) \\
\hline & & $2 \mathrm{AS}$ & STS & Seah et al. (2001) \\
\hline & & $2 \mathrm{AS}$ & CAPS & Helguera et al. (2003) \\
\hline & $\operatorname{Yr} 18$ & 7DS & RFLP & Singh et al. (2000) \\
\hline & & 7DS & SSR, AFLP & Bariana et al. (2001) \\
\hline & & 7DS & SSR & Suenaga et al. (2003) \\
\hline & Yr26 & $1 B S$ & SSR & Ma et al. (2001) \\
\hline & Yr28 & $4 \mathrm{DS}$ & RFLP & Singh et al. (2000) \\
\hline & Yr29 & $1 \mathrm{BL}$ & RFLP, AFLP & Bariana et al. (2001) \\
\hline & & $1 \mathrm{BL}$ & AFLP & William et al. (2003c) \\
\hline & Yr30 & $3 \mathrm{BS}$ & SSR & Suenaga et al. (2003) \\
\hline & Yr32 & $2 \mathrm{AL}$ & AFLP, SSR & Eriksen et al. (2003b) \\
\hline & YrKat & 2DS & SSR & Bariana et al. (2001) \\
\hline & Yrns-B1 & $3 B S$ & SSR & Börner et al. (2000) \\
\hline & YrH52 & $1 \mathrm{BS}$ & SSR & Peng et al. (2000a) \\
\hline & YrMoro & Group 1 & STS & Smith et al. (2002) \\
\hline & $Y r Q z$ & $2 \mathrm{~B}$ & AFLP, SSR & Deng et al. (2004) \\
\hline & QTL & $3 \mathrm{BS}$ & RFLP & Singh et al. (2000) \\
\hline & QTL & 3DS & RFLP & Singh et al. (2000) \\
\hline & QTL & $5 \mathrm{DS}$ & RFLP & Singh et al. (2000) \\
\hline & QYR1 & $2 \mathrm{BL}$ & SSR & Boukhatem et al. (2002) \\
\hline & QYR2 & $2 \mathrm{AL}$ & SSR & Boukhatem et al. (2002) \\
\hline & QYR3 & 2BS & RFLP & Boukhatem et al. (2002) \\
\hline & QYR4 & 7DS & RFLP & Boukhatem et al. (2002) \\
\hline \multirow[t]{12}{*}{ Brown (leaf) rust } & $\operatorname{Lr} 1$ & $5 \mathrm{DL}$ & RFLP, SSR & Ling et al. (2003) \\
\hline & Lr3 & $6 \mathrm{BL}$ & AFLP & Dieguez et al. (2003) \\
\hline & $\operatorname{Lr} 9$ & $6 \mathrm{~B}$ & RFLP & Autrique et al. (1995) \\
\hline & $\operatorname{Lr} 10$ & $1 \mathrm{AS}$ & RFLP & Nelson et al. (1997) \\
\hline & & $1 \mathrm{AS}$ & STS & Schachermayr et al. (1997) \\
\hline & $\operatorname{Lr} 19$ & $7 \mathrm{DL}$ & RFLP & Autrique et al. (1995) \\
\hline & & $7 \mathrm{DL}$ & STS & Prins et al. (2001) \\
\hline & & $7 \mathrm{DL}$ & SCAR & Cherukuri et al. (2003) \\
\hline & $\operatorname{Lr} 21 / \operatorname{Lr} 40$ & $1 \mathrm{DS}$ & STS & Huang and Gill (2001) \\
\hline & $\operatorname{Lr} 23$ & 2BS & RFLP & Nelson et al. (1997) \\
\hline & $\operatorname{Lr} 24$ & $3 \mathrm{DL}$ & RFLP & Autrique et al. (1995) \\
\hline & $\operatorname{Lr} 25$ & $4 \mathrm{~A} / 2 \mathrm{R}$ & SCAR & Procunier et al. (1995) \\
\hline
\end{tabular}


Table 3. (continued)

\begin{tabular}{|c|c|c|c|c|}
\hline Disease & Gene/QTLs & Chromosome & Marker type & Reference \\
\hline & Lr26 & $1 \mathrm{BL} / 1 \mathrm{RS}$ & SCAR & Mago et al. (2002) \\
\hline & Lr27 & $3 \mathrm{BS}$ & RFLP & Nelson et al. (1997) \\
\hline & $\operatorname{Lr} 28$ & $4 \mathrm{AL}$ & STS & Naik et al. (1998) \\
\hline & & $4 \mathrm{AL}$ & SSR & Vikal et al. (2004) \\
\hline & $\operatorname{Lr} 29$ & 7DS & SCAR & Procunier et al. (1995) \\
\hline & $\operatorname{Lr} 31$ & $4 \mathrm{BL}$ & RFLP & Nelson et al. (1997) \\
\hline & Lr32 & $3 \mathrm{DS}$ & RFLP & Autrique et al. (1995) \\
\hline & Lr34 & 7DS & RFLP & Nelson et al. (1997) \\
\hline & & 7DS & SSR & Suenaga et al. (2003) \\
\hline & & 7DS & SSR & Schnurbusch et al. (2003b) \\
\hline & Lr35 & $2 \mathrm{~B}$ & STS & Seyfarth et al. (1999) \\
\hline & & $2 \mathrm{~B}$ & SCAR & Gold et al. (1999) \\
\hline & Lr37 & $2 \mathrm{AS}$ & SCAR & Robert et al. (1999) \\
\hline & & $2 \mathrm{AS}$ & STS & Seah et al. (2001) \\
\hline & & $2 \mathrm{AS}$ & CAPS & Helguera et al. (2003) \\
\hline & Lr39 & 2DS & SSR & Raupp et al. (2001) \\
\hline & $\operatorname{Lr} 41$ & $2 \mathrm{D}$ & SSR & Singh et al. (2004b) \\
\hline & Lr46 & $1 \mathrm{BL}$ & SSR & Suenaga et al. (2003) \\
\hline & & $1 \mathrm{BL}$ & AFLP & William et al. (2003c) \\
\hline & Lr47 & 7AS & STS, CAPS & Helguera et al. (2000) \\
\hline & $\operatorname{Lr} 50$ & $2 \mathrm{BL}$ & SSR & Brown-Guedira et al. (2003) \\
\hline & Lr-undesignated & $\mathrm{BSA}^{\mathrm{a}}$ & AFLP & Craven et al. (2003) \\
\hline & QTLs & $7 \mathrm{BL}$ & RAPD & Nelson et al. (1997) \\
\hline Durable broad & $\mathrm{Sr} 2$ & $3 \mathrm{BS}$ & SSR & Spielmeyer et al. (2003) \\
\hline spectrum stem rust & $\operatorname{Sr} 2$ & $3 \mathrm{BS}$ & ESTs & Spielmeyer and Lagudah (2003) \\
\hline Fusarium head blight/ & QTL & $1 \mathrm{~B}$ & Glutenin & Buerstmayr et al. (2002) \\
\hline \multirow[t]{16}{*}{ Scab } & QTL & $1 \mathrm{~B}$ & SSR & Shen et al. (2003a) \\
\hline & QFhs.ndsu-2A & $2 \mathrm{AL}$ & RFLP & Waldron et al. (1999) \\
\hline & QFhs.inra-2A & $2 \mathrm{~A}$ & SSR & Gervais et al. (2003) \\
\hline & QTL & $2 \mathrm{BL}$ & SSR & Zhou et al. (2002) \\
\hline & QFhs.inra-2B & $2 \mathrm{~B}$ & SSR & Gervais et al. (2003) \\
\hline & QTL & 2DS & SSR & Shen et al. (2003b) \\
\hline & QTL & $2 \mathrm{DL}$ & SSR & Somers et al. (2003a) \\
\hline & QTL & $3 \mathrm{AL}$ & RFLP & Anderson et al. (2001) \\
\hline & QTL & $3 \mathrm{AS}$ & SSR & $\begin{array}{l}\text { Bourdoncle and Ohm (2003), } \\
\text { Shen et al. (2003a) }\end{array}$ \\
\hline & QFhs.ndsu-3AS & $3 \mathrm{AS}$ & SSR & Otto et al. (2002) \\
\hline & QFhs.inra-3A & $3 \mathrm{~A}$ & RFLP & Gervais et al. (2003) \\
\hline & $Q T L$ & $3 \mathrm{~A}$ & SSR & Steiner et al. (2003) \\
\hline & QFhs.ndsu-3B & $3 B S$ & RFLP & $\begin{array}{l}\text { Waldron et al. (1999), } \\
\text { Liu and Anderson (2003b) }\end{array}$ \\
\hline & QTLs & 3BS & SSR & $\begin{array}{l}\text { Anderson et al. (2001), } \\
\text { Liu and Anderson (2003b), } \\
\text { Buerstmayr et al. (2002, 2003), } \\
\text { Zhou et al. (2002), } \\
\text { Bourdoncle and Ohm (2003), } \\
\text { Shen et al. (2003b), } \\
\text { Somers et al. (2003a) }\end{array}$ \\
\hline & QTL & $3 B S$ & STS & Guo et al. (2003) \\
\hline & QTL & $3 \mathrm{BL}$ & SSR & Bourdoncle and Ohm (2003) \\
\hline
\end{tabular}


Table 3. (continued)

\begin{tabular}{|c|c|c|c|c|}
\hline Disease & Gene/QTLs & Chromosome & Marker type & Reference \\
\hline & QFhs.inra-3B & $3 B$ & SSR & Gervais et al. (2003) \\
\hline & QTL & 4BS & RFLP & Anderson et al. (2001) \\
\hline & QTL & 4BS & SSR & Somers et al. (2003a) \\
\hline & QFhs.ifa-5A & $5 \mathrm{~A}$ & SSR & Buerstmayr et al. $(2002,2003)$ \\
\hline & QFhs.inra-5A.1, & $5 \mathrm{~A}$ & SSR & Gervais et al. (2003) \\
\hline & QFhs.inra-5A.2 & & & \\
\hline & QFhs.inra-5A.3 & $5 \mathrm{~A}$ & Awns & Gervais et al. (2003) \\
\hline & $Q T L$ & $5 \mathrm{~A}$ & SSR & Ma et al. (2003) \\
\hline & QTL & $5 \mathrm{AS}$ & SSR & Somers et al. (2003a) \\
\hline & QTL & $5 B \mathrm{BL}$ & SSR & Bourdoncle and Ohm (2003) \\
\hline & QFhs.inra-5D & $5 \mathrm{D}$ & & Gervais et al. (2003) \\
\hline & QTL & $6 \mathrm{AS}$ & RFLP & Anderson et al. (2001) \\
\hline & QTL & $6 \mathrm{BS}$ & RFLP & $\begin{array}{l}\text { Waldron et al. (1999), } \\
\text { Anderson et al. (2001) }\end{array}$ \\
\hline & QTL & 6BS & SSR & $\begin{array}{l}\text { Anderson et al. (2001), } \\
\text { Shen et al. (2003b) }\end{array}$ \\
\hline & QFhs.inra-6D & $6 \mathrm{D}$ & & Gervais et al. (2003) \\
\hline & QTLs (2) & $3 \mathrm{~B}$ & SSR & del Blanco et al. (2003) \\
\hline & QTLS & 11 & AFLP & Bai et al. (1999) \\
\hline & QTLs(3) & BSA & RAPD & Sun et al. (2003) \\
\hline & QTLs(3) & 3 & AFLP & Schmolke et al. (2003) \\
\hline \multirow[t]{2}{*}{ Eyespot } & Pch1 & $7 \mathrm{D}$ & SSR & Groenewald et al. (2003) \\
\hline & Pch2 & $7 \mathrm{~A}$ & RFLP & de la Pena et al. $(1996,1997)$ \\
\hline Karnal bunt & Unspecified & $4 \mathrm{~B}$ & SSR, AFLP & Singh et al. $(1999,2003)$ \\
\hline Loose smut & Major gene & & STS from AFLP & Knox et al. (2002) \\
\hline Bunt & Bt10 & BSA & SCAR (RAPD) & Laroche et al. (2000) \\
\hline Septoria nodorum & $s n b T M$ & BSA & SCAR (RAPD) & Cao et al. (2001) \\
\hline Leaf or glume blotch & QSng.sfr-3BS & $3 \mathrm{~B}$ & SSR & Schnurbusch et al. (2003a) \\
\hline \multirow[t]{3}{*}{ (Stagonospora nodorum) } & QSng.sfr-34BL & $4 \mathrm{~B}$ & SSR & Schnurbusch et al. (2003a) \\
\hline & QTLs (2) & $5 \mathrm{~A}$ & SSR & Toubia-Rahme et al. (2003) \\
\hline & QTLs (1) & 3B & SSR & Toubia-Rahme et al. (2003) \\
\hline Pyrenophora tritici & Pti2 & $1 \mathrm{~A} / 4 \mathrm{~A}$ & RFLP & Faris et al. (1997) \\
\hline repentis & Pti2 & $1 \mathrm{AS}$ & RFLP & Effertz et al. (2002) \\
\hline \multicolumn{5}{|l|}{ II. Viral resistances } \\
\hline \multirow[t]{2}{*}{ Barley yellow dwarf virus } & $B d v 2$ & & STS (RAPD) & Stoutjesdijk et al. (2001) \\
\hline & $B Y D V$ & $7 \mathrm{DL}$ & SSR & Ayala et al. (2001) \\
\hline $\begin{array}{l}\text { Wheat streak mosaic } \\
\text { virus }\end{array}$ & Wsm1 & Group 4 & STS (RAPD) & Talbert et al. (1996) \\
\hline Wheat spindle streak & WSSMV & $2 \mathrm{D}$ & RFLP & Khanet al. (2000a) \\
\hline mosaic virus & & $2 \mathrm{DL}$ & SSR & Wang et al. (2003) \\
\hline \multicolumn{5}{|l|}{ III. Nematode resistances } \\
\hline \multirow[t]{3}{*}{ Cereal cyst nematode } & Cre1 & - & STS & Ogbonnaya et al. (2001) \\
\hline & Cre3 & - & STS & Ogbonnaya et al. (2001) \\
\hline & Cre6 & - & STS & Ogbonnaya et al. (2001) \\
\hline Root lesion nematode & $R \ln n 1$ & $7 \mathrm{~A}$ & RFLP & Williams et al. (2002) \\
\hline \multirow[t]{2}{*}{ Root knot nematode } & $R k n-m n 1$ & $\mathrm{TLs}^{\mathrm{b}}$ & RAPD & Barloy et al. (2000) \\
\hline & & TLs & SCAR (RAPD) & Yu et al. (2003) \\
\hline
\end{tabular}


Table 3. (continued)

\begin{tabular}{|c|c|c|c|c|}
\hline Disease & Gene/QTLs & Chromosome & Marker type & Reference \\
\hline \multicolumn{5}{|l|}{ IV. Insect resistances } \\
\hline \multirow[t]{13}{*}{ Russian wheat aphid } & $D n 1$ & $7 \mathrm{D}$ & SSR & Liu et al. (2001b) \\
\hline & & 7DS & RGA & Swanepoel et al. (2003) \\
\hline & Dn2 & NILs & SCAR (RAPD) & Myburg et al. (1998) \\
\hline & & $7 \mathrm{D}$ & STS (RFLP) & Ma et al. (1998) \\
\hline & & $7 \mathrm{D}$ & SSR & $\begin{array}{l}\text { Liu et al. (2001b), } \\
\text { Miller et al. (2001) }\end{array}$ \\
\hline & Dn4 & $1 \mathrm{D}$ & RFLP & Ma et al. (1998) \\
\hline & & $1 \mathrm{D}$ & SSR, & $\begin{array}{l}\text { Liu et al. (2002a), } \\
\text { Arzani et al. (2003) }\end{array}$ \\
\hline & $D n 5$ & $7 \mathrm{D}$ & SSR & Liu et al. (2001b) \\
\hline & Dn6 & $7 \mathrm{D}$ & SSR & Liu et al. (2002a) \\
\hline & Dn8 & $7 \mathrm{D}$ & SSR & Liu et al. (2001b) \\
\hline & Dn9 & $7 \mathrm{D}$ & SSR & Liu et al. (2001b) \\
\hline & $\operatorname{Dnx}$ & $7 \mathrm{D}$ & SSR & Liu et al. (2001b) \\
\hline & Unspecified & NILs & SCAR (RAPD) & Venter and Botha (2000) \\
\hline \multirow[t]{2}{*}{ Hessian fly } & 11 loci & $1 \mathrm{~A}, 5 \mathrm{~A}$ & RAPD & Dweikat et al. (1997) \\
\hline & $\mathrm{H} 31$ & $5 B S$ & AFLP/STS & Williams et al. (2003) \\
\hline \multirow[t]{2}{*}{ Wheat curl mite } & $\mathrm{Cmc3}$ & T1AL.1RS & SSR, RFLP & Malik et al. (2003) \\
\hline & $\mathrm{Cmc4}$ & $6 \mathrm{D}$ & SSR, RFLP & Malik et al. (2003) \\
\hline Greenbug & $G b 3$ & $7 \mathrm{DL}$ & SSR, AFLP & Weng and Lazar (2002a) \\
\hline Sawfly cutting & Sc & $3 \mathrm{~B}$ & SSR & Houshmand et al. (2003) \\
\hline
\end{tabular}

${ }^{\mathrm{a}} \mathrm{BSA}=$ bulked segregant analysis

${ }^{\mathrm{b}} \mathrm{TLs}=$ translocation lines

collections (Zhou et al. 2003). Similarly, markers associated with preharvest sprouting (Kato et al. 2001; Mares and Mrva 2001), plant height (Ellis et al. 2002), and barley yellow dwarf virus (Ayala et al. 2001) were validated and used for enriching favourable allele frequency in early generation segregating populations and tracking donor parent alleles during backcrossing (Cakir et al. 2003). Microsatellite markers were linked to two major QTLs for FHB and were subsequently used in a marker-assisted backcross scheme to transfer these QTLs from bread wheat to durum wheat (Gladysz et al. 2003). Similarly, STS markers were used in the marker-assisted introgression of $P m 13$ into 18 bread wheat cultivars, where $\mathrm{BC}_{5}$ lines had already been developed (Reffo et al. 2003). Two effective leaf rust resistance genes $L r 29+L r 24$ were also successfully transferred into registered wheat cultivars with the assistance of molecular markers (Kraic et al. 2003). Molecular markers have also facilitated the pyramiding of multiple disease resistance genes in wheat as demonstrated by Liu et al. (2000), who inte- grated three powdery mildew resistance gene combinations $(P m 2+P m 4 a, P m 2+P m 21, P m 4 a+P m 21)$ into an elite wheat cultivar 'Yang158'.

The use of MAS in wheat has a history of about 20 years and also involves the exploitation of non-DNA-based assays. For example, the correlation between bread-making quality and allelic status at the Glu-1 (endosperm storage protein subunit glutenin) loci (Payne et al. 1983, 1987; Rogers et al. 1989) has been widely used in breeding programs. Some more recent examples of the utilization of MAS for glutenin alleles include Ahmad (2000), de Bustos et al. (2001), Radovanovic and Cloutier (2003), among others. More recently, a particular effort to use MAS in wheat breeding has been initiated in Australia. Over 1,000 marker assays covering five loci were performed at the University of Adelaide in the fiscal year 1999-2000 (Eagles et al. 2001), rising to $>6,000$ assays for 10 loci in 2002 and to $\sim 20,000$ assays in 2003 (Kuchel et al. 2003) and around 50,000 assays in 2004 (SP Jefferies, Australia, pers. commun.). Loci 
Table 4. A list of some grain quality traits of wheat for which genes or QTLs have been identified with molecular markers

\begin{tabular}{|c|c|c|c|c|c|}
\hline Trait & $\begin{array}{l}\text { Chromo- } \\
\text { some }\end{array}$ & $\begin{array}{l}\text { Molecular } \\
\text { marker }\end{array}$ & $\begin{array}{l}\text { Number of } \\
\text { QTLs/gene } \\
\text { identified }\end{array}$ & $\begin{array}{l}\text { Per cent } \\
\text { phenotypic } \\
\text { variation } \\
\text { explained }\end{array}$ & Reference \\
\hline \multirow[t]{2}{*}{ Awn length } & $4 \mathrm{~A}$ & SSR & $H d$ & 8.5 & Sourdille et al. (2002) \\
\hline & $6 \mathrm{~B}$ & SSR & $B 2$ & 45.9 & Sourdille et al. (2002) \\
\hline Coleoptile length & $4 \mathrm{~B}$ & RFLP & & $27-45$ & Rebetzke et al. (2001) \\
\hline \multirow[t]{8}{*}{ Culm thickness } & $2 \mathrm{~A}$ & RFLP & 1 & & Keller et al. (1999a) \\
\hline & $2 \mathrm{~B}$ & RFLP & 1 & 13.2 & Keller et al. (1999a) \\
\hline & $3 \mathrm{~A}$ & RFLP & 1 & 21 & Keller et al. (1999a) \\
\hline & $3 \mathrm{~B}$ & RFLP & 1 & 11.3 & Keller et al. (1999a) \\
\hline & $4 \mathrm{~A}$ & RFLP & 1 & 16 & Keller et al. (1999a) \\
\hline & $4 \mathrm{~B}$ & RFLP & 1 & 12.9 & Keller et al. (1999a) \\
\hline & $5 \mathrm{~A}$ & RFLP & 1 & 37.6 & Keller et al. (1999a) \\
\hline & $5 \mathrm{~B}$ & RFLP & 1 & 11.1 & Keller et al. (1999a) \\
\hline \multirow[t]{3}{*}{ Dormancy } & $2 \mathrm{AL}$ & RFLP & 1 & - & Mares et al. (2002) \\
\hline & $2 \mathrm{DL}$ & RFLP & 1 & - & Mares et al. (2002) \\
\hline & $4 \mathrm{AL}$ & RFLP & 1 & - & Mares et al. (2002) \\
\hline Grain length & $3 B$ & RFLP & 1 & 21.9 & Campbell et al. (1999) \\
\hline Ear compactness & $2 \mathrm{~B}$ & RFLP & $P p d 2$ region & $9-22$ & Sourdille et al. (2000a) \\
\hline Floral fertility & $1 \mathrm{~B}$ & SSR & 1 & 10 & Rousset et al. (2003) \\
\hline \multirow[t]{3}{*}{ Flour colour } & $3 \mathrm{~A}$ & RFLP & 1 & 13 & Parker et al. (1998) \\
\hline & $7 \mathrm{~A}$ & RFLP/AFLP & 1 & 60 & Parker et al. (1998) \\
\hline & $7 \mathrm{~A}$ & STS/AFLP & 1 & 60 & Parker and Langridge (2000) \\
\hline \multirow[t]{9}{*}{ Flowering time } & $1 \mathrm{Am}$ & RFLP & Eps-Am1 & 47 & Bullrich et al. (2002) \\
\hline & $2 \mathrm{~A}$ & SSR & 1 & 11.5 & Huang XQ et al. (2003a) \\
\hline & $2 \mathrm{~A}$ & RFLP & 1 & $14.1-16.6$ & Ahmed et al. (2000) \\
\hline & $2 \mathrm{~B}$ & RFLP & $E s p-2 B S$ & $13.5-13.7$ & Ahmed et al. (2000) \\
\hline & $2 \mathrm{D}$ & SSR & 1 & 15 & Huang XQ et al. (2003a) \\
\hline & $2 \mathrm{D}$ & RFLP & $P p d-D 1$ & $29-31$ & Li et al. (2002a) \\
\hline & $6 \mathrm{~A}$ & SSR & 2 & $13.7-16.9$ & Huang et al. (2003b) \\
\hline & $7 \mathrm{~A}$ & RFLP & Esp-7A & $14.5-20.9$ & Ahmed et al. (2000) \\
\hline & $2 \mathrm{~A}$ & SSR & $P p d-A 1$ & $10-11$ & Li et al. (2002a) \\
\hline \multirow[t]{13}{*}{ Grain protein content } & $2 \mathrm{~A}$ & SSR & 1 & 20.8 & Prasad et al. (2003) \\
\hline & $2 \mathrm{~A}$ & SSR & 1 & $13.4-19.6$ & Prasad et al. (2003) \\
\hline & $2 \mathrm{D}$ & SSR & 1 & 18.7 & Prasad et al. $(1999,2003)$ \\
\hline & $3 \mathrm{D}$ & SSR & 1 & $13.9-16.2$ & Prasad et al. (2003) \\
\hline & $4 \mathrm{~A}$ & SSR & 1 & $8.2-13.6$ & Prasad et al. (2003) \\
\hline & $6 \mathrm{~B}$ & RFLP & 1 & 72 & Mesfin et al. (1999), \\
\hline & & & & & Chee et al. (2001), \\
\hline & & & & & Distelfeld et al. (2004) \\
\hline & $6 \mathrm{~B}$ & STS/SSRs & - & up to 16.4 & $\begin{array}{l}\text { Khan et al. (2000b), } \\
\text { Prasad et al. (2003) }\end{array}$ \\
\hline & BSA & ISSR, RAPD & 9 & $13.4-13.5$ & Dholakia et al. (2001) \\
\hline & $5 \mathrm{~A}$ & SSR & 1 & 6.2 & Singh et al. (2001) \\
\hline & $7 \mathrm{~A}$ & SSR & 1 & 32.4 & Prasad et al. (2003) \\
\hline & $7 \mathrm{D}$ & SSR & 1 & 15.9 & Prasad et al. (2003) \\
\hline \multirow[t]{3}{*}{ Grains/spike } & $3 \mathrm{~A}$ & RFLP & 2 & $12.3-18.3$ & Shah et al. (1999) \\
\hline & $4 \mathrm{~A}$ & RFLP & 1 & $12-27$ & Araki et al. (1999) \\
\hline & $5 \mathrm{~A}$ & RFLP & 3 & $10-42$ & Kato et al. (2000) \\
\hline
\end{tabular}


Table 4. (continued)

\begin{tabular}{|c|c|c|c|c|c|}
\hline Trait & $\begin{array}{l}\text { Chromo- } \\
\text { some }\end{array}$ & $\begin{array}{l}\text { Molecular } \\
\text { marker }\end{array}$ & $\begin{array}{l}\text { Number of } \\
\text { QTLs/gene } \\
\text { identified }\end{array}$ & $\begin{array}{l}\text { Per cent } \\
\text { phenotypic } \\
\text { variation } \\
\text { explained }\end{array}$ & Reference \\
\hline \multirow[t]{18}{*}{ Grain weight } & $1 \mathrm{~A}$ & RFLP & 1 & 11.8 & Campbell et al. (1999) \\
\hline & $1 \mathrm{~A}$ & SSR & 1 & 15.1 & Varshney et al. (2000b) \\
\hline & $1 \mathrm{~B}$ & RFLP & 1 & 11.1 & Campbell et al. (1999) \\
\hline & $2 \mathrm{~A}$ & SSR & 1 & 17.2 & Huang et al. (2003b) \\
\hline & $2 \mathrm{D}$ & SSR & 1 & 15.4 & Huang et al. (2003b) \\
\hline & $3 \mathrm{~A}$ & RFLP & 1 & 12.2 & Shah et al. (1999) \\
\hline & $3 \mathrm{~A} / 3 \mathrm{~B}$ & RFLP & 1 & 10.9 & Campbell et al. (1999) \\
\hline & 3B & RFLP & 1 & 12.2 & Campbell et al. (1999) \\
\hline & $3 B$ & AFLP & 2 & 6 & Elouafi and Nachit (2004) \\
\hline & $4 \mathrm{~B}$ & AFLP & 1 & 3 & Elouafi and Nachit (2004) \\
\hline & $4 \mathrm{D}$ & SSR & 1 & 14.3 & Huang et al. (2003b) \\
\hline & $4 \mathrm{D}$ & SSR & 1 & $6.8-13.1$ & Liu et al. (2003) \\
\hline & $5 \mathrm{~A}$ & RFLP & 1 & $11.0-19.0$ & Kato et al. (2000) \\
\hline & $5 \mathrm{~B}$ & SSR & 1 & 16 & Huang et al. (2003b) \\
\hline & $6 \mathrm{~B}$ & SSR & 2 & 28 & Elouafi and Nachit (2004) \\
\hline & $7 \mathrm{~A}$ & SSR & 1 & 14.5 & Huang et al. (2003b) \\
\hline & $7 \mathrm{~B}$ & SSR & 2 & $20.6-25.9$ & Huang et al. (2003b) \\
\hline & $7 \mathrm{D}$ & SSR & 1 & 17.3 & Huang et al. (2003b) \\
\hline \multirow[t]{3}{*}{ Heading time } & 2BS & RFLP & Ppd-B1 & $23.4-44.4$ & Sourdille et al. (2000a) \\
\hline & 7BS & RFLP & earliness & $7.3-15.3$ & Sourdille et al. (2000a) \\
\hline & & & perse & & \\
\hline \multirow[t]{5}{*}{ Leaf angle } & $1 \mathrm{~A}$ & RFLP & 1 & 12.1 & Keller et al. (1999a) \\
\hline & 3B & RFLP & 1 & 11.1 & Keller et al. (1999a) \\
\hline & $4 \mathrm{~A}$ & RFLP & 1 & 16.4 & Keller et al. (1999a) \\
\hline & $5 \mathrm{~A}$ & RFLP & 1 & 11.2 & Keller et al. (1999a) \\
\hline & $7 \mathrm{D}$ & RFLP & 1 & 16.4 & Keller et al. (1999a) \\
\hline \multirow[t]{4}{*}{ Leaf width } & $1 \mathrm{~B}$ & RFLP & 1 & 14 & Keller et al. (1999a) \\
\hline & $3 \mathrm{~B}$ & RFLP & 1 & 19.7 & Keller et al. (1999a) \\
\hline & $5 \mathrm{~A}$ & RFLP & 1 & 14.9 & Keller et al. (1999a) \\
\hline & $5 \mathrm{~B}$ & RFLP & 1 & 11.2 & Keller et al. (1999a) \\
\hline Milling yield & $3 \mathrm{~A}, 7 \mathrm{D}$ & AFLP & 2 & $19-22$ & Parker et al. (1999) \\
\hline \multirow[t]{2}{*}{ Number of spikeltes } & $2 \mathrm{D}$ & SSR & 1 & - & Rousset et al. (2003) \\
\hline & $5 \mathrm{~B}$ & SSR & 1 & - & Rousset et al. (2003) \\
\hline \multirow{13}{*}{$\begin{array}{l}\text { Pre-harvest sprouting } \\
\text { tolerance (PHST) }\end{array}$} & $2 \mathrm{~B}$ & RFLP/SSR & 2 & $4-16.2$ & Kulwal et al. (2004) \\
\hline & $2 \mathrm{D}$ & RFLP/SSR & 1 & 14.9 & Kulwal et al. (2004) \\
\hline & $3 \mathrm{~A}$ & RFLP & 1 & 5.6 & Groos et al. (2002) \\
\hline & 3B & RFLP/SSR & 2 & 24.9 & Groos et al. (2002) \\
\hline & $3 \mathrm{~B}$ & RFLP/SSR & 5 & $3-20$ & Kulwal et al. (2004) \\
\hline & $3 \mathrm{D}$ & SSR & 1 & 11.6 & Groos et al. (2002) \\
\hline & $3 \mathrm{D}$ & RFLP & 3 & $3.2-17.4$ & Kulwal et al. (2004) \\
\hline & $4 \mathrm{~A}$ & \multicolumn{3}{|c|}{ rice sequence (in GA20-oxidase-silico analysis) } & Li et al. (2004a) \\
\hline & $5 \mathrm{~A}$ & RFLP & 1 & 10.7 & Groos et al. (2002) \\
\hline & $5 \mathrm{~B}$ & SSR & 1 & - & Kulwal et al. (2004) \\
\hline & $5 \mathrm{D}$ & RFLP & 1 & - & Kulwal et al. (2004) \\
\hline & $6 \mathrm{~A}$ & RFLP & 1 & - & Kulwal et al. (2004) \\
\hline & $6 \mathrm{~B}$ & SSR & 1 & - & Roy et al. (1999) \\
\hline
\end{tabular}


Table 4. (continued)

\begin{tabular}{|c|c|c|c|c|c|}
\hline Trait & $\begin{array}{l}\text { Chromo- } \\
\text { some }\end{array}$ & $\begin{array}{l}\text { Molecular } \\
\text { marker }\end{array}$ & $\begin{array}{l}\text { Number of } \\
\text { QTLs/gene } \\
\text { identified }\end{array}$ & $\begin{array}{l}\text { Per cent } \\
\text { phenotypic } \\
\text { variation } \\
\text { explained }\end{array}$ & Reference \\
\hline \multirow{24}{*}{ Plant height } & $7 \mathrm{~A}$ & RFLP & 1 & 5.6 & Groos et al. (2002) \\
\hline & $7 \mathrm{~B}$ & RFLP/SSR & 1 & - & Kulwal et al. (2004) \\
\hline & $7 \mathrm{D}$ & STS & 1 & - & Roy et al. (1999) \\
\hline & $1 \mathrm{~B}$ & RFLP & 1 & $15-30$ & Cadalen et al. (1998) \\
\hline & $1 \mathrm{~B}$ & SSR & 1 & 13.3 & Keller et al. (1999a) \\
\hline & $2 \mathrm{~A}$ & PCR & 1 & 29.3 & Keller et al. (1999a) \\
\hline & $2 \mathrm{~B}$ & SSR & 1 & 17.4 & Huang et al. (2003b) \\
\hline & $2 \mathrm{D}$ & SSR & Rht8 & $\sim 100$ & Korzun et al. (1998) \\
\hline & $3 \mathrm{~A}$ & Gene & Eps & 42.4 & Shah et al. (1999) \\
\hline & $3 \mathrm{~A}$ & RFLP & 1 & 10.4 & Shah et al. (1999) \\
\hline & $4 \mathrm{~A}$ & RFLP & 2 & $20-29$ & Araki et al. (1999) \\
\hline & $4 \mathrm{~A}$ & SSR & 1 & 23 & Keller et al. (1999a) \\
\hline & $4 \mathrm{~B}$ & RFLP & $2(R h t-B 1)$ & $10-20$ & Cadalen et al. (1998) \\
\hline & $4 \mathrm{~B}$ & SSR & $R h t-B 1$ & 11.8 & Huang et al. (2003b) \\
\hline & $4 \mathrm{D}$ & RFLP & Rht-D1 & $9-15$ & Cadalen et al. (1998) \\
\hline & $4 \mathrm{D}$ & SSR & $R h t-D 1$ & 29.5 & Huang et al. (2003b) \\
\hline & $5 \mathrm{~A}$ & RFLP/SSR & Rht-12 & - & Korzun et al. (1997b) \\
\hline & $5 \mathrm{~A}$ & PCR & 1 & 31 & Keller et al. (1999a) \\
\hline & $5 \mathrm{~B}$ & PCR & 1 & 20 & Keller et al. (1999a) \\
\hline & $6 \mathrm{~A}$ & SSR & 1 & 16.5 & Huang et al. (2003b) \\
\hline & $6 \mathrm{~B}$ & PCR & 1 & 7 & Keller et al. (1999a) \\
\hline & $7 \mathrm{~A}$ & RFLP & 1 & $10.3-11.7$ & Cadalen et al. (1998) \\
\hline & $7 \mathrm{~B}$ & RFLP & 1 & $7.7-16.5$ & Cadalen et al. (1998) \\
\hline & $7 \mathrm{~B}$ & PCR & 1 & 7 & Keller et al. (1999a) \\
\hline Spike length & $1 \mathrm{AL}$ & RFLP & - & 12 & Sourdille et al. (2000a) \\
\hline \multirow[t]{4}{*}{ Spikes/plant } & $2 \mathrm{D}$ & Gene-Ppd-D1 & 1 & $16-22$ & Li et al. (2002a) \\
\hline & $4 \mathrm{~A}$ & RFLP & 1 & $46-52$ & Araki et al. (1999) \\
\hline & $5 \mathrm{~A}$ & RFLP & 1 & $26-39.1$ & Kato et al. (2000) \\
\hline & $7 \mathrm{~A}$ & RFLP & 1 & $16-22$ & Li W et al. (2002) \\
\hline \multirow[t]{2}{*}{ Test weight } & $6 \mathrm{~B}$ & SSR & 1 & 9 & Elouafi and Nachit (2004) \\
\hline & $7 \mathrm{~A}$ & SSR & 1 & 17 & Elouafi and Nachit (2004) \\
\hline \multirow[t]{2}{*}{ Tiller angle } & $2 \mathrm{~A}$ & RFLP & 1 & $12-14$ & Li et al. (2002a) \\
\hline & $3 \mathrm{~A}$ & RFLP & 1 & $14-19$ & Li et al. (2002a) \\
\hline \multirow[t]{5}{*}{ Tiller number } & $1 \mathrm{D}$ & RFLP & 1 & $14-15$ & Li et al. (2002a) \\
\hline & $2 \mathrm{D}$ & RFLP & 1 & $11-15$ & Li et al. (2002a) \\
\hline & $5 \mathrm{~A}$ & RFLP & Vrn1 & $7-37$ & Kato et al. (2000) \\
\hline & $5 \mathrm{~A}$ & RFLP & 1 & $10-19$ & Kato et al. (2000) \\
\hline & $6 \mathrm{~A}$ & RFLP & 1 & $12-31$ & Li et al. (2002a) \\
\hline \multirow{6}{*}{$\begin{array}{l}\text { Vernalization } \\
\text { sensitivity }\end{array}$} & $5 \mathrm{~B}$ & RFLP & $\operatorname{Vrn1} / / \mathrm{Fr} 1$ & - & Galiba et al. (1995) \\
\hline & $5 B$ & SSR & $V r n-B 1$ & - & Salina et al. (2003) \\
\hline & $5 \mathrm{~B}$ & SSR/AFLP & $V r n-B 1$ & - & Barrett et al. (2002) \\
\hline & SB & dCAPs & $\begin{array}{l}\operatorname{Vrn} 2 \\
(=V r n-B 1)\end{array}$ & - & Iwaki et al. (2002) \\
\hline & $5 \mathrm{~B}$ & SSR & $\begin{array}{l}\operatorname{Vrn} 2 \\
(=V r n-B 1)\end{array}$ & - & Iwaki et al. (2002) \\
\hline & $5 \mathrm{~B}$ & AFLP & $P p d-B 1$ & - & William et al. (2003b) \\
\hline
\end{tabular}


Table 4. (continued)

\begin{tabular}{|c|c|c|c|c|c|}
\hline Trait & $\begin{array}{l}\text { Chromo- } \\
\text { some }\end{array}$ & $\begin{array}{l}\text { Molecular } \\
\text { marker }\end{array}$ & $\begin{array}{l}\text { Number of } \\
\text { QTLs/gene } \\
\text { identified }\end{array}$ & $\begin{array}{l}\text { Per cent } \\
\text { phenotypic } \\
\text { variation } \\
\text { explained }\end{array}$ & Reference \\
\hline & $5 \mathrm{D}$ & SSR & $\begin{array}{l}\operatorname{Vrn} 4 \\
(=V r n-D 1)\end{array}$ & - & Kato et al. (2003) \\
\hline & $7 \mathrm{~A}$ & AFLP & VrnA-2 & - & William et al. (2003b) \\
\hline \multirow[t]{5}{*}{ Yield } & $2 \mathrm{D}$ & SSR & 1 & 11.5 & Huang et al. (2003b) \\
\hline & $3 \mathrm{~B}$ & SSR & 2 & $9.6-21.6$ & Huang et al. (2003b) \\
\hline & $4 \mathrm{~A}$ & RFLP & 1 & $17-27$ & Araki et al. (1999) \\
\hline & $4 \mathrm{D}$ & SSR & 2 & $10.1-12.3$ & Huang et al. (2003b) \\
\hline & $5 \mathrm{~A}$ & Gene- $q$ & 1 & $23-27$ & Kato et al. (2000) \\
\hline \multicolumn{6}{|l|}{ Others } \\
\hline \multirow[t]{5}{*}{ Alpha-amylase } & $1 \mathrm{~B}$ & SSR & 1 & $7.9-14.7$ & Zanetti et al. (2000) \\
\hline & $3 B$ & RFLP & 1 & $7-15.5$ & Zanetti et al. (2000) \\
\hline & $5 \mathrm{~A}$ & RFLP & 2 & $13.0-38.5$ & Zanetti et al. (2000) \\
\hline & $6 \mathrm{~A}$ & RFLP & 1 & $13.5-17.7$ & Zanetti et al. (2000) \\
\hline & 7B & RFLP & 1 & $7.7-25.0$ & Zanetti et al. (2000) \\
\hline \multirow[t]{4}{*}{ Starch quality } & $4 \mathrm{~A}$ & AS-PCR ${ }^{a}$ & $W x-B 1$ & - & McLauchlan et al. (2001) \\
\hline & $7 \mathrm{~A}$ & AS-PCR & $W x-A 1$ & - & McLauchlan et al. (2001) \\
\hline & $7 \mathrm{D}$ & AS-PCR & $W x-D 1$ & - & McLauchlan et al. (2001) \\
\hline & $4 \mathrm{~A}$ & GS-PCR ${ }^{b}$ & GBSS $^{c}$ & - & Briney et al. (1998) \\
\hline \multirow[t]{4}{*}{ Polyphenol oxidase } & $2 \mathrm{D}$ & RFLP & 1 & 23 & Demeke et al. (2001) \\
\hline & $2 \mathrm{~A}$ & RFLP & 1 & $12-16$ & Demeke et al. (2001) \\
\hline & $3 \mathrm{~B}$ & RFLP & 1 & $11-14$ & Demeke et al. (2001) \\
\hline & $6 \mathrm{~B}$ & RFLP & 1 & $12-14$ & Demeke et al. (2001) \\
\hline Anther culturability & $5 \mathrm{~B}$ & SSR & 2 & 76.7 & Zhang et al. (2003a) \\
\hline Crossability (wheat-rye) & $5 \mathrm{~B}$ & RFLP & $K r 1$ & 65 & Tixier et al. (1998) \\
\hline \multirow[t]{2}{*}{ Flag leaf senescence } & $2 \mathrm{~B}$ & AFLP/SSR & & $10.2-11.4$ & Verma et al. (2004) \\
\hline & $2 \mathrm{D}$ & AFLP/SSR & 1 & $21.7-32.9$ & Verma et al. (2004) \\
\hline Glume colour & $1 \mathrm{D}$ & SSR & $\operatorname{Rg} 2$ & - & Arzani et al. (2003) \\
\hline Species cytoplasm & $1 \mathrm{~A}$ & RFLP & $s c s^{t i}$ & - & Simons et al. (2003) \\
\hline specific (scs) & $1 \mathrm{~A}$ & RH mapping & $s c s^{a e}$ & - & $\begin{array}{l}\text { Kianian et al. (2003), } \\
\text { Hossain et al. (2004) }\end{array}$ \\
\hline $\begin{array}{l}\text { Thermosensitive genic } \\
\text { male sterlity (TGMS) }\end{array}$ & $2 \mathrm{~B}$ & AFLP/SSR & $w t m s 1$ & - & Xing et al. (2003) \\
\hline Photoperiod & - & ISSR & ptms1 & - & Cao et al. (2003) \\
\hline $\begin{array}{l}\text { temperature sensitive } \\
\text { genic malesterlity } \\
\text { (PTSGMS) }\end{array}$ & $3 \mathrm{~A}$ & ISSR & ptms2 & - & Cao et al. (2003) \\
\hline
\end{tabular}

\footnotetext{
${ }^{\mathrm{a}} \mathrm{AS}-\mathrm{PCR}=$ allele-specific PCR GS-PCR = gene-specific PCR GBSS $=$ granule bound starch synthetase
}

for which markers have been successfully tested within experimental populations in Australia include tolerance to high soil boron (Bo1), tolerance to late-maturity $\alpha$-amylase (LMA) (7BL), barley yellow dwarf virus resistance $(B d v 2)$ (7DL), cereal cyst nematode resistance Cre1 (2BL), Cre8 (6BL), waxy or granule-bound starch synthase $(W x-B 1)(4 \mathrm{~A})$, high-molecular-weight glutenin subunits (GluD1) 
(1DL), leaf rust resistances (Lr46) (1BL), (Lr34) (7DS), height or dwarfing genes (Rht1) (4BS), (Rht2) (4DS), (Rht8) (2DS), root lesion nematode resistance ( $R \ln n 1)$ and yellow flour colour (7AL), stem rust resistances (Sr2) (3BS), (Sr36) (2B) and VPM (Ventricosa $\mathrm{x}$ Persicum $\mathrm{x}$ Marne), a source for eyespot resistance gene Pch1, obtained by introgrossion) segment (2AS). Additional loci for which markers are under investigation include aluminium toxicity tolerance (4B), Glu-A3 (1AS), Glu-B3 (1BS), Lr1 (5DL), Lr13 (2B), Lr19 (7DL) and polyphenol oxidase activity (2D) (Pallotta et al. 2003). At CIMMYT (Mexico), marker implementation in wheat breeding involves the routine deployment of markers for the four genes Cre1, Cre3, BYDV resistance, ph1b mutant, and for the Ae. ventricosa segment carrying Yr17, Lr37and Sr38 translocated 2AS. Approximately 7,000 marker assays are performed annually (William et al. 2003a).

With the availability of many more markers than in earlier years, the potential for uptake is now much greater than in the past. Reflecting this, a consortium of 12 wheat-breeding and research programmes across the US named 'MASwheat' (http://maswheat.ucdavis.edu/index.htm) has recently been launched, aiming to 'transfer new developments in wheat genomics and biotechnology to wheat production'. However, with a unit assay cost in the range of US\$1-2 (Dreher et al. 2003; Koebner and Summers 2003), the widespread application of MAS must compete with alternative assay methods for the scarce funds available to most breeding programs. Although it was recently suggested that the bulk of MAS uptake remains restricted to low volume applications, such as genotype construction by backcrossing, and to the development of niche genotypes such as waxy wheats (Koebner 2004), this is clearly not the case for some breeding programmes such as the Australian programme described above. As the unit assay costs fall with the development of automated platforms and high-throughput marker systems, one can anticipate that MAS assays will become increasingly feasible for commercial wheat breeding.

\subsection{2}

\section{Map-Based Cloning (MBC) of Genes in Wheat}

In addition to their use for indirect selection of genes or QTLs of agronomic importance (including resistance to diseases), molecular markers offer the pos- sibility of isolating genes of interest by positional cloning with an ultimate objective of producing transgenic plants for crop improvement. There are three major requirements for positional gene isolation: (i) a high-resolution, high-density genetic map spanning the gene or region of interest; (ii) availability of a large insert genomic YAC, BAC or PAC library for preparation of a physical map to isolate the candidate gene; and (iii) multiple independent mutant stocks, an efficient transformation system for use in functional complementation or an alternative technique for functional analysis of candidate genes. All these resources have become available in wheat (Lagudah et al. 2001; Stein and Graner 2004).

However, long-distance chromosome walking is not efficient in wheat because of the large amount of repetitive DNA and the physical size of the genome. To overcome this problem, several strategies have been developed for isolating genes from wheat.

\section{Genome Collinearity}

The gene order appears to be well conserved among various species of grass. This is referred to as synteny. Since the rice genome has been sequenced, it can be used as an intergenomic vehicle in cereals including wheat (Moore et al. 1995a; Keller and Feuillet 2000). This approach was used for the isolation of the vernalization response gene Vrn1 from Triticum monococcum (Yan et al. 2003b). Complete marker/gene collinearity was observed for the putative orthologous regions on T. monococcum chromosome $5 \mathrm{~A}^{\mathrm{m}}$ and rice chromosome 3 , and a BAC contig of the target region was constructed from a T. monococcum BAC library. It was collinear to two BACs representing the orthologous locus in rice. However, both physical maps showed a gap between the same two collinear genes. Interestingly, screening of a sorghum BAC library revealed a collinear BAC that bridged the gap in the other two species leading to a consensus physical map across three cereal species. The most promising candidate gene for Vrn1 proved to be an orthologue in all three species. Similarly, using the genome collinearity approach, Sutton et al. (2003) have identified candidate meiotic genes at the $\mathrm{Ph} 2 \mathrm{lo-}$ cus of wheat. They identified the rice genomic region syntenous to the region deleted in wheat chromosome pairing mutant $p h 2 a$. With the help of markers known to reside within the region deleted in ph $2 a$ and data from wheat, barley and rice genetic maps, markers 
delimiting the region deleted on wheat chromosome $3 \mathrm{DS}$ in the ph $2 a$ mutant were used to locate the syntenous region on rice chromosome $1 \mathrm{~S}$. A 6.58-Mb rice contig generated from 60 overlapping rice $\mathrm{PAC}$ clones spanning the syntenous rice region has enabled identification of 218 wheat ESTs putatively located in the region deleted in $p h 2 a$. The candidate gene approach may sometimes also fail, as suggested by the reports of variation in the content and order of orthologous genomic sequences from several cereal species (for a review see Bennetzen and Ramakrishna 2002; Feuillet and Keller 2002). In particular, the identification of candidate genes for race-specific disease resistance loci, which are less conserved between species and prone to genomic rearrangements (Leister et al. 1998), has proved problematic, and the earlier optimism regarding the use of the model genome strategy has diminished recently (Brueggeman et al. 2002; Bennetzen and Ma 2003).

\section{Subgenome Chromosome Walking}

In addition to the high proportion of repetitive DNA in wheat, polyploidy poses another level of complexity to positional cloning. As mentioned earlier, the three homoeologous subgenomes A, B and D are highly collinear and most of the functional loci occur as triplicate genes. Therefore, screening of a large insert library will yield two thirds of clones, which are not related to a target locus in a specific subgenome. In order to tackle this problem, large insert libraries were constructed from diploid and tetraploid wheat species (Stein and Graner 2004). Therefore an approach called 'subgenome chromosome walking', employing these libraries, has been used to isolate disease resistance genes. The first successful example of this approach involved map-based cloning of the Lr10 leaf rust resistance locus (located on chromosome 1AS) of bread wheat. A three-step chromosome walk in a T. monococcum BAC library initiated from a closely linked RFLP marker allowed a BAC contig to be established, which contained the flanking markers and two candidate resistance genes (Stein et al. 2000; Wicker et al. 2001). Markers cosegregating with the gene were derived from the initial contig, and additional markers were developed from low-copy sequences obtained after low-pass shotgun sequencing of neighbouring BAC clones. All markers derived from the T. monococcum contig mapped to collinear segments of the $T$. aestivum genetic map. The T. aestivum orthologues of the two candidate genes were subsequently isolated.
One of the candidate genes, Rgal, proved to be $\operatorname{Lr} 10$ as confirmed after sequence analysis of mutant alleles and complementation via transformation into a susceptible genotype (Feuillet et al. 2003).

Similarly, the powdery mildew resistance gene $P m 3 b$ was isolated from T. aestivum using a subgenomic BAC library. Since chromosome walking in $T$. monococcum was not successful due to a gap in the BAC library, a BAC library of the tetraploid relative T. turgidum ssp. durum (Cenci et al. 2003) was used, allowing construction of a contig covering Pm3b. Resistance conferred by transient expression was monitored in the epidermis of detached wheat leaves of a susceptible T. aestivum cultivar after biolistic bombardment with the homoeologue of the identified candidate gene and subsequent powdery mildew infection (Yahiaoui et al. 2003). The $Q$ locus of T. aestivum, conferring free-threshing and square-headed spikes, was physically delimited by the same strategy (Faris et al. 2003) and should lead to the isolation of the $Q$ locus.

Another gene conferring resistance to wheat leaf rust was isolated through the use of a Aegilops tauschii (D genome) subgenomic cosmid library (Huang et al. 2003a). Lr21 was previously introgressed into T. aestivum via synthetic wheat derived from a cross between T. turgidum and the resistant Ae. tauschii accession TA1649. A closely linked RFLP probe was used to screen the cosmid library. A single cosmid clone harbouring the closely linked RFLP fragment could be isolated. The $L r 21$ gene spans $4,318 \mathrm{bp}$ and encodes a 1,080-amino-acid protein containing a conserved nucleotide-binding site (NBS) domain, 13 imperfect leucine-rich repeats (LRRs), and a unique 151-aminoacid sequence missing from known NBS-LRR proteins at the $\mathrm{N}$ terminus. The whole cosmid was used for complementation via stable transformation, and resistance was achieved.

However, unlike disease resistance, many agronomically important traits are controlled by QTLs (Table 3). In recent years, significant progress has been made in the isolation of QTLs such as those controlling fruit weight ( fw2.2) in tomato (Alpert and Tanksley 1996) and photoperiod sensitivity ( $H d 1, H d 3 a, H d 6)$ in rice (Yano et al. 2000; Takahashi et al. 2001; Kojima et al. 2002). Due to systematic development of resources in wheat, it is now becoming possible to clone QTLs for some important traits in wheat for crop-improvement programs. 


\subsection{3}

\section{Allelic Diversity}

An understanding of germplasm diversity and genetic relationships among breeding materials is an invaluable aid for crop-improvement strategies. Conventional analyses of genetic diversity in germplasm accessions, breeding lines and populations have relied on pedigree information and morphological and agronomic performance data. The advent of biochemical and particularly DNA marker technology has improved the accuracy and number of lines that can be assessed in germplasm collections (Tanksley and McCouch 1997; Mohammadi and Prasanna 2003).

For practical reasons many of the early attempts to study diversity employed RAPDs (Vierling and Nguyen 1992; Joshi and Nguyen 1993). However, it soon became clear that the greater reproducibility of RFLPs was advantageous (for example, Siedler et al. 1994; Autrique et al. 1996). Now, SSRs and AFLPs have largely replaced these for genetic diversity studies (Table 4). In particular, some SSR loci can show such high levels of variability that even closely related genotypes can be distinguished from one another (Plaschke et al. 1995; Prasad et al. 2000; Stachel et al. 2000). On the other hand, AFLPs have the advantage of delivering a much higher multiplex ratio and are particularly useful for fingerprinting and the assessment of genetic diversity (Law et al. 1998; Bohn et al. 1999; Schwarz et al. 2000). As some differences in AFLP pattern have been found to be specific for particular plant organs (Donini et al. 1997), it is important to extract template DNA from physiologically uniform tissues. Recently developed genic microsatellites (or EST-SSRs) have been found to be superior to genomic SSRs due to improved quality of banding pattern (Eujayl et al. 2001; Leigh et al. 2003). Although the informativeness of genic SSRs is generally lower than for genomic SSRs, their origin from the conserved proportion of a genome have made them more suitable as a tool to assess genetic diversity across species (Gupta et al. 2003; Bandopadhyay et al. 2004; for a review see Varshney et al. 2005a). Recently, retrotransposon-based molecular markers have also been used for diversity studies in wheat by using the SSAP (sequence-specific amplification polymorphism) assay (Queen et al. 2004). A summary of some genetic diversity studies involving with different marker systems in Triticum species is given in Table 5.

Molecular-marker evaluations have indicated that genetic diversity among varieties or inbred lines is higher than expected, although it is lower than that among landraces (Chen et al. 1994; Autrique et al. 1996; Zhang et al. 2002; Röder et al. 2003). For example, Röder et al. (2003) found 198 alleles across 19 SSR loci in 502 European varieties, 280 alleles in 450 European landraces and 323 alleles in 544 non-European landraces. Of the 339 alleles found in 994 landraces, 147 are present only in landraces but not in varieties, suggesting a genetic similarity of $57 \%$.

Evidence of temporal flux in genetic diversity has been observed in wheat varieties released at different times within a country or region. Genetic diversity appears to be decreasing in Iranian wheats (SayedTabatabaei and Shahnejat-Bushehri 2003), increasing in Italian durum wheats (Maccaferri et al. 2003), but has remained constant in the wheat varieties of Argentina (Manifseto et al. 2001), UK (Donini et al. 2000; Koebner et al. 2003) and the Yaqui Valley of Mexico (Souza et al. 1994). Interestingly, genetic diversity in Nordic spring wheat was enhanced by plant breeding in the first quarter of the 20th century and, following a decrease during the second quarter, increased again by plant breeding (Christiansen et al. 2002).

The use of molecular markers has also shown that diversity within a genome is largely shaped by recombination and selection and is not homogenous. In Aegilops, the polymorphism level of a locus has been correlated with recombination rate along the centromere to telomere axis (Dvorák et al. 1998b). Intraspecific nuclear genome variation appears lower in einkorn wheats and higher in Ae. speltoides, while this pattern is reversed for chloroplast DNA (Mizumoto et al. 2002). Comparison of landraces and improved varieties of Chinese wheat revealed a significant difference in the level of diversity within the D genome (Zhang et al. 2003b), indicating that high selection pressure has been applied to the $\mathrm{D}$ genome during the breeding process.

Genetic diversity studies involving germplasm from different countries or regions often allow separation of accessions into distinct groupings (Stachel et al. 2000; Bai et al. 2003; Pester et al. 2003). Among wild emmer wheats from Israel and Turkey, DNA polymorphisms have been associated with microclimatic stress (Fahima et al. 1999, 2002; Li et al. 1999, 2002). Associations between allelic constitutions at marker loci with agronomically important traits have been proposed in some diversity studies (Kobiljski et al. 2002; Roy et al. 2002; Bai et al. 2003). However, although suitable genotypes for hybridization were identified in this way (Roy et al. 2004), the overall ge- 


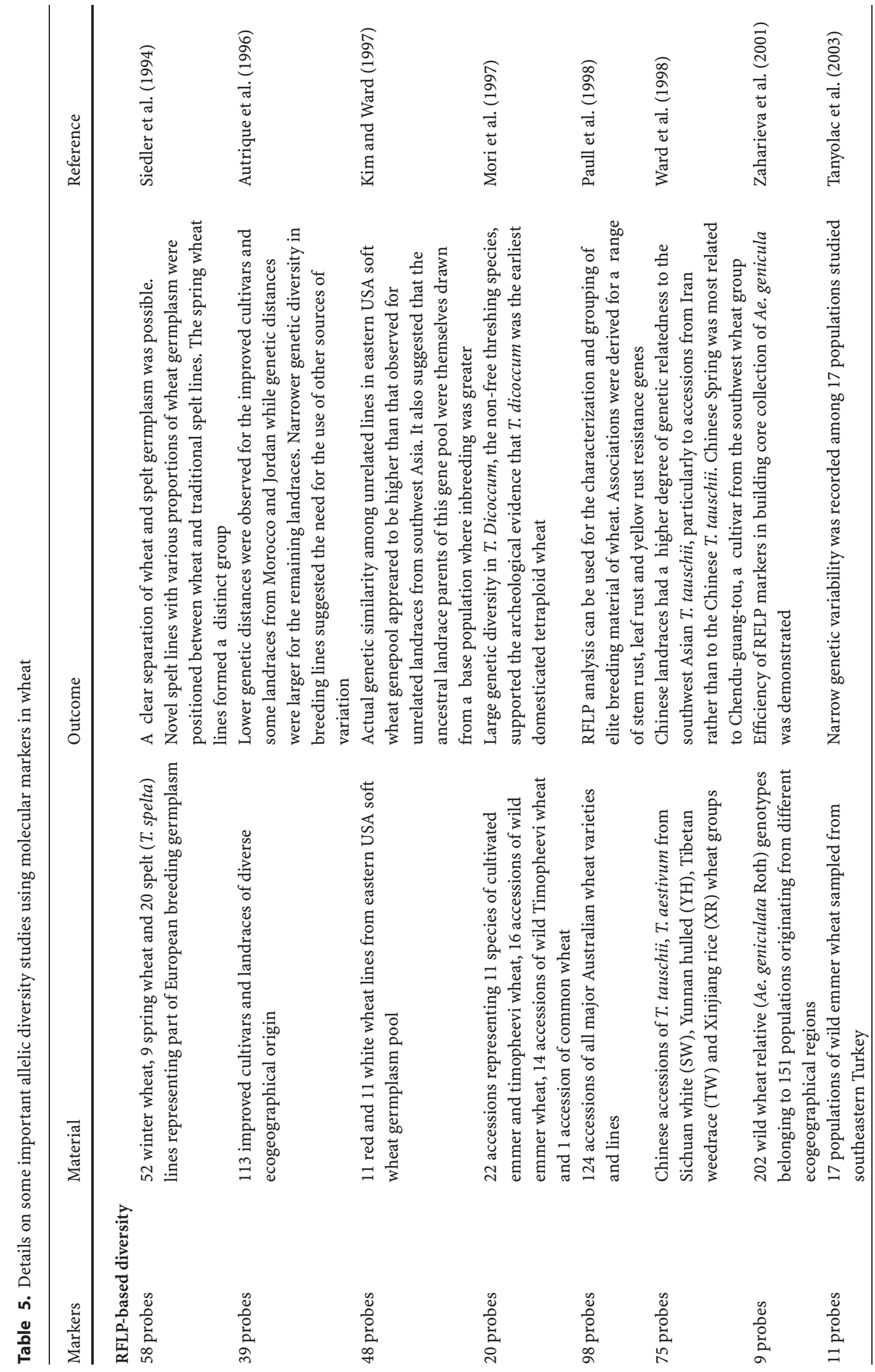




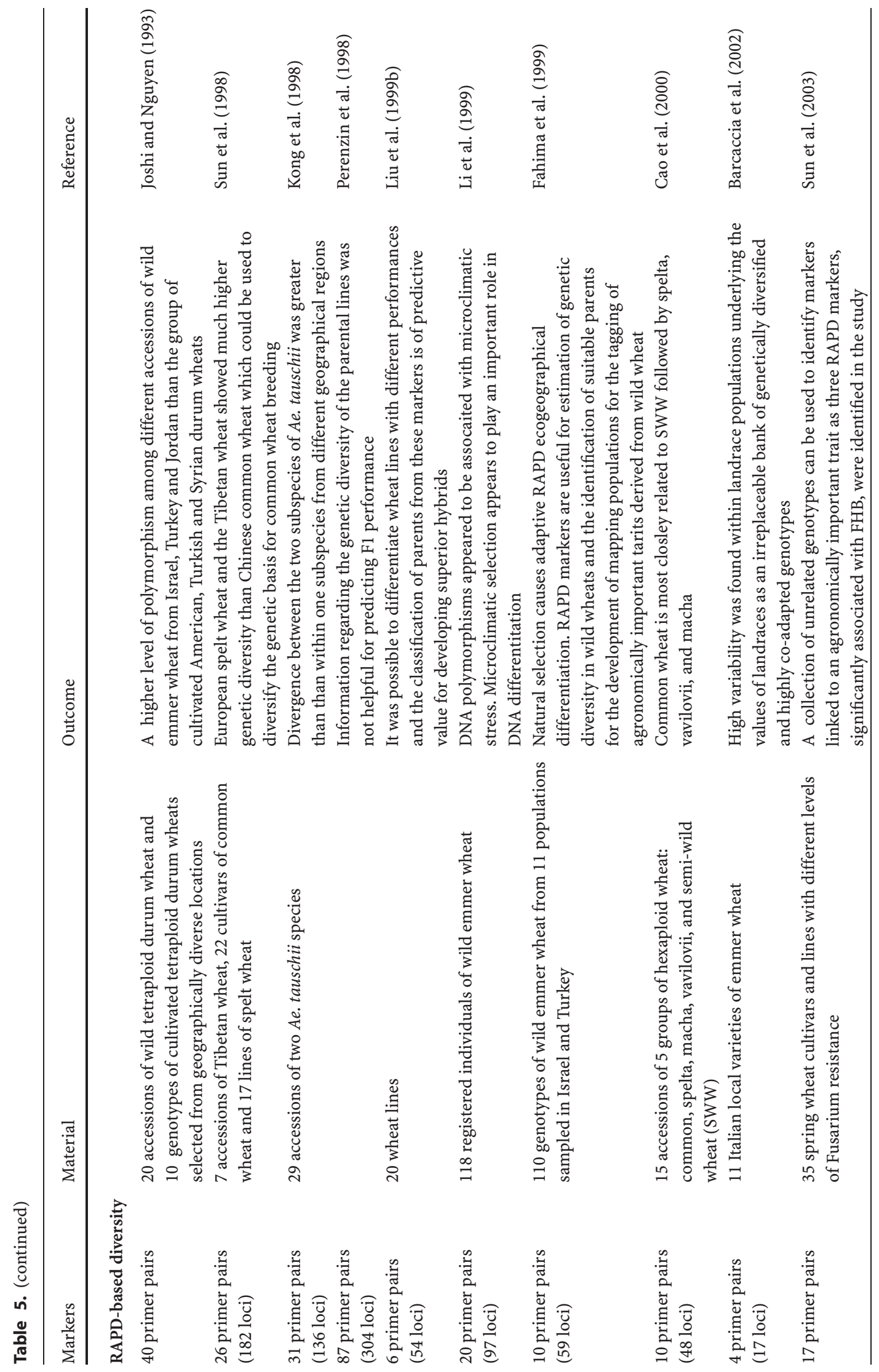




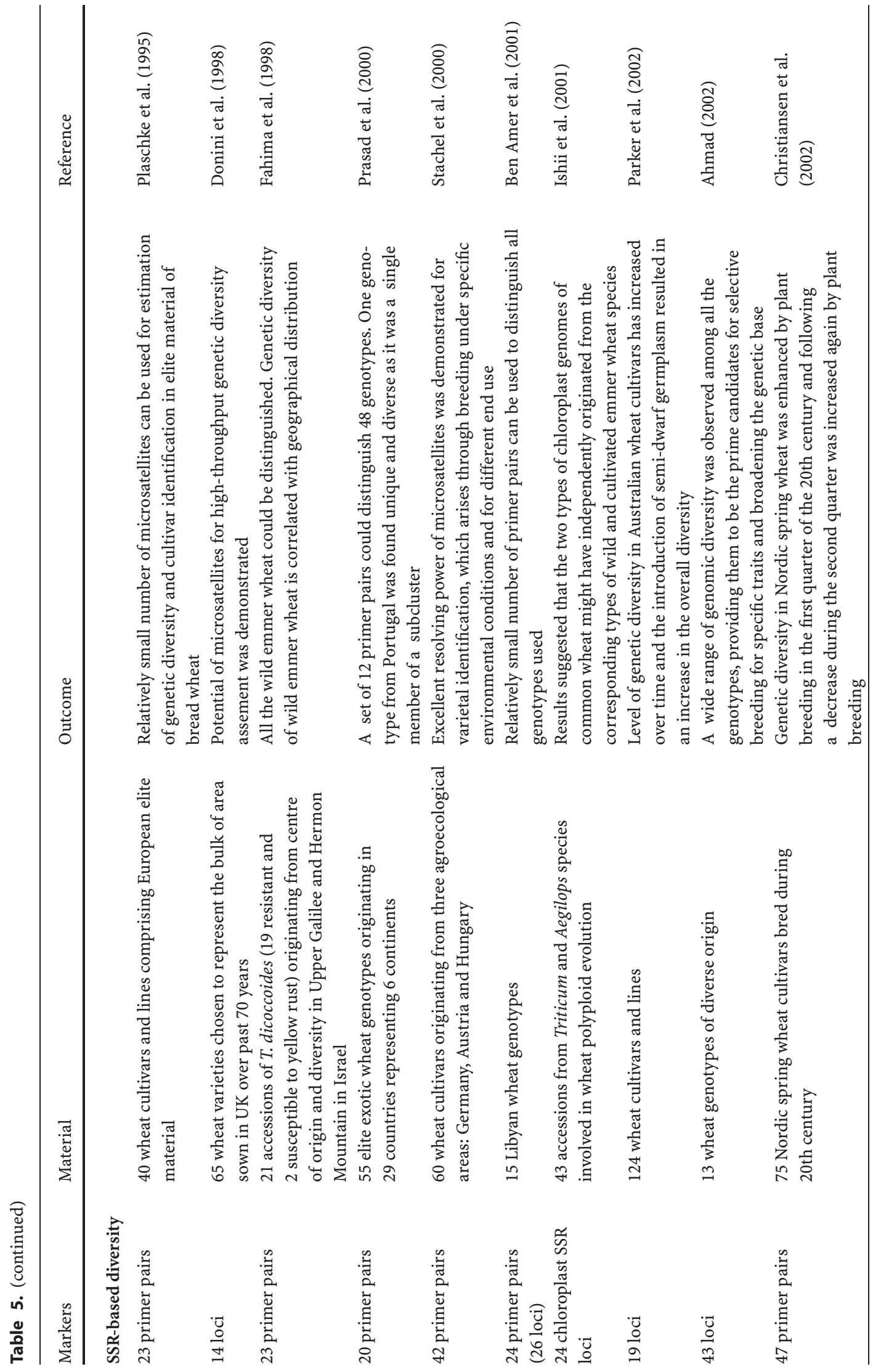




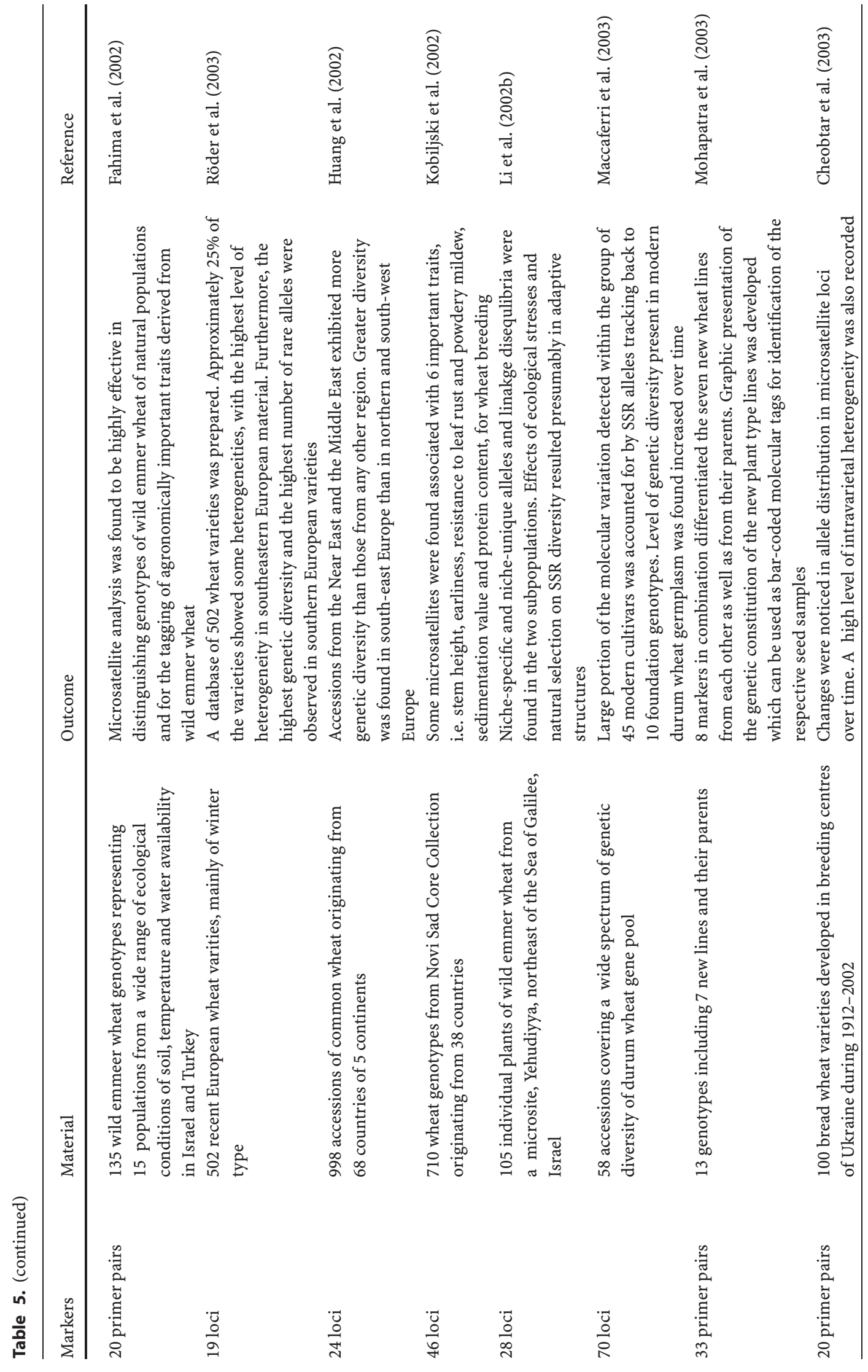




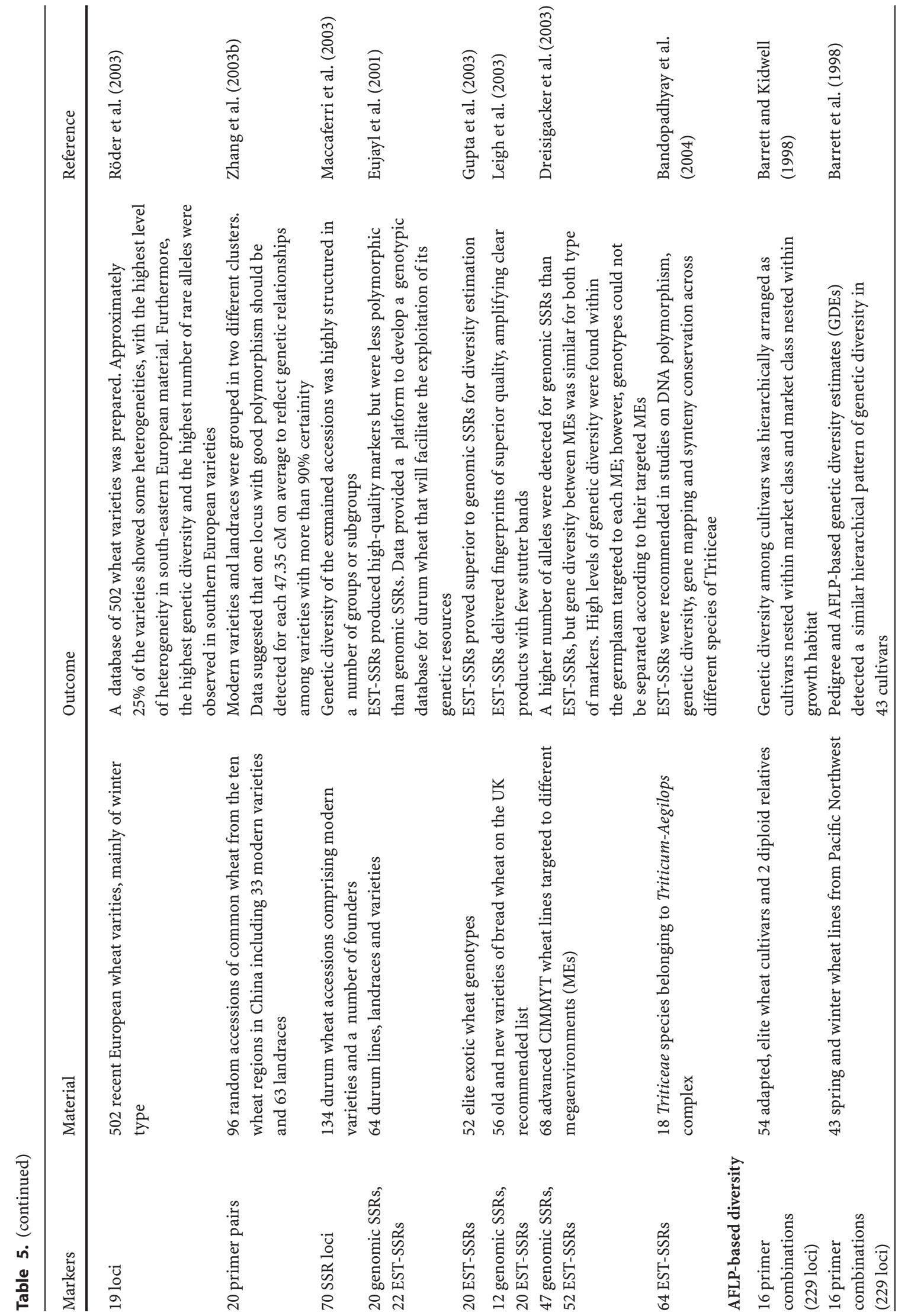




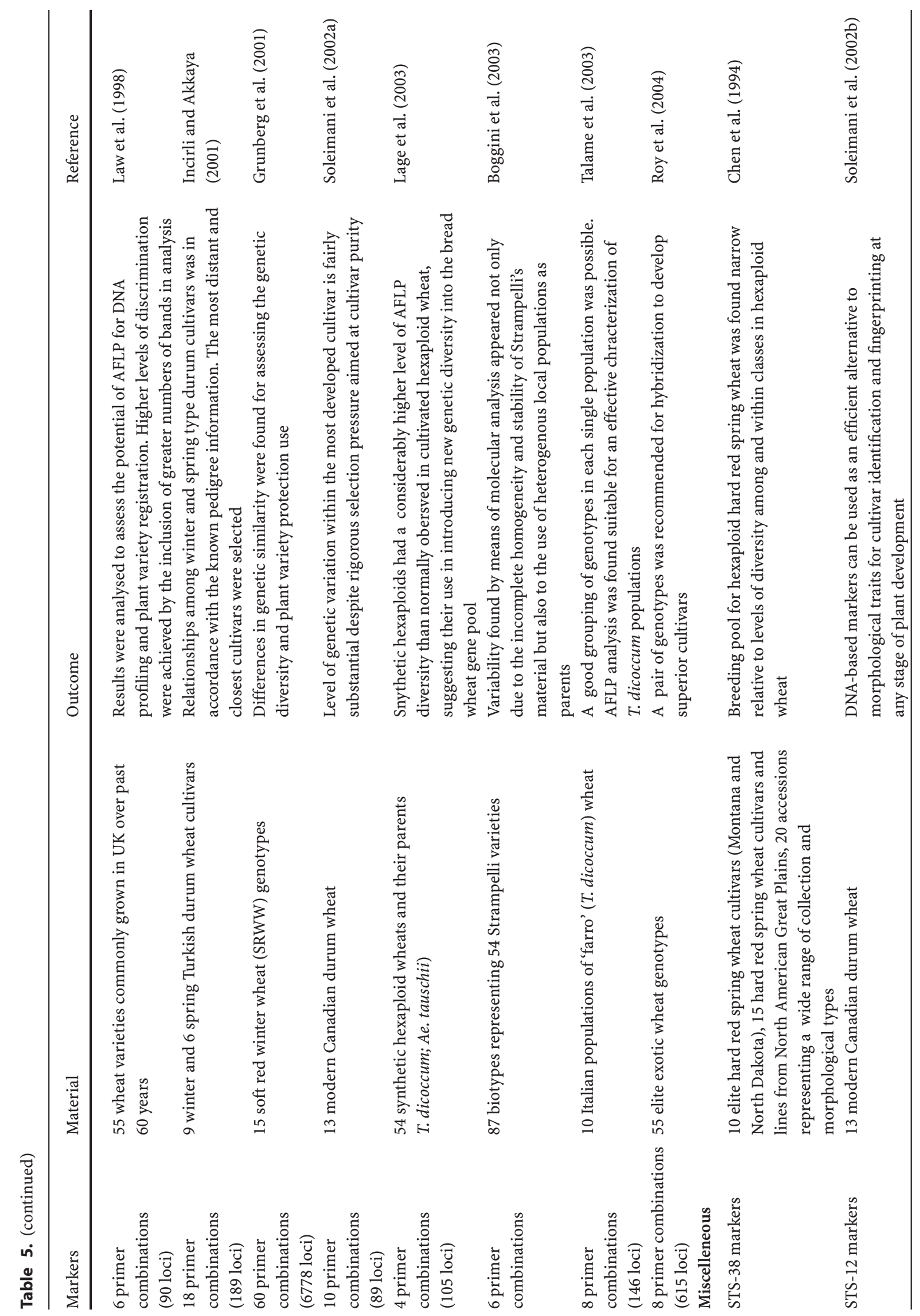




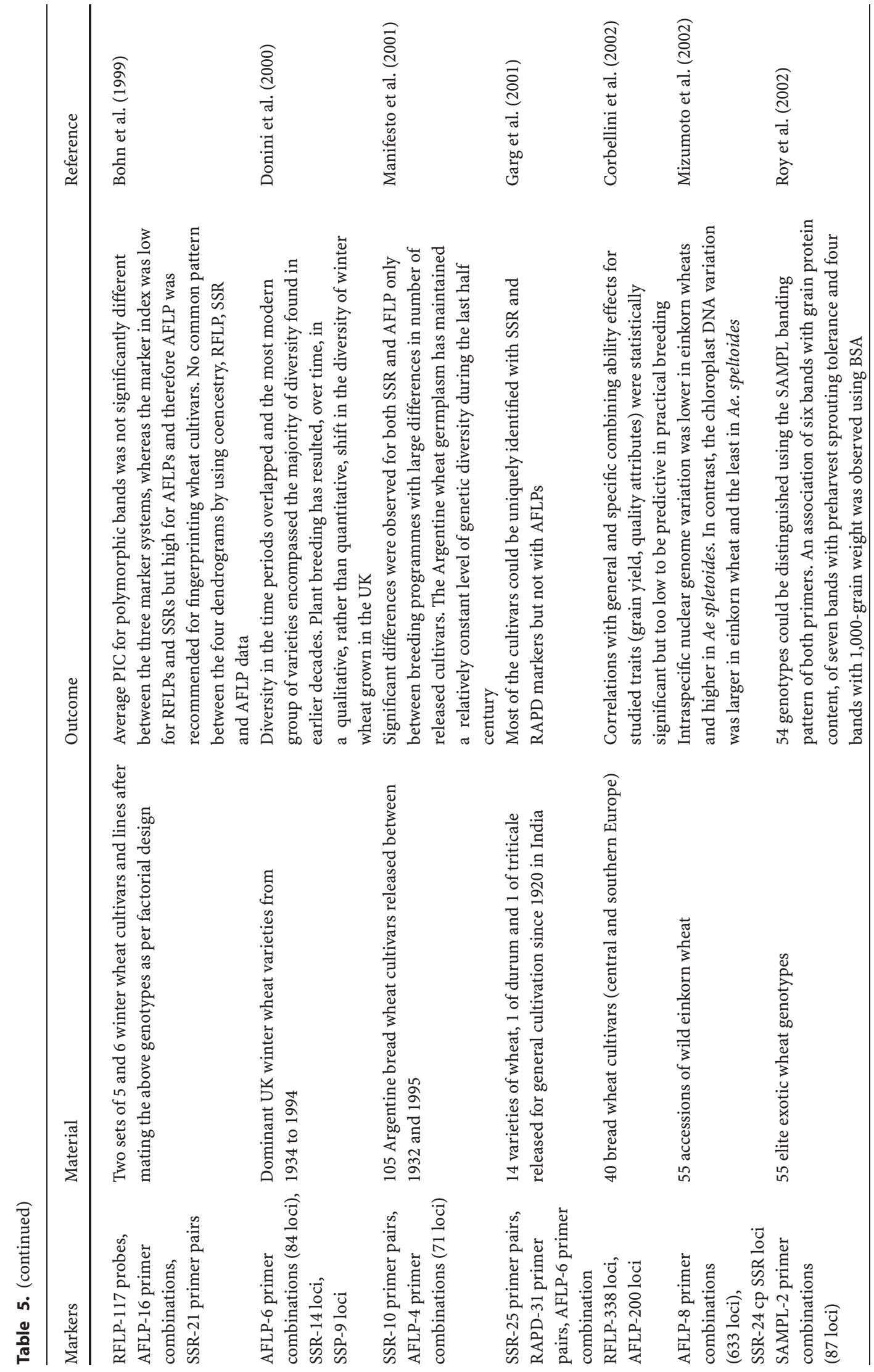




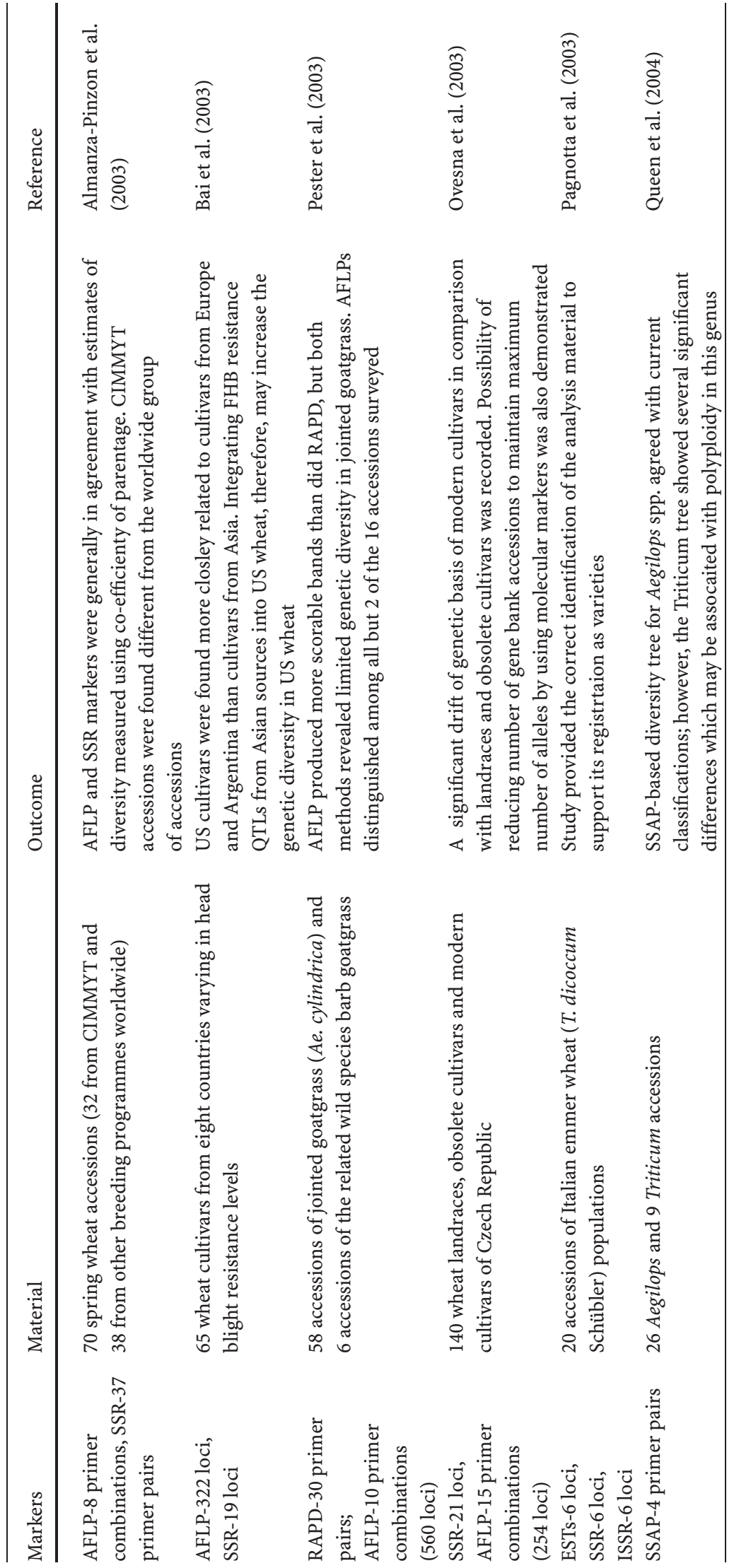


netic diversity of the parental lines was inadequate for predicting either progeny variance or $\mathrm{F}_{1}$ performance (Perenzin et al. 1998; Bohn et al. 1999; Dreisigacker et al. 2003).

Marker analysis of common wheats with presumptive wild ancestors has provided insights into the crop's domestication and guided strategies for collecting, evaluating and utilizing germplasm. AFLP fingerprinting of einkorn and emmer wheats and barley, along with their wild progenitors, indicated that both einkorn (Heun et al. 1997) and emmer wheats (Özkan et al. 2002) were domesticated in a very small area of southeastern Turkey near the Tigris and Euphrates rivers more than 10,000 years ago. More recently, microsatellite sequences have been used to generate molecular clock estimates of the dates of wheat domestication. These ranged from 9,000 to 19,000 years for the transition from T. dicoccoides and T. aestivum and 8,705 to 18,414 years between T. dicoccoides and T. durum (Fahima et al. 2003). Sequence variation at a number of D genome STS loci has suggested that multiple $\mathrm{D}$ genome diploid parents were involved in the origin of common wheat (Talbert et al. 1998) and that all wheats share a single D-genome gene pool, which is the strangulata form of Ae. tauschii (Dvorák et al. 1998a). The strangulata gene pool is larger than expected because of gene flow from the tauschii form of Ae. tauschii (Lubbers et al. 1991; Dvorák et al. 1998a).

\subsection{4}

\section{Comparative Mapping and Synteny}

Molecular mapping of wheat and other grass species suggested that despite more than 60 million years of evolution within the subfamily of the Poaceae, the individual grass genomes are characterized by large segments of conserved linkage blocks that display collinear marker orders between different species. Similar to a LEGO-model, grass genomes are considered to be made up of conserved segments (Moore 1995). This model was extended by Gale and Devos (1998), and it was shown that the grass genomes can be displayed in concentric circles in which orthologous genes, which are derived from a common ancestor locus, are located on a radial line. Some reports on comparative mapping dealing with wheat and other cereal species are listed in Table 6 . These studies provide important clues about the structural organization of the cereal genomes. For instance, the com-

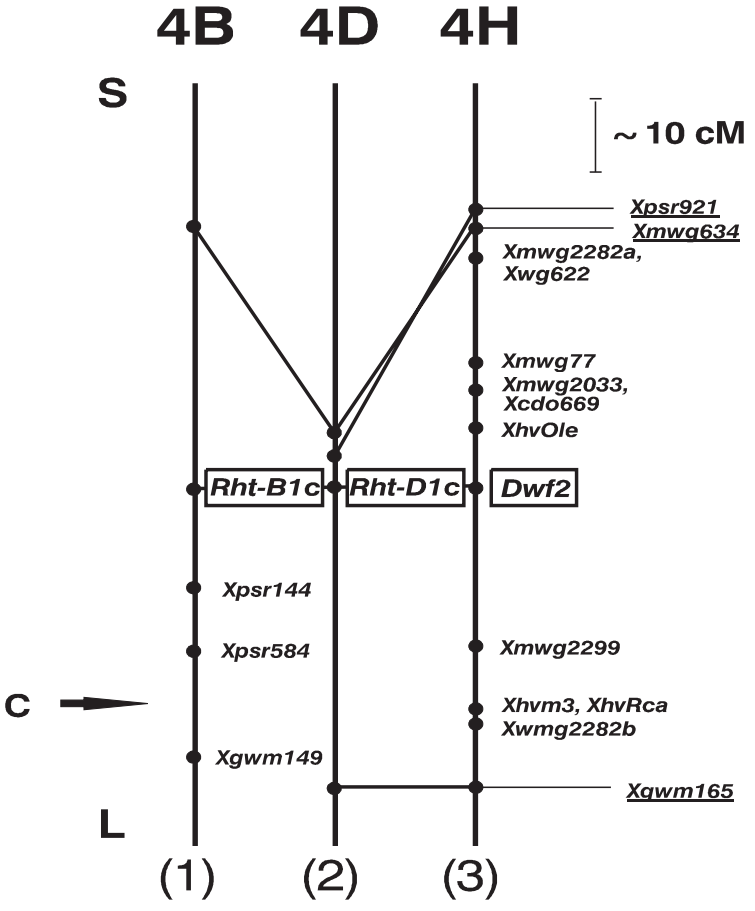

Fig. 1. Comparative location of genes determining dwarfness (GA insensitive) on chromosomes $4 \mathrm{~B}$ and $4 \mathrm{D}$ of wheat and $4 \mathrm{H}$ of barley using the following basic maps: $(1,2)$ Börner et al. (1997), (3) Ivandic et al. (1998). Mapped loci are marked with a point. The connecting lines between chromosomes indicate common loci which are underlined. Genetic distances (roughly estimated) are given in centimorgans (cM). The gene loci are boxed. $c=$ estimated centromere position, $S=$ short $\operatorname{arm}, L=$ long arm

parative mapping of GA-insensitive dwarfing genes suggested that the dominant $R h t$ genes of wheat and the codominat $D w f 2$ gene of barley are members of a homoeoallelic series existing in the triticeae species (Fig. 1). In a similar way, Fig. 2 shows that the wal locus (determining the waxless plant character) of rye is homoeoallelic to the glaucousness (waxiness) loci $w 1$ or $w 2^{1}$ of wheat and genes/alleles for glossy sheat/spike ( $g s 1, g s 6, g s 8)$ of barley. Furthermore, the alignment of the $g l 2$ (responsible for altering cuticle wax) gene region of maize with the $w 2^{1}$ of wheat suggests the conservation of genes responsible for similar traits acrosss different cereal genomes. In addition to revealing evolutionary patterns within the Poaceae subfamily; comparative mapping provides access to the model genome of rice. An obvious strategy emerging from the concept of syntenous relationships is the transfer of the vast amount of genomic information 
Table 6. A list of some important comparative mapping and genomics studies revealing the syntenic relationship of wheat with other cereal species

\begin{tabular}{ll}
\hline Species & References \\
\hline Wheat, barley & Namuth et al. (1994), Hohmann et al. (1995), Dubcovsky et al. (1996), \\
& Hernandez et al. (2001), Salvo-Garrido et al. (2001), Weng and Lazar (2002b), \\
& Varshney et al. (2005b) \\
Wheat, maize & Devos et al. (1994) \\
Wheat, rice & Kurata et al. (1994), Kato et al. (1999), Sarma et al. (1998, 2000), \\
& Lamoureaux et al. (2002), Liu and Anderson (2003b), Laubin et al. (2003), \\
& Sorrells et al. (2003), Francki et al. (2003), La Rota and Sorrells (2004), \\
& Singh et al. (2004a), Li et al. (2004b), Yu et al. (2004b) \\
Wheat, rye & Devos et al. (1992, 1993a), Khlestkina et al. (2004) \\
Wheat, barley, rye & Devos et al. (1993b), Devos and Gale (1993), Börner et al. (1998), \\
& Gudu et al. (2002) \\
Wheat, barley, rice & Dunford et al. (1995), Gallego et al. (1998), Kato et al. (2001) \\
Wheat, maize, rice & Ahn et al. (1993), Moore et al. (1995b) \\
Wheat, maize, oat, rice & Van Deynze et al. (1995a,b) \\
Wheat, foxtail-millet, maize, rice & Moore et al. (1995a) \\
\hline
\end{tabular}

and resources available in rice genome to the wheat genome (see paragraph above, Genome Collinearity).

Our present knowledge of synteny is mainly based on comparative mapping of cross-hybridizing RFLP markers. Comparisons of genetic linkage maps are severely limited in their resolution by the number of orthologous loci detected and by population sizes. Early comparative maps (e.g., Hulbert et al. 1990; Ahn and Tanksley 1993; Ahn et al. 1993; Kurata et al. 1994; Moore et al. 1995a,b; Devos and Gale 1997; Gale and Devos 1998) greatly underestimated the complexity of genome relationships. Those low-resolution comparative maps are biased by the use of single-copy probes that do not sample multicopy regions, simplifying assumptions about collinearity and placing excessive emphasis of gene-rich regions (Bennetzen 2000; Gaut 2001, 2002). In silico comparison of DNA sequences among different cereals makes it possible to transfer the sequence information between species to greatly enhance the resolution of comparative maps. For instance, in silico comparison of 974 genetically mapped barley ESTs with 524,720 wheat ESTs provided a potential set of 934 (95.4\% of the loci tested) EST-derived markers to wheat genetic maps (Varshney et al. 2004c). However, large-scale comparative DNA sequence analysis of physically mapped wheat ESTs with the rice genome suggested that there has been an abundance of rearrangements, insertions, deletions and duplications eroding the wheat-rice genome relationship that may complicate the use of rice as a model for cross-species transfer of information in non-conserved regions (Sorrells et al. 2003; La Rota and Sorrells 2004; see Sect. 2.5.2 below).

\section{5 \\ Impact of Genomics Research on Wheat Genetics and Breeding}

The publication of the complete genome sequence for Arabidopsis (TAGI 2000) and drafts of rice genome (Goff et al. 2002; Yu et al. 2002) provides the basis for elucidating the gene and protein networks that control biological processes. These model systems provide the basis for determining the genes and the respective proteins that control key components of complex traits in crop plants like wheat (Appels et al. 2003; Gupta and Varshney 2004). A large amount of EST data has been generated for wheat, which is being used to study and analyse the transcriptome of wheat (Powell and Langridge 2004). In addition to these advances in wheat genomics, novel approaches such as linkage disequilibrium (LD) analysis and association 


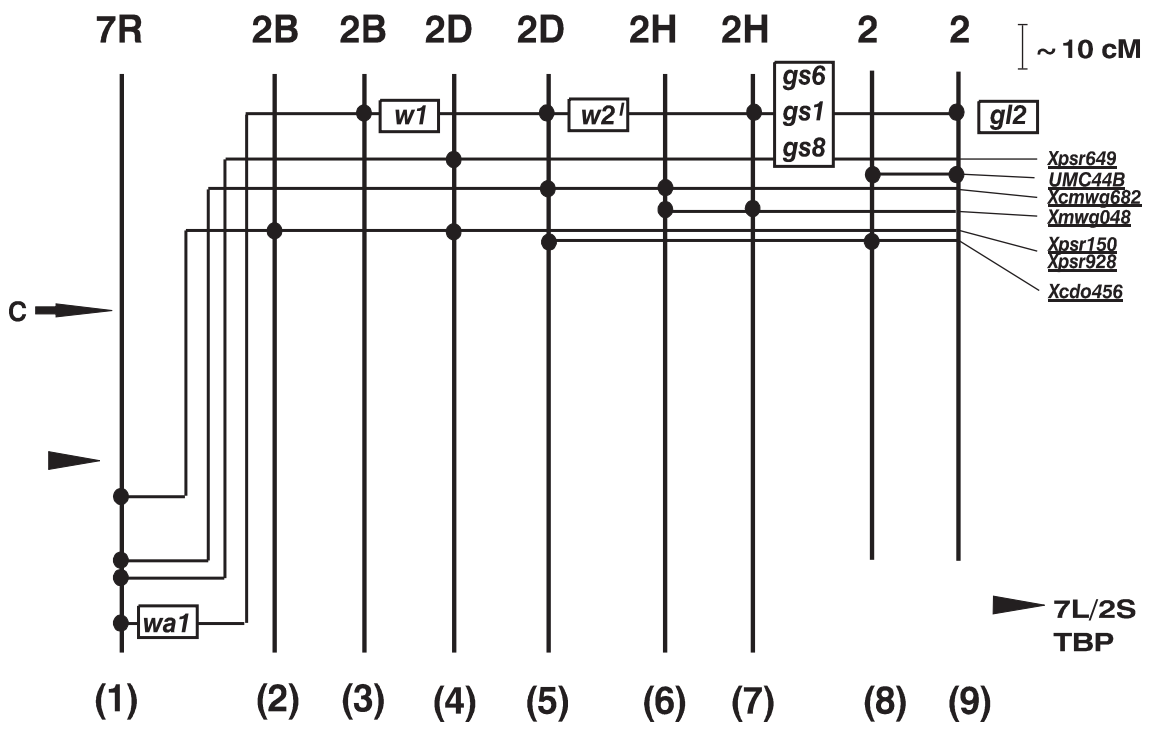

Fig. 2. Comparative location of genes determining waxless plant on chromosomes $7 \mathrm{R}$ of rye, $2 \mathrm{~B}$ and $2 \mathrm{D}$ of wheat, $2 \mathrm{H}$ of barley and 2 of maize using the following basic maps: (1) Korzun et al. (1997a), (2, 4) Devos et al. (1993b), (3) Driscoll (1966), (5) Nelson et al. (1995a), (6) Graner et al. (1991), (7) Franckowiak (unpublished, cf. Börner 1999), (8) Ahn and Tanksley (1993), (9) Coe and Neuffer (1993). Mapped loci are marked with a point. The connecting lines between chromosomes indicate common loci which are underlined. Genetic distances (roughly estimated) are given in centimorgans (cM). The gene loci are boxed. $c=$ estimated centromere position, $S=$ short arm, $L=$ long arm, $T P B=$ translocation break point

mapping and genetical genomics would have a major impact on wheat genetics and breeding in the near future with the ultimate objective of crop improvement.

\subsection{1}

\section{Transcriptomics and Functional Genomics}

In order to establish an inventory of expressed genes in wheat, an international consortium (International Triticeae EST Cooperative) was established to launch the development of a wheat and barley EST database. This effort provided the first serious collection of ESTs and helped lead to other initiatives. In particular a project entitled 'The Structure and Function of Expressed Portion of Wheat Genome' involving 13 laboratories was established in 1999 and funded by the National Science Foundation (NSF), USA (http://wheat.pw.usda.gov/NSF/). The project had as its objective to decipher the chromosomal location and biological function of a large set of wheat genes, to enhance our understanding of the biology of the wheat plant and to create a new paradigm for the improvement of this important crop. To this end, a total of 117,510 ESTs $\left(101,912\right.$ are $5^{\prime}$ ESTs and 15,605 are $3^{\prime}$ ESTs, as of July 2003) from 20 cDNA libraries were generated (Zhang et al. 2004). Computational analysis of this dataset yielded 18,876 contigs and 23,034 singletons (http://wheat.pw.usda.gov/ NSF/curator/assembly.html; Lazo et al. 2004). In addition to these ESTs, generated in NSF-sponsored projects, other public laboratories and private organizations such as the DuPont Corporation also generated wheat ESTs and submitted them to public databases. As a result, 587,650 wheat ESTs are available in the public domain as of dbEST release 012805 (http://www.ncbi.nlm.nih.gov/dbEST/ dbEST_summary.html). A computational analysis of 554,379 wheat ESTs suggested the presence of 44,513 TCs (tentative consensi) and 83,420 singleton ESTs, as per TIGR Wheat Gene Index Release 9.0, 20 September 2004 (http://www.tigr.org).

The extensive EST databases prepared from many different tissues can be used to estimate gene expression levels by measuring the frequency of the appearance of specific sequences, employing computational tools such as Digital Differential Display (http:// www.ncbi.nlm.nih.gov/UniGene/info_ddd.shtml) or HarvEST (http://harvest.ucr.edu/). An example of the use of wheat ESTs from multiple cDNA libraries to study developmental processes was shown by Ogihara et al. (2003). After the analysis of 116,232 ESTs, generated from ten wheat tissues, the re- 
searchers identified correlated expression patterns of genes across the tissues. Furthermore, relationships of gene expression profiles among the ten wheat tissues were inferred from global gene expression patterns. However, the use of EST databases to study expression profiles is limited by the availability of cDNA libraries used to develop ESTs and by the depth of EST sequencing. There are also problems in tracking genes that may be represented by several partial EST sequences.

Newer techniques allow the estimation of mRNA abundance for large numbers of genes simultaneously. The methods include serial analysis of gene expression (SAGE), microarrays, macroarrays and massively parallel signature sequencing (MPSS). These methods have not been extensively applied in wheat, although nearly all have been applied to some aspects in other cereals such as rice and maize (Milligan et al. 2004).

SAGE (serial analysis of gene expression), a logical extension of EST sequencing, can be used to study expression patterns (Velculescu et al. 1995). Unfortunately, SAGE does suffer from several problems. In particular, SAGE experiments require large amounts of RNA and can be very expensive if many samples are to be analysed, for example from a developmental series. As with MPSS (Brenner et al. 2000; http://www.lynxgen.com/), the signatures generated can be difficult to assign to particular genes when the technique is applied to wheat, where a full genome sequence is not available.

Microarrays and macroarrays offer a technique for screening the expression profile of very large numbers of genes simultaneously (Sreenivasulu et al. 2002). Both types of arrays have been used to study grain development in cereals. Macroarrays have the advantage of ease of manufacture and low cost relative to microarrays, but macroarrays do not provide the same level of gene or probe density for screening. Although macro-/microarrays have been used extensively in some cereals such as maize, rice and barley, use of these technologies in wheat has been limited. Recently cDNA microarrays containing approximately 9,000 wheat cDNAs were used to monitor gene expression during the first $28 \mathrm{~d}$ of grain development following anthesis (Leader et al. 2003). This study revealed 66 differentially regulated genes, which showed a sequence similar to transcription factors. Identified genes can be used for gene-specific marker development and synteny with rice to determine if any of the genes map within regions corresponding to QTL for grain yield or quality traits. Similarly, exploita- tion of cDNA microarrays is under way to identify the genes for endosperm development (Shinbata et al. 2003), for studying the Russian wheat aphid (RWA) defense response mechanisms (Botha et al. 2003) and assessment after fungicide application (Pasquer et al. 2003).

Real-time PCR (RT-PCR) has also been used to study drought stress tolerance (Rampino et al. 2003). Such approaches hold great potential for identifying the genes corresponding to QTLs for use in breeding as recently demonstrated in barley (Potokina et al. 2004). In addition, proteomic approaches have been recently used to assess the relationship between the wheat grain transcriptome and proteome (Branlard et al. 2003). It is hoped that in the near future, the above technologies will be put to extensive use in wheat.

\subsection{2 \\ Comparative Genomics and Bioinformatics}

The availability of a large number of ESTs of wheat and other cereals and the complete genome sequence of rice has allowed sequence comparisons between wheat and other cereal genomes and opened a new area of comparative genomics. Over the last decade, developments in the field of bioinformatics responded to the needs of wheat (or Triticeae) genomics researchers (Matthews et al. 2004). Several databases and Web sites including GrainGenes (http://wheat.pw.usda.gov/) for Triticeae, GRAMENE (http://www.gramene.org/) for comparative mapping in cereals, and TIGR (http://www.tigr.org/) for genome analysis have been developed. For instance, the GrainGenes database at present contains over 70 map sets and linkage data for T. aestivum, T. turgidum and diploid species (Carollo et al. 2003). The 'Genomics' page on the GrainGenes website, http://wheat.pw.usda.gov/ggpages/genomics provides resources for wheat genomics researchers such as assemblies of the ESTs, alignment of wheat ESTs to the rice genome sequence, co-operative international projects to develop wheat SNPs and SSRs, an assembly of large DNA clones (BACs) into the physical map of the $\mathrm{D}$ genome, and a database of repeat sequences from the Triticeae (TREP) (Matthews et al. 2003).

The use of DNA-sequence-based comparative genomics for evolutionary studies and for transferring information from model species to related largegenome species has revolutionized molecular genetics 
and breeding strategies for improving these crops ( $\mathrm{Pa}$ terson 2004). Comparative sequence analysis methods provide cross-referencing of genes between species maps, enhance the resolution of comparative maps, study patterns of gene evolution, identify conserved regions of the genomes and facilitate interspecies gene cloning.

A comparison (BLASTN analysis) of 5,780 ESTs that were physically mapped in wheat chromosome bins to 3,280 ordered BAC/PAC clones of rice revealed numerous chromosomal rearrangements that will significantly complicate the use of rice as a model for cross-species transfer of information in nonconserved regions (La Rota and Sorrells 2004). In addition, the physical locations of non-conserved regions were not consistent across rice chromosomes. Some wheat ESTs with multiple wheat genome locations were found associated with the non-conserved regions. An average of $35 \%$ of the putative single-copy genes that were mapped to the most conserved bins matched rice chromosomes other than the one that was most similar.

As noted above, interruption of microcollinearity was observed in other studies when extensive comparisons were made across smaller regions between collinear chromosomes (arms) of wheat and rice. For instance, a gene-by-gene BLASTN search of 2,932 genes from rice chromosome $11(57.3 \mathrm{cM}$ to $116.2 \mathrm{cM})$ to wheat ESTs and physically mapped wheat ESTs revealed that about one-third of the genes (homologous rice genes) were mapped to the homoeologous group 4 chromosome of wheat, suggesting a common evolutionary origin (Singh et al. 2004a). Location of bin-mapped wheat contigs to chromosomes of all seven homoeologous groups was attributed to the movement of genes (transpositions) or chromosome segments (translocations) within the rice or the hexaploid wheat genomes. In another study on the investigation of microcollinearity between the rice genome and a total of $1,500 \mathrm{~kb}$ from physical BAC contigs on wheat chromosome $1 \mathrm{AS}$, a total of 27 conserved orthologous sequences between wheat chromosome $1 \mathrm{AS}$ and a region of $1,210 \mathrm{~kb}$ located on rice chromosome $5 \mathrm{~S}$ were identified. However, microcollinearity was found to be frequently disrupted by rearrangements (Guyot et al. 2004). Similarly, microcollinearity was disrupted between a $2.6 \mathrm{cM}$ region (encompassing the grain protein content locus $G p c$ $6 \mathrm{~B} 1)$ on wheat chromosome $6 \mathrm{~B}$ and a $350 \mathrm{~kb}$ region on rice chromosome 2 (Distelfeld et al. 2004). Nevertheless, the region encompassing the Gpc-6B1 lo- cus showed excellent conservation between the two genomes, which facilitated the saturation of the target region of the wheat genetic map with molecular markers, and the $G p c-6 B 1$ locus was delimited to $0.3 \mathrm{cM}$ containing five candidate genes in the collinear $64-\mathrm{kb}$ region in rice. Comparative genomics also facilitated the identification of genes controlling seed dormancy and preharvest sprouting in wheat, barley and rice ( $\mathrm{Li}$ et al. 2004a).

\subsection{3 \\ Novel Approaches}

\section{AB-QTL Analysis}

For the long-term sustainability of wheat production, introduction of alien or exotic genes from wild species is imperative. In the past, many useful genes were transferred from wild relatives into wheat, most of which were single genes or gene clusters conferring resistance to various diseases. Fifty-seven genes for resistance to diseases and pests were introduced into wheat from other genera of the Triticeae family via alien translocations. In many cases, the size of the alien fragments and the translocation breakpoints were precisely determined by genomic in situ hybridization (for review see Friebe et al. 1996). For transferring the QTLs of agronomically important traits from a wild species to a crop variety, an approach named 'Advanced backcross QTL analysis (ABQA)' was proposed by Tanksley and Nelson (1996). In this approach, a wild species is backcrossed to a superior cultivar, and during backcrossing cycles the transfer of a desirable gene/QTL is monitored with molecular markers. The segregating $\mathrm{BC}_{2} \mathrm{~F}_{2}$ or $\mathrm{BC}_{2} \mathrm{~F}_{3}$ population is then used not only for recording data on the trait of interest but also for genotyping with polymorphic molecular markers. These data are then used for QTL analysis, leading to the simultaneous discovery of QTLs, while transferring these QTLs by conventional backcrossing. This approach has been used in wheat recently (Huang et al. 2003b, 2004). After genotyping 72 preselected $\mathrm{BC}_{2} \mathrm{~F}_{2}$ plants derived from a cross between a German variety and synthetic wheat, Hunag et al. (2003b) have identified 40 putative QTLs, including 11 for yield, 16 for yield components, 8 for ear emergence and 8 for plant height. Thus this approach has the potential for direct use in wheat improvement. 


\section{Association and Linkage Disequlibrium Analysis}

Conventional techniques of molecular mapping require a mapping population based on the products of one (doubled haploids) or two $\left(\mathrm{F}_{2} \mathrm{~s}\right)$ cycles of recombinations, limiting the resolution of genetic maps. In addition, such populations are often not representative of the germplasm that is being actively used in breeding programmes. In contrast, association mapping, based on linkage disequilibrium (LD), does not require a conventional segregating population and may in some cases be more powerful than conventional analysis for identifying the genes responsible for the variation in a quantitative trait (Buckler and Thornsberry 2002; for review see Flint-Garcia et al. 2003). Combined with a consideration of population structure (Pritchard et al. 2000), this association mapping allows for large-scale assessment of allele/trait relationships. A high degree of LD facilitates association analysis of markers linked to a QTL but reduces the resolution of the analysis (for review see Flint-Garcia et al. 2003). For instance, in maize the rapid decay of LD provides a means of mapping candidate genes with high precision and at the same time allows one to associate alleles with phenotypic values (Thornsberry et al. 2001). For those species with high LD, comparative mapping and transcript profiling are necessary for narrowing the list of candidate genes. Various kinds of populations can be designed with the appropriate resolution. For example, segmental introgression lines would have high LD while long-term breeding populations that have been intermated for many generations would have low LD (Sorrells 2004).

In wheat, some studies on association analysis have already been conducted and provided markers linked with some traits (Paull et al. 1994, 1998). Some efforts have been expended to study the association between growth habit and haplotype using a set of 80 hexaploid cultivars and assaying a total of seven SNPs located within a 3-kb region of molecular marker PSR6001, a candidate marker for vernalization responsive gene Vrn-A1 (Devos and Beales 2003). However, large-scale studies on the estimation of LD in the wheat genome are currently under way in several laboratories. Such high-resolution mapping of traits/QTLs to the level of individual genes will provide a new possibility for studying the molecular and biochemical basis of variation in quantitative traits and will help to identify specific targets for crop improvement in wheat. Though LD-based approaches hold great promise for accelerating fine mapping, conventional linkage mapping will continue to be useful particularly when trying to 'mendelize' QTLs and assessing the effect of QTL in isolation (Rafalski and Morgante 2004).

\section{Genetical Genomics}

Recently, a new approach, called 'genetical genomics', has also been proposed, where QTL mapping is combined with expression profiling of individual genes in a segregating (mapping) population (Jansen and Nap 2001). In this approach, total mRNA or cDNA of the organ/tissue from each individual of a mapping population is hybridized onto a microarray carrying a high number of cDNA fragments representing the species/tissue of interest and quantitative data are recorded reflecting the level of expression of each gene on the filter. Under the presumption that every gene showing transcriptional regulation is mapped within the genome of the species of interest, the expression data can be subjected to QTL analysis, thus making it possible to identify the so-called 'ExpressQTLs' (eQTLs). The recently developed software tool Expressionview for combined visualization of gene expression data and QTL mapping (Fischer et al. 2003) will be very useful in this connection. Based on segregating populations, eQTL analysis identifies gene products influencing the quantitative trait (level of mRNA expression) in cis (mapping of the regulated gene within the QTL) or trans (the gene is located outside the QTL). The latter gene product (secondorder effect) is of specific interest because more than one QTL can be connected to such a trans-acting factor (genes acting on the transcription of other genes) (Schadt et al. 2003). The mapping of eQTLs allows multifactorial dissection of the expression profile of a given mRNA/cDNA, protein or metabolite into its underlying genetic components and also makes it possible to locate these components on the genetic map (Jansen and Nap 2001; Jansen 2003). Eventually, for each gene or gene product analysed in the segregating population (by using expression profiling methodology), eQTL analysis will underline the regions of the genome influencing its expression. This approach has been used in maize (Schadt et al. 2003) and is being investigated by several groups for wheat. 


\section{6 \\ Concluding Remarks}

The development of genomics and genetics resources in wheat has lagged behind that of many other plant species. This has been largely related to concerns about the large size and the polyploid nature of the wheat genome. Therefore, despite its importance as a food crop and the extensive genetic and cytogentic resources that were available for wheat, genomics programmes were slow to develop. However, over the past few years this situation has changed dramatically. Firstly, several programmes worked together to build a resource base that now allows most genomics approaches to be applied to wheat. Secondly, it has become clear that the behaviour of the wheat genome is different from that of many other species. This means that genomics-based improvement of wheat will be dependent on studies on wheat itself and also that the study of the wheat genome offers some exciting scientific challenges.

A large number of molecular markers have been generated and mapped to produce dense genetic physical maps. Based on the available marker resources, a number of agronomically important genes and an even larger number of quantitative trait loci have been tagged with molecular markers. Further progress in trait mapping will critically depend on the availability of appropriate plant material. The generation and phenotypic analysis of experimental populations $\left(\mathrm{F}_{2}\right.$, $\mathrm{DH}, \mathrm{RIL}$, etc.) is time consuming and the development of novel approaches of association genetics based on the exploitation of linkage disequilibrium (LD) may lead to the verification of candidate genes in natural populations or collections of various genotypes (Rafalski 2002).

While the isolation of a given gene is usually a prerequisite to understanding its cellular function, the identification and subsequent introgression of superior alleles will be of seminal importance to breedimproved cultivars. The launch of several new initiatives to analyse the wheat genome structure will facilitate the systematic development of wheat genetic and genomic resources.

Acknowledgement. Thanks are due to Robert M.D. Koebner, John Innes Centre, Norwich (United Kingdom), for his useful suggestions for improving the quality of the manuscript and Andreas Boerner, IPK, Gatersleben (Germany), for providing the figures used in this chapter. We apologize for any missing citation in the summarized data as it was not possible to include all available references due to page limits.

\section{References}

Adhikari TB, Anderson JM, Goodwin SB (2003) Identification and molecular mapping of a gene in wheat conferring resistance to Mycosphaerella graminicola. Phytopathology 93:1158-1164

Adhikari TB, Cavaletto JR, Dubcovsky J, Gieco J, Schlatter AR, Goodwin SB (2004a) Molecular mapping of the Stb4 gene for resistance to septoria tritici blotch in wheat. Phytopathology 94:1198-1206

Adhikari T, Yang, X, Cavaletto JR, Hu X, Buechley G, Ohm HW, Shaner G, Goodwin SB (2004b) Molecular mapping of Stb1, a potentially durable gene for resistance to septoria tritici blotch in wheat. Theor Appl Genet 109:944-953

Adhikari TB, Wallwork H, Goodwin SB (2004c) Microsatellite markers linked to the $S t b 2$ and $S t b 3$ genes for resistance to Septoria tritici blotch in wheat. Crop Sci 44:1403-1411

Ahmad M (2000) Molecular marker-assisted selection of HMW glutenin alleles related to wheat bread quality by PCRgenerated DNA markers. Theor Appl Genet 101:892-896

Ahmad M (2002) Assessment of genomic diversity among wheat genotypes as determined by simple sequence repeats. Genome 45:646-651

Ahmed TA, Tsujimoto H, Sasakuma T (2000) Identification of RFLP markers linked with heading date and its heterosis in hexaploid wheat. Euphytica 116:111-119

Ahn SN, Tanksley SD (1993) Comparative linkage maps of the rice and maize genomes. Proc Natl Acad Sci USA 90:79807984

Ahn S, Anderson JA, Sorrells ME, Tanksley SD (1993) Homeologous relationships of rice, wheat and maize chromosomes. Mol Gen Genet 241:483-490

Akhunov ED, David L, Chao S, Lazo G, Anderson OD, Qi LL, Echalier B, Gill BS, Linkiewicz AM, Dubcovsky J et al (2003a) GC composition and codon usage in genes of inbreeding and outcrossing Triticeae species. In: Pogna NE, Romano M, Pogna EA, Galterio G (eds) Proc 10th Int Wheat Genet Symp, Paestum, Italy, pp 203-206

Akhunov ED, Goodyear AW, Geng S, Qi L-L, Echalier B, Gill BS, Miftahudin Gustafson JP, Lazo G, Chao SM et al (2003b) The organization and rate of evolution of wheat genomes are correlated with recombination rates along chromosome arms. Genome Res 13:753-763

Almanza-Pinzon MI, Khairallah M, Fox PN, Warburton ML (2003) Comparison of molecular markers and coefficients of parentage for the analysis of genetic diversity among spring bread wheat accessions. Euphytica 130:77-86

Alpert KB, Tanksley SD (1996) High-resolution mapping and isolation of a yeast artificial chromosome contig containing 
fw22: a major fruit weight quantitative trait locus in tomato. Proc Natl Acad Sci USA 93:15503-15507

Anderson JA, Stack RW, Liu S, Waldron BL, Fjeld AD, Coyne C, Moreno-Sevilla B, Fetch JM, Song Q J, Cregan PB et al (2001) DNA markers for fusarium head blight resistance QTLs in two wheat populations. Theor Appl Genet 102:1164-1168

Angerer N, Lengauer D, Steiner B, Lafferty J, Loeschenberger F, Buerstmayr H (2003) Validation of molecular markers linked to two Fusarium head blight resistance QTLs in wheat. In: Pogna NE, Romano M, Pogna EA, Galterio G (eds) Proc 10th Int Wheat Genet Symp, Paestum, Italy, pp 1096-1098

Appels R (2003) A consensus molecular genetic map for wheata cooperative international effort. In: Pogna NE, Romano M, Pogna EA, Galterio G (eds) Proc 10th Int Wheat Genet Symp, Paestum, Italy, pp 211-214

Appels R, Francki M, Chibbar R (2003) Advances in cereal functional genomics. Funct Integr Genom 3:1-24

Araki E, Miura H, Sawada S (1999) Identification of genetic loci affecting amylose content and agronomic traits on chromosome 4A of wheat. Theor Appl Genet 98:977-984

Arraiano LS, Worland AJ, Ellerbrook C, Brown JKM (2001) Chromosomal location of a gene for resistance to septoria tritici blotch (Mycosphaerella graminicola) in the hexaploid wheat 'Synthetic 6x'. Theor Appl Genet 103:758764

Arzani A, Peng JH, Lapitan NLV (2003) Genetic mapping of genes coding for Russian wheat aphid resistance (Dn4) and glume colour ( $R g 2)$ using microsatellite markers. In: Pogna NE, Romano M, Pogna EA, Galterio G (eds) Proc 10th Int Wheat Genet Symp, Paestum, Italy, pp 1099-1101

Autrique E, Singh RP, Tanksley SD, Sorrells ME (1995) Molecular markers for four leaf rust resistance genes introgressed into wheat from wild relatives. Genome 38:75-83

Autrique E, Nachit MM, Monneveux P, Tanksley SD, Sorrells ME (1996) Genetic diversity in durum wheat based on RFLPs, morphophysiological traits, and coefficient of parentage. Crop Sci 36:735-742

Ayala L, Henry M, Gonzalez-de-Leon D, van Ginkel M, MujeebKazi A, Keller B, Khairallah M (2001) A diagnostic molecular marker allowing the study of Th intermedium-derived resistance to BYDV in bread wheat segregating populations. Theor Appl Genet 102:942-949

Bai GH, Kolb FL, Shaner G, Domier LL (1999) Amplified fragment length polymorphism markers linked to a major quantitative trait locus controlling scab resistance in wheat. Phytopathology 89:343-348

Bai GH, Guo PG, Kolb FL (2003) Genetic relationships among head blight resistant cultivars of wheat assessed on the basis of molecular markers. Crop Sci 43:498-507

Bandopadhyay R, Sharma S, Rustgi S, Singh R, Kumar A, Balyan HS, Gupta PK (2004) DNA polymorphism among 18 species of Triticum-Aegilops complex using wheat EST-SSRs. Plant Sci 166:349-356
Barcaccia G, Molinari L, Porfiri O, Veronesi F (2002) Molecular characterization of emmer (Triticum dicoccom Schrank) Italian landraces. Genet Resource Crop Evol 49:415-426

Bariana HS, Hayden MJ, Ahmed NU, Bell JA, Sharp PJ, McIntosh RA (2001) Mapping of durable adult plant and seedling resistances to stripe rust and stem rust diseases in wheat. Aust J Agric Res 52:1247-1255

Bariana HS, Brown GN, Ahmed NU, Khatkar S, Conner RL, Wellings CR, Haley S, Sharp PJ, Laroche A (2002) Characterisation of Triticum vaviloviiderived stripe rust resistance using genetic, cytogenetic and molecular analyses and its markerassisted selection. Theor Appl Genet 104:315-320

Barloy D, Lemoine J, Dredryver F, Jahier J (2000) Molecular markers linked to the Aegilops variabilisderived rootknot nematode resistance gene Rknmn1 in wheat. Plant Breed 119:169-172

Barrett BA, Kidwell KK (1998) AFLP-based genetic diversity assessment among wheat cultivars from the Pacific Northwest. Crop Sci 38:1261-1271

Barrett BA, Kidwell KK, Fox PN (1998) Comparison of AFLP and pedigree-based genetic diversity assessment methods using wheat cultivars from the Pacific Northwest. Crop Sci 38:1271-1278

Barrett B, Bayram M, Kidwell K (2002) Identifying AFLP and microsatellite markers for vernalization response gene Vrn$B 1$ in hexaploid wheat using reciprocal mapping populations. Plant Breed 121:400-406

Ben Amer IM, Borner A, Röder MS (2001) Detection of genetic diversity in Libyan wheat genotypes using wheat microsatellite markers. Genet Resource Crop Evol 48:579-585

Benard V, Boyer D, Bastide C, Rouviere C, Duranton N, Praud S, Dufour P, Murigneux A, Sourdille P, Bernard M (2003) Chromosomal location of wheat cDNA clones derived from expressed sequence tags (ESTs). In: Pogna NE, Romano M, Pogna EA, Galterio G (eds) Proc 10th Int Wheat Genet Symp, Paestum, Italy, pp 925-927

Bennetzen JL (2000) Comparative sequence analysis of plant nuclear genomes: Microcolinearity and its many exceptions. Plant Cell 12:1021-1029

Bennetzen JL, Ma J (2003) The genetic colinearity of rice and other cereals on the basis of genomic sequence analysis. Curr Opin Plant Biol 6:128-133

Bennetzen JL, Ramakrishna W (2002) Numerous small rearrangements of gene content, order and orientation differentiate grass genomes. Plant Mol Biol 48:821-827

Bernatzky R, Tanksley SD (1986) Toward a saturated linkage map in tomato based on isozyme and random cDNA sequences. Genetics 112:887-898

Blanco A, Bellomo MP, Cenci A, Degiovanni C, Dovidio R, Iacono E, Laddomada, B, Pagnotta MA, Porceddu E, Sciancalepore A et al (1998) A genetic linkage map of durum wheat. Theor Appl Genet 97:721-728

Blazkova V, Bartos P, Park RF, Goyeau H (2002) Verifying the presence of leaf rust resistance gene $\operatorname{Lr} 10$ in sixteen wheat 
cultivars by use of a PCR-based STS marker. Cereal Res Commun 30:9-16

Boggini G, Vaccino P, Brandolini A, Cattaneo M (2003) Genetic variability of Strampelli bread wheat realisations detected by storage protein composition and by AFLP. In: Pogna NE, Romano M, Pogna EA, Galterio G (eds) Proc 10th Int Wheat Genet Symp, Paestum, Italy, pp 101-104

Bohn M, Utz HF, Melchinger AE (1999) Genetic similarities among winter wheat cultivars determined on the basis of RFLPs, AFLPs, and SSRs and their use for predicting progeny variance. Crop Sci 39:228-237

Börner A (1999) Comparative genetic mapping in triticeae. In: van Raamsdonk LWD, den Nijs JCM (eds) Plant evolution in man-made habitats, Proc VIIth Symp IOPB, Amsterdam, pp 197-210

Börner A, Röder M, Korzun V (1997) Comparative molecular mapping of GA insensititive Rht loci on chromosomes $4 \mathrm{~B}$ and $4 \mathrm{D}$ of common wheat (Triticum aestivum L.). Theor Appl Genet 95:1133-1137

Börner A, Korzun V, Worland AJ (1998) Comparative genetic mapping of loci affecting plant height and development in cereals. Euphytica 100:245-248

Börner A, Röder MS, Unger O, Meinel A (2000) The detection and molecular mapping of a major gene for non-specific adult-plant disease resistance against stripe rust (Puccinia striiformis) in wheat. Theor Appl Genet 100:1095-1099

Börner A, Simon MR, Röder MS, Ayala FM, Cordo CA (2003) Molecular mapping of QTLs determining resistance/tolerance to biotic and abiotic stress in hexaploid wheat. In: Pogna NE, Romano M, Pogna EA, Galterio G (eds) Proc 10th Int Wheat Genet Symp, Paestum, Italy, pp 331-333

Botha A-M, Lacock L, van Niekerk C, Matsioloko MT, du Preez FB, Myburg AA, Kunert K, Cullis CA (2003) Gene expression profiling during Diuraphis noxia infestation of Triticum aestivum $\mathrm{cv}$ 'Tugela DN' using microarrays. In: Pogna NE, Romano M, Pogna EA, Galterio G (eds) Proc 10th Int Wheat Genet Symp, Paestum, Italy, pp 334-338

Botstein D, White RL, Skolnick M, Davis RW (1980) Construction of a genetic linkage map in man using restriction fragment length polymorphisms. Am J Hum Genet 32:314-331

Bougot Y, Lemoine J, Pavoine MT, Barloy D, Doussinault G (2002) Identification of a microsatellite marker associated with $P m 3$ resistance alleles to powdery mildew in wheat. Plant Breed 121:325-329

Boukhatem N, Baret PV, Mingeot D, Jacquemin JM (2002) Quantitative trait loci for resistance against yellow rust in two wheat-derived recombinant inbred populations. Theor Appl Genet 104:111-118

Bourdoncle W, Ohm HW (2003) Quantitative trait loci for resistance to Fusarium head blight in recombinant inbred wheat lines from the cross Huapei 57-2/Patterson. Euphytica 131:131-136

Boyko EV, Gill KS, Mickelson-Young L, Nasuda S, Raupp WJ, Yiegle JN, Singh S, Hassawi DS, Frity AK, Namuth D et al (1999) A high-density genetic linkage map of Aegilops tauschii, the D-genome progenitor of bread wheat. Theor Appl Genet 99:16-26

Boyko E, Kalendar R, Korzun V, Fellers J, Korol A, Schulman AH, Gill BS (2002) A high-density cytogenetic map of the Aegilops tauschii genome incorporating retrotransposons and defense-related genes: insights into cereal chromosome structure and function. Plant Mol Biol 48:767-790

Brading PA, Verstappen ECP, Kema GHJ, Brown JKM (2002) A gene-for-gene relationship between wheat and Mycosphaerella graminicola, the septoria tritici blotch pathogen. Phytopathology 92:439-445

Branlard G, Bancel E, Merlino M, Hamon I, Amiour N (2003) Proteome analysis of the soluble proteins of wheat kernels in ITMI progeny In: Pogna NE, Romano M, Pogna EA, Galterio G (eds) Proc 10th Int Wheat Genet Symp, Paestum, Italy, pp 221-224

Breiman A, Graur D (1995) Wheat evolution. Israel J Plant Sci 43:85-98

Brenner S, Johnson M, Bridgham J, Golda G, Lloyd DH, Johnson D, Luo S, McCurdy S, Foy M, Ewan M et al (2000) Gene expression analysis by massively parallel signature sequencing (MPSS) on microbead arrays. Nat Biotechnol 18:630-634

Briney A, Wilson R, Potter RH, Barclay I, Crosbie G, Appels R, Jones MGK (1998) A PCR-based marker for selection of starch and potential noodle quality in wheat. Mol Breed 1998 4:427-433

Brown-Guedira GL, Singh S, Fritz AK (2003) Performance and mapping of leaf rust resistance transferred to wheat from Triticum timopheevii subsp armeniacum. Phytopathology 93:784-789

Brueggeman R, Rostoks N, Kudrna D, Kilian A, Han F, Chen J, Druka A, Steffenson, B, Kleinhofs A (2002) The barley stem rust-resistance gene Rpg1 is a novel disease-resistance gene with homology to receptor kinases. Proc Natl Acad Sci USA 99:9328-9333

Buckler ES, Thornsberry J (2002) Plant moleculer diversity and applications to genomics. Curr Opin Plant Biol 5:107-111

Buerstmayr H, Lemmens M, Hartl L, Doldi L, Steiner B, Stierschneider M, Ruckenbauer P (2002) Molecular mapping of QTLs for Fusarium head blight resistance in spring wheat, I: Resistance to fungal spread (type II resistance). Theor Appl Genet 104:84-91

Buerstmayr H, Steiner B, Hartl L, Griesser M, Angerer N, Lengauer D, Miedaner T, Schneider B, Lemmens M (2003) Molecular mapping of QTLs for Fusarium head blight resistance in spring wheat. II. Resistance to fungal penetration and spread. Theor Appl Genet 107:503-508

Bullrich L, Appendino ML, Tranquilli G, Lewis S, Dubcovsky J (2002) Mapping of a thero-sensitive earliness per se gene on Triticum monococcum chromosome $1 \mathrm{~A}^{m}$. Theor Appl Genet 105:585-593

Cadalen T, Boeuf C, Bernard S, Bernard M (1997) An intervarietal molecular marker map in Triticum aestivum $\mathrm{L}$ em. 
Thell and comparison with a map from wide cross. Theor Appl Genet 94:367-377

Cadalen T, Sourdille P, Charmet G, Tixier MH, Gay G, Boeuf C, Bernard S, Leroy P, Bernard M (1998) Molecular markers linked to genes affecting plant height in wheat using a doubled-haploid population. Theor Appl Genet 96:933940

Cakir M, Appels R, Carter M, Loughman R, Francki M, Li C, Johnson J, Bhave M, Wilson R, McLean R et al (2003) Accelerated wheat breeding using molecular marker. In: Pogna NE, Romano M, Pogna EA, Galterio G (eds) Proc 10th Int Wheat Genet Symp, Paestum, Italy, pp 117-120

Campbell KG, Bergman CJ, Gualberto DG, Anderson JA, Girox MJ, Hareland G, Fulcher RG, Sorrells ME Finney PL (1999) Quantitative trait loci associated with kernel traits in a soft $\times$ hard wheat cross. Crop Sci 39:1184-1195

Cao WG, Scoles G, Hucl P, Chibbar RN (2000) Phylogenetic relationships of five morphological groups of hexaploid wheat (Triticum aestivum $\mathrm{L}$ em Thell) based on RAPD analysis. Genome 43:724-727

Cao W, Hughes GR, Ma H, Dong Z (2001) Identification of molecular markers for resistance to Septoria nodorum blotch in durum wheat. Theor Appl Genet 102:551-554

Cao S, Guo X, Liu D, Zhang X, Zhang A (2003) Preliminary gene-mapping of photoperiod-temperature sensitive genic male sterility in wheat (Triticum aestivum L). In: Pogna NE, Romano M, Pogna EA, Galterio G (eds) Proc 10th Int Wheat Genet Symp, Paestum, Italy, pp 928-930

Carollo V, Matthews DE, Lazo GR, Anderson OD (2003) Wheat maps on GrainGenes: Past, present and coming attractions. In: Pogna NE, Romano M, Pogna EA, Galterio G (eds) Proc 10th Int Wheat Genet Symp, Paestum, Italy, pp 225-228

Carter M, Drake-Brockman F, Cakir M, Jones M, Appels R (2003) Conversion of RFLP markers into PCR based markers in wheat. In: Pogna NE, Romano M, Pogna EA, Galterio G (eds) Proc 10th Int Wheat Genet Symp, Paestum, Italy, pp 681-683

Cenci A, D’Ovidio R, Tanzarella OA, Ceoloni C, Porceddu E (1999) Identification of molecular markers linked to PM13, an Aegilops longissima gene conferring resistance to powdery mildew in wheat. Theor Appl Genet 98:448-454

Cenci A, Chantret N, Kong X, Gu Y, Anderson OD, Fahima T, Distelfeld A, Dubcovsky J (2003) Construction and characterization of a half million clone BAC library of durum wheat (Triticum turgidum ssp durum). Theor Appl Genet 107:931-939

Chagué V, Fahima T, Dahan A, Sun GL, Korol AB, Ronin YI, Grama A, Röder MS, Nevo E (1999) Isolation of microsatellite and RAPD markers flanking the Yr15 gene of wheat using NILs and bulked segregant analysis. Genome 42:10501056

Chalmers KJ, Campbell AW, Kretschmer J, Karakousis A, Henschke PH, Pierens S, Harker N, Pallota M, Cornish GB, Shariflou MR et al (2001) Construction of three linkage maps in bread wheat, Triticum aestivum. Aust J Agric Res 52:1089-1119

Chao SP, Sharp PJ, Worland AJ, Warham EJ, Koebner RMD, Gale MD (1989) RFLP-based genetic maps of wheat homoeologous group 7 chromosomes. Theor Appl Genet 78:493-504

Chee PW, Elias EM, Anderson JA, Kianian SF (2001) Evaluation of a high grain protein QTL from Triticum turgidum L var dicoccoides in an adapted durum wheat background. Crop Sci 41:295-301

Chen HB, Martin JM, Lavin M, Talbert LE (1994) Genetic diversity in hard red spring wheat-based on sequence-taggedsite PCR markers. Crop Sci 34:1628-1632

Chen XM, Soria MA, Yan GP, Sun J, Dubcovsky J (2003) Development of sequence tagged site and cleaved amplified polymorphic sequence markers for wheat stripe rust resistance gene Yr5. Crop Sci 43:2058-2064

Cheobtar SV, Röder MS, Börner A, Sivolap YM (2003) Microsatellite analysis of Ukrainian wheat varieties cultivated in 1912-2002. In: Pogna NE, Romano M, Pogna EA, Galterio G (eds) Proc 10th Int Wheat Genet Symp, Paestum, Italy, pp 57-60

Cherukuri DP, Gupta SK, Charpe A, Koul S, Prabhu KV, Singh RB, Haq QMR, Chauhan SVS (2003) Identification of a molecular marker linked to an Agropyron elongatumderived gene $\operatorname{Lr} 19$ for leaf rust resistance in wheat. Plant Breed 122:204-208

Christiansen MJ, Andersen SB, Ortiz R (2002) Diversity changes in an intensively bred wheat germplasm during the 20(th) century. Mol Breed 9:1-11

Coe EH, Neuffer MG (1993) Gene loci and linkage map of corn (maize) (Zea mays L.) (2n=20). In: O’Brian SJ (ed) Genetic maps, locus maps of complex genomes, 6th edn. Cold Spring Harbor Laboratory Press, Cold Spring Harbor, NY, pp 6.157-6.189

Conley EJ, Nduati V, Gonzalez-Hernandez JL, Mesfin A, Trudeau-Spanjers M, Chao S, Lazo GR, Hummel DD, Anderson OD, Qi LL et al (2004) A 2600-locus chromosome bin map of wheat homoeologous group 2 reveals interstitial gene-rich islands and colinearity with rice. Genetics 168:625-637

Corbellini M, Perenzin M, Accerbi M, Vaccino P, Borghi B (2002) Genetic diversity in bread wheat, as revealed by coefficient of parentage and molecular markers, and its relationship to hybrid performance. Euphytica 123:273-285

Cox DR, Burmeister M, Price ER, Kim S, Mayers RM (1990) Radiation hybrid mapping-a somatic-cell genetic method for constructing high-resolution maps of mammalian chromosomes. Science 250:245-250

Craven M, Prins R, Pretorius ZA (2003) Developement of AFLP markers for a wheat leaf rust resistance gene transferred from Triticum monococcum. In: Pogna NE, Romano M, Pogna EA, Galterio G (eds) Proc 10th Int Wheat Genet Symp, Paestum, Italy, pp 1124-1126

Davis GL, McMullen MD, Baysdorfer C, Musket T, Grant D, Staebell M, Xu G, Polacco M, Koster L, Melia-Hancock S 
et al (1999) A maize map standard with sequenced core markers, grass genome reference points and 932 expressed sequence tagged sites (ESTs) in a 1736-locus map. Genetics 152:1137-1172

Dear PH, Cook RR (1989) HAPPY mapping-a proposal for linkage mapping the human genome. Nucleic Acids Res 17:6795-6807

de Bustos A, Rubio P, Soler C, Garcia P, Jouve N (2001) Marker assisted selection to improve HMW-glutenins in wheat. Euphytica 119:69-73

Delaney DE, Nasuda S, Endo TR, Gill BS, Hulbert SH (1995a) Cytologically based physical maps of the group- 2 chromosomes of wheat. Theor Appl Genet 91:568-573

Delaney DE, Nasuda S, Endo TR, Gill BS, Hulbert SH (1995b) Cytologically based physical maps of the group-3 chromosomes of wheat. Theor Appl Genet 91:780-782

de la Pena RC, Murray TD, Jones SS (1996) Linkage relations among eyespot resistance gene $P$ ch2, endopeptidase Ep$A 1 b$, and RFLP marker Xpsr121 on chromosome 7A of wheat. Plant Breed 115:273-275

de la Pena RC, Murray TD, Jones SS (1997) Identification of an RFLP interval containing Pch 2 on chromosome 7AL in wheat. Genome 40:249-252

del Blanco IA, Frohberg RC, Stack RW, Berzonsky WA, Kianian SF (2003) Detection of QTL linked to Fusarium head blight resistance in Sumai 3-derived North Dakota bread wheat lines. Theor Appl Genet 106:1027-1031

Demeke T, Morris CF, Campbell KG, King GE, Anderson JA, Chang H-G (2001) Wheat polyphenol oxidase: distribution and genetic mapping in three inbred line populations. Crop Sci 41:1750-1757

Deng ZY, Zhang XQ, Wang XP, Jing JK, Wang DW (2004) Identification and molecular mapping of a stripe rust resistance gene from a common wheat line Qz180. Acta Bot Sin 46:236-241

Devos KM, Gale MD (1992) The use of random amplified polymorphic DNA markers in wheat. Theor Appl Genet 84:567572

Devos KM, Gale MD (1993) Extended genetic maps of the homoeologous group-3 chromosomes of wheat, rye and barley. Theor Appl Genet 85:649-652

Devos KM, Gale MD (1997) Comparative genetics in the grasses. Plant Mol Biol 35:3-15

Devos KM, Atkinson MD, Chinoy CN, Liu CJ, Gale MD (1992) RFLP-based genetic map of the homoeologous group 3 chromosomes of wheat and rye. Theor Appl Genet 83:931939

Devos KM, Atkinson MD, Chinoy CN, Francis HA, Harcourt RL, Koebner RMD, Liu CJ, Masojć P, Xie DX, Gale MD (1993a) Chromosomal rearrangement in the rye genome relative to that of wheat. Theor Appl Genet 85:673-680

Devos KM, Millan T, Gale MD (1993b) Comparative RFLP maps of the homoeologous group-2 chromosomes of wheat, rye and barley. Theor Appl Genet 85:784-792
Devos KM, Chao S, Li Y, Simonetti MC, Gale MD (1994) Relationship between chromosome 9 of maize and wheat homoeologous group 7 chromosomes. Genetics 138:12871292

Devos KM, Beales J (2003) Single nucleotide polymorphisms (SNPs) associated with the vernalization response in wheat In: Pogna NE, Romano M, Pogna EA, Galterio G (eds) Proc 10th Int Wheat Genet Symp, Paestum, Italy, pp 937-940

Dholakia BB, Ammiraju JSS, Santra DK, Singh H, Katti MV, Lagu MD, Tamhankar SA, Rao VS, Gupta VS, Dhaliwal HS, Ranjekar PK (2001) Molecular marker analysis of protein content using PCR-based markers in wheat. Biochem Genet 39:325-338

Dieguez MJ, Ingala L, Perera E, Sacco F, Naranjo T (2003) Physical mapping of AFLPs on chromosome 6BL of wheat, which includes the $L r 3$ gene for leaf rust resistance. In: Pogna NE, Romano M, Pogna EA, Galterio G (eds) Proc 10th Int Wheat Genet Symp, Paestum, Italy, pp 937-940

Dilbirligi M, Gill KS (2003) Identification and characterization of candidate expressed genes of wheat. In: Pogna NE, Romano M, Pogna EA, Galterio G (eds) Proc 10th Int Wheat Genet Symp, Paestum, Italy, pp 940-942

Distelfeld A, Uauy C, Olmos S, Schlatter AR, Dubcovsky J, Fahima T (2004) Microcolinearity between a 2-cM region encompassing the grain protein content locus $G p c-6 B 1$ on wheat chromosome $6 \mathrm{~B}$ and a $350 \mathrm{~kb}$ region on rice chromosome 2. Funct Integr Genom 4:59-66

Donini P, Elias ML, Bougourd SM, Koebner RMD (1997) AFLP fingerprinting reveals pattern differences between template DNA extracted from different plant organs. Genome 40:521-526

Donini P, Stephenson P, Bryan GJ, Koebner RMD (1998) The potential of microsatellites for high throughput genetic diversity assessment in wheat and barley. Genet Resource Crop Evol 45:415-421

Donini P, Law JR, Koebner RMD, Reeves JC, Cooke RJ (2000) Temporal trends in the diversity of UK wheat. Theor Appl Genet 100:912-917

Dreher K, Khairallah M, Ribaut JM, Morris M (2003) Money matters (I): costs of field and laboratory procedures associated with conventional and marker-assisted maize breeding at CIMMYT. Mol Breed 11:221-234

Dreisigacker S, Zhang P, Warburton ML, Van Ginkel M, Hoisington D, Bohn M, Melchinger AE (2003) SSR and pedigree analyses of genetic diversity among CIMMYT wheat lines targeted to different megaenvironments. Crop Sci 44:381388

Driscoll CJ (1966) Gene-centromere distances in wheat by aneuploid F2 observations. Genetics 54:131-135

Dubcovsky J, Luo MC, Zhong GY, Bransteitter R, Desai A, Kilian A, Kleinhofs A, Dvorak J (1996) Genetic map of diploid wheat, Triticum monococcum L., and its comparison with maps of Hordeum vulgare L. Genetics 143:983-999

Dunford RP, Kurata N, Laurie DA, Money TA, Minobe Y, Moore G (1995) Conservation of fine-scale DNA marker order in 
the genomes of rice and the Triticeae. Nucleic Acids Res 23:2724-2728

Dvorák J, Luo M-C, Yang Z-L, Zhang H-B (1998a) The structure of the Aegilops tauschii genepool and the evolution of hexaploid wheat. Theor Appl Genet 97:657-670

Dvorák J, Luo MC, Yang ZL (1998b) Restriction fragment length polymorphism and divergence in the genomic regions of high and low recombination in self-fertilizing and crossfertilizing Aegilops species. Genetics 148:423-434

Dvorák J, Akhunov ED, Akhunov AR, Luo M-C, Linkiewicz AM, Dubcovsky J, Hummel D, Lazo G, Chao S, Anderson OD et al (2003) New insights into the organization and evolution of wheat genomes. In: Pogna NE, Romano M, Pogna EA, Galterio G (eds) Proc 10th Int Wheat Genet Symp, Paestum, Italy, pp 247-253

Dweikat I, Ohm H, Patterson F, Cambron S (1997) Identification of RAPD markers for 11 Hessian fly resistance genes in wheat. Theor Appl Genet 94:419-423

Eagles HA, Bariana HS, Ogbonnaya FC, Rebetzke GJ, Hollamby GJ, Henry RJ, Henschke PH, Carter M (2001) Implementation of markers in Australian wheat breeding. Aust J Agric Res 52:1349-1356

Effertz RJ, Meinhardt SW, Anderson JA, Jordahl JG, Francl LJ (2002) Identification of a chlorosis-inducing toxin from Pyrenophora tritici-repentis and the chromosomal location of an insensitivity locus in wheat. Phytopathology 92:527533

Ellis MH, Spielmeyer W, Gale KR, Rebetzke GJ, Richards RA (2002) "Perfect" markers for the RhtB1b and RhtD $1 b$ dwarfing genes in wheat. Theor Appl Genet 105:1038-1042

Elouafi I, Nachit MM (2004) A genetic linkage map of the Durum $\mathrm{x}$ Triticum dicoccoides backcross population based on SSRs and AFLP markers, and QTL analysis for milling traits. Theor Appl Genet 108:401-413

Endo TR, Gill BS (1996) The deletion stocks of common wheat. J Hered 87:295-307

Eriksen L, Afshari F, Christiansen MJ, McIntosh RA, Jahoor A, Wellings CR (2003a) Yr32 for resistance to stripe (yellow) rust present in the wheat cultivar Carstens V. Theor Appl Genet 108:567-575

Eriksen L, Borum F, Jahoor A (2003b) Inheritance and localisation of resistance to Mycosphaerella graminicola causing septoria tritici blotch and plant height in the wheat (Triticum aestivum L) genome with DNA markers. Theor Appl Genet 107:415-527

Eujayl I, Sorrells M, Baum M, Wolters P, Powell W (2001) Assessment of genotypic variation among cultivated durum wheat based on EST-SSRS and genomic SSRs. Euphytica 119:39-43

Fahima T, Röder MS, Grama A, Nevo E (1998) Microsatellite DNA polymorphism divergence in Triticum dicoccoides accessions highly resistant to yellow rust. Theor Appl Genet 96:187-195

Fahima T, Sun GL, Beharav A, Krugman T, Beiles A, Nevo E (1999) RAPD polymorphism of wild emmer wheat popu- lations, Triticum dicoccoides, in Israel. Theor Appl Genet 98:434-447

Fahima T, Röder MS, Wendehake K, Kirzhner VM, Nevo E (2002) Microsatellite polymorphism in natural populations of wild emmer wheat, Triticum dicoccoides, in Israel. Theor Appl Genet 104:17-29

Fahima T, Ramachandran S, Krugman T, Röder MS, Nevo E, Feldman MW (2003) Estimation of domestication times of wheat and barley based on microsatellite polymorphism. In: Pogna NE, Romano M, Pogna EA, Galterio G (eds) Proc 10th Int Wheat Genet Symp, Paestum, Italy, pp 481-483

Faris JD, Anderson JA, Francl LJ, Jordahl JG (1997) RFLP mapping of resistance to chlorosis induction by Pyrenophora tritici-repentis in wheat. Theor Appl Genet 94:98-103

Faris JD, Haen KM, Gill BS (2000) Saturation mapping of a gene-rich recombination hot spot region in wheat. Genetics154:823-835

Faris JD, Fellers JP, Brooks SA, Gill BS (2003) A bacterial artificial chromosome contig spanning the major domestication locus $Q$ in wheat and identification of a candidate gene. Genetics 164:311-321

Feuillet C, Keller B (1999) High gene density is conserved at syntenic loci of small and large grass genomes. Proc Natl Acad Sci USA 96:8265-8270

Feuillet C, Keller B (2002) Comparative genomics in the grass family: molecular characterization of grass genome structure and evolution. Ann Bot 89:3-10

Feuillet, C, Travella S, Stein N, Albar L, Nublat A, Keller B (2003) Map-based isolation of the leaf rust disease resistance gene Lr10 from the hexaploid wheat (Triticum aestivum L) genome. Proc Nat Acad Sci USA 100:15253-15258

Fischer G, Ibrahim SM, Brockmann GA, Pahnke J, Bartocci E, Thiesen H-J, Serrano-Fernandez P, Möller S (2003) Expressionview: visualization of quantitative trait loci and gene-expression data in Ensembl. Genome Biol 4:R477

Flint-Garcia SA, Thornsberry JM, Buckler IV ES (2003) Structure of linkage disequilbrium in plants. Annu Rev Plant Biol 54:357-374

Francki MG, Appels R, Hunter A, Bellgard M (2003) Comparative organization of 3BS and 7AL using wheat-rice synteny. In: Pogna NE, Romano M, Pogna EA, Galterio G (eds) Proc 10th Int Wheat Genet Symp, Paestum, Italy, pp 254-257

Friebe B, Jiang J, Raupp J, McIntosh RA, Gill BS (1996) Characterization of wheat-alien translocations conferring resistance to disease and pests: current status. Euphytica 91:59-87

Gale MD, Atkinson MD, Chinoy CN, Harcourt R, Jia J, Li QY, Devos KM (1995) Genetic maps of hexaploid wheat. In: Chen $S$ (ed) Proc 8th Int Wheat Genet Symp. China Agricultural Scientech Press, Beijing, pp 29-40

Gale MD, Devos KM (1998) Comparative genetics in the grasses. Proc Natl Acad Sci USA 95:1971-1974

Galiba G, Quarrie SA, Sutka J, Morgunov A, Snape JW (1995) RFLP mapping of the vernalisation $(\operatorname{Vrn} 1)$ and frost resis- 
tance (Fr1) genes on chromosome 5A of wheat. Theor Appl Genet 90:1174-1179

Gallego F, Feuillet C, Messmer M, Penger A, Graner A, Yano M, Sasaki T, Keller B (1998) Comparative mapping of the two wheat leaf rust resistance loci $\operatorname{Lr} 1$ and $\operatorname{Lr} 10$ in rice and barley. Genome 41:328-336

Gandon B, Chiquet V, Guyomarc'h H, Baron C, Sourdille P, Specel S, Foisset N, Murigneux A, Dufour P, Bernard M (2002) Development of microsatellite markers for wheat genetic mapping improvement. In: Plant, Animal \& Microbe Genomes X Conf, San Diego, CA. http://www.intlpag.org/pag/10/abstracts/PAGX_P187.html

Gao LF, Tang JF, Li HW, Jia JZ (2003) Analysis of microsatellites in major crops assessed by computational and experimental approaches. Mol Breed 12:245-261

Gao LF, Jing RL, Huo NX, Li Y, Li XP, Zhou RH, Chang XP, Tang JF, Ma ZW, Jia JZ (2004) One hundred and one new microsatellite loci derived from ESTs (EST-SSRs) in bread wheat. Theor Appl Genet 108:1392-1400

Gardiner J, Schroeder S, Polacco ML, Sanchez-Villeda H, Fang ZW, Morgante M, Landewe T, Fengler K, Useche F, Hanafey M, Tingey S, Chou H, Wing R, Soderlund C, Coe EH (2004) Anchoring 9,371 maize expressed sequence tagged unigenes to the bacterial artificial chromosome contig map by two-dimensional overgo hybridization. Plant Physiol 134:1317-1326

Garg M, Singh S, Singh B, Singh K, Dhaliwal HS (2001) Estimates of genetic similarities and DNA fingerprinting of wheats (Tritium species) and triticale cultivars using molecular markers. Indian J Agril Sci 71:438-443

Gaut BS (2001) Patterns of chromosomal duplication in maize and their implications for comparative maps of the grasses. Genome Res 11:55-66

Gaut BS (2002) Evolutionary dynamics of grass genomes. New Phytologist 154:15-28

Gervais L, Dedryver F, Morlais JY, Bodusseau V, Negre S, Bilous M, Groos C, Trottet M (2003) Mapping of quantitative trait loci for field resistance to Fusarium head blight in an European winter wheat. Theor Appl Genet 106:961-970

Giese H, Holm-Jensen AG, Mathiassen H, Kjær B, Rasmussen SK, Bay H, Jensen J (1994) Distribution of RAPD markers on a linkage map of barley. Hereditas 120:267-273

Gill KS (2004) Gene distribution in cereal genomes In: Gupta PK, Varshney RK (eds) Cereal Genomics. Kluwer, Dordrecht, pp 361-38

Gill KS, Gill BS (1994) Mapping in the realm of polyploidy: the wheat model. BioEssays 16:841-846

Gill KS, Gill BS, Endo TR (1993) A chromosome regionspecific mapping strategy reveals gene-rich telomeric ends in wheat. Chromosoma 102:374-381

Gill KS, Gill BS, Endo TR, Taylor T (1996a) Identification and high-density mapping of gene-rich regions in chromosome group 1 of wheat. Genetics 144:1883-1891
Gill KS, Gill BS, Boyko EV (1996b) Identification and high density mapping of gene-rich regions in chromosome group 5 of wheat. Genetics 143:1001-1012

Gill BS, Qi L, Echalier B, Chao S, Lazo G, Anderson OD, Akhunov ED, Dvorak J, Linkiewicz AM, Dubcovsky J et al (2003) A transcriptome map of wheat. In: Pogna NE, Romano M, Pogna EA, Galterio G (eds) Proc 10th Int Wheat Genet Symp, Paestum, Italy, pp 261-264

Gilpin BJ, McCallum JA, Frew GM, Timmerman-Vaughan GM (1997) A linkage map of the pea (Pisum sativum L) genome containing cloned sequences of known functions and expressed sequence tags (ESTs). Theor Appl Genet 95:12891299

Gladysz A, Steiner B, Castro M, Burestmayr H (2003) Transfer of QTLs for resistance to Fusarium head blight from bread wheat into durum wheat by marker-assisted breeding. In: Pogna NE, Romano M, Pogna EA, Galterio G (eds) Proc 10th Int Wheat Genet Symp, Paestum, Italy, pp 715-717

Goff SA, Ricke D, Lan TH, Presting G, Wang RL, Dunn M, Glazebrook J, Sessions A, Oeller P, Varma H et al (2002) A draft sequence of the rice genome (Oryza sativa L ssp japonica). Science 296:92-100

Gold J, Harder D, Townley-Smith F, Aung T, Procunier J (1999) Development of a molecular marker for rust resistance genes Sr39 and Lr35 in wheat breeding lines. Electr J Biotech 2:35-40

Graner A, Jahoor A, Schondelmaier J, Siedler H, Pillen K, Fischbeck G, Wenzel G, Herrmann RG (1991) Construction of an RFLP map of barley. Theor Appl Genet 83:250-256

Groenewald JZ, Marais AS, Marais GF (2003) Amplified fragment length polymorphism-derived microsatellite sequence linked to the Pch1 and EP-D1 loci in common wheat. Plant Breed 122:83-85

Groos C, Gay G, Perretant MR, Gervais L, Bernard M, Dedryver F, Charmet D (2002) Study of the relationship between pre-harvest sprouting and grain color by quantitative trait loci analysis in a whitexred grain bread-wheat cross. Theor Appl Genet 104:39-47

Grunberg AM, Costa JM, Kratochvil RJ (2001) Amplified fragment length polymorphism in a selected sample of soft red winter wheat. Cereal Res Commun 29:251-258

Gudu S, Laurie DA, Kasha KJ, Xia JJ, Snape JW (2002) RFLP mapping of a Hordeum bulbosum gene highly expressed in pistils and its relationship to homoeologous loci in other Gramineae species. Theor Appl Genet 105:271-276

Guo PG, Bai GH, Shaner GE (2003) AFLP and STS tagging of a major QTL for Fusarium head blight resistance in wheat. Theor Appl Genet 106:1011-1017

Gupta PK, Varshney RK (2000) The development and use of microsatellite markers for genetic analysis and plant breeding with emphasis on bread wheat. Euphytica 113:163-185

Gupta PK, Varshney RK (2004) Cereal genomics: An overview. In: Gupta PK, Varshney RK (eds) Cereal Genomics. Kluwer, Dordrecht, pp 1-18 
Gupta PK, Varshney RK, Sharma PC, Ramesh B (1999) Molecular markers and their applications in wheat breeding. Plant Breed 118:369-390

Gupta PK, Balyan HS, Edwards KJ, Isaac P, Korzun V, Röder M, Gautier MF, Joudrier P, Schlatter AR, Dubcovsky J et al (2002a) Genetic mapping of 66 new microsatellite (SSR) loci in bread wheat. Theor Appl Genet 105:413-422

Gupta PK, Varshney RK, Prasad M (2002b) Molecular markers: principles and methodology. In: Jain SM, Brar DS, Ahloowalia BS (eds) Molecular Techniques in Crop Improvement. Kluwer, Dordrecht, pp 9-54

Gupta PK, Rustgi S, Sharma S, Singh R, Kumar N, Balyan HS (2003) Transferable EST-SSR markers for the study of polymorphism and genetic diversity in bread wheat. Mol Gen Genom 270:315-323

Guyomarc'h H, Sourdille P, Edwards KJ, Bernard M (2002) Studies of the transferability of microsatellites derived from Triticum tauschii to hexaploid wheat and to diploid related species using amplification, hybridization and sequence comparisons. Theor Appl Genet 105:736-744

Guyot R, Yahiaoui N, Feuillet C, Keller B (2004) In silico comparative analysis reveals a mosaic conservation of genes within a novel colinear region in wheat chromosome $1 \mathrm{AS}$ and rice chromosome 5S. Funct Integr Genom 4:47-58

Han F, Fedak G, Ouellet T, Somers D (2003) Isolation, characterization and physical mapping of differential clones from SSH library for Fusarium head blight (FHB) resistance In: Pogna NE, Romano M, Pogna EA, Galterio G (eds) Proc 10th Int Wheat Genet Symp, Paestum, Italy, pp 952-954

Harker N, Rampling LR, Shariflou MR, Hayden MJ, Holton TA, Morell MK, Sharp PJ, Henry RJ, Edwards KJ (2001) Microsatellites as markers for Australian wheat improvement. Aust J Agric Res 52:1121-1130

Hartl L, Weiss H, Zeller FJ, Jahoor A (1993) Use of RFLP markers for the identification of alleles of the Pm3 locus conferring powdery mildew resistance in wheat (Triticum aestivum $\mathrm{L}$ ). Theor Appl Genet 86:959-963

Hartl L, Weiss H, Stephan U, Zeller FJ, Jahoor A (1995) Molecular identification of powdery mildew resistance genes in common wheat (Triticum aestivum L). Theor Appl Genet 90:601-606

Hartl L, Mohler V, Zeller FJ, Hsam SLK, Schweizer G (1999) Identification of AFLP markers closely linked to the powdery mildew resistance genes Pm1c and Pm4a in common wheat (Triticum aestivum L). Genome 42:322-329

Harushima Y, Yano M, Shomura A, Sato M, Shimono T, Kuboki Y, Yamamoto T, Lin SY, Antonio BA, Parco A et al (1998) A high density rice genetic linkage map with 2275 markers using a single $\mathrm{F}_{2}$ population. Genetics 148:479-494

Hazen SP, Leroy P, Ward RW (2002) AFLP in Triticum aestivum L: patterns of genetic diversity and genome distribution. Euphytica 125:89-102

Helguera M, Khan IA, Dubcovsky J (2000) Development of PCR markers for wheat leaf rust resistance gene Lr47. Theor Appl Genet 101:625-631
Helguera M, Khan IA, Kolmer J, Lijavetzky D, Zhong-qi L, Dubcovsky J (2003) PCR assays for the Lr37-Yr17-Sr38 cluster of rust resistance genes and their use to develop isogenic hard red spring wheat lines. Crop Sci 43:1839-1847

Hernandez P, Dorado G, Prieto P, Gimenez MJ, Ramirez MC, Laurie DA, Snape JW, Martin A (2001) A core genetic map of Hordeum chilense and comparisons with maps of barley (Hordeum vulgare) and wheat (Triticum aestivum). Theor Appl Genet 102:1259-1264

Heun M, SchaferPregl R, Klawan D, Castagna R, Accerbi M, Borghi B, Salamini F (1997) Site of einkorn wheat domestication identified by DNA fingerprinting. Science 278:13121314

Hohmann U, Graner A, Endo TR, Gill BS, Herrmann RG (1995) Comparison of wheat physical maps with barley linkage maps for group 7 chromosomes. Theor Appl Genet 91:618626

Holton TA, Christopher JT, McClure L, Harker N, Henry RJ (2002) Identification and mapping of polymorphic SSR markers from expressed gene sequences of barley and wheat. Mol Breed 9:63-71

Hossain KG, Kalavacharla V, Lazo GR, Hegstad J, Wentz MJ, Kianian PMA, Simons K, Gehlhar S, Rust JL, Syamala RR et al (2004a) A chromosome bin map of 2,148 expressed sequence tag loci of wheat homoeologous group 7. Genetics 168:687-699

Hossain KG, Riera-Lizarazu O, Kalavacharla V, Vales MI, Rust JL, Maan SS, Kianian SF (2004b) Molecular cytogenetic characterization of an alloplasmic durum wheat line with a portion of chromosome 1D of Triticum aestivum carrying the $s c s^{a e}$ gene. Genome 47:206-214

Houshmand S, Knox RE, Clarke FR, Clarke JM (2003) Microsatellite markers associated with sawfly cutting in durum wheat. In: Pogna NE, Romano M, Pogna EA, Galterio G (eds) Proc 10th Int Wheat Genet Symp, Paestum, Italy, pp 1151-1153

Hu XY, Ohm HW, Dweikat I (1997) Identification of RAPD markers linked to the gene $P m 1$ for resistance to powdery mildew in wheat. Theor Appl Genet 94:832-840

Huang L, Gill BS (2001) An RGA like marker detects all known Lr21 leaf rust resistance gene family members in Aegilops tauschii and wheat. Theor Appl Genet 103:1007-1013

Huang XQ, Röder MS (2003) High-denisty genetic and physical mapping of the powdery mildew resistance gene Pm24 on chromosome 1D of wheat. In: Pogna NE, Romano M, Pogna EA, Galterio G (eds) Proc 10th Int Wheat Genet Symp, Paestum, Italy, pp 961-964

Huang XQ, Hsam SLK, Zeller FJ, Wenzel G, Mohler V (2000) Molecular mapping of the wheat powdery mildew resistance gene Pm24 and marker validation for molecular breeding. Theor Appl Genet 101:407-414

Huang XQ, Börner A, Röder MS, Ganal MW (2002) Assessing genetic diversity of wheat (Triticum aestivum $\mathrm{L}$ ) germplasm using microsatellite markers. Theor Appl Genet 105:699707 
Huang L, Brooks SA, Li W, Fellers JP, Trick HN, Gill BS (2003a) Map-based cloning of leaf rust resistance gene Lr21 from the large and polyploid genome of bread wheat. Genetics 164:655-664

Huang XQ, Cöster H, Ganal MW, Röder MS (2003b) Advanced backcross QTL analysis for the identification of quantitative trait loci alleles from wild relatives of wheat (Triticum aestivum L). Theor Appl Genet 106:1379-1389

Huang XQ, Wang LX, Xu MX, Röder MS (2003c) Microsatellite mapping of the powdery mildew resistance gene Pm5e in common wheat (Triticum aestivum L). Theor Appl Genet 106:858-865

Huang XQ, Kempf H, Ganal MW, Röder MS (2004) Advanced backcross QTL analysis in progenies derived from a cross between a German elite winter wheat variety and a synthetic wheat (Triticum aestivum L.). Theor Appl Genet 109:933-941

Hulbert SH, Richter TE, Axtell JD, Bennetzen JL (1990) Genetic mapping and characterization of sorghum and related crops by means of maize DNA probes. Proc Natl Acad Sci USA 87:4251-4255

Incirli A, Akkaya MS (2001) Assessment of genetic relationships in durum wheat cultivars using AFLP markers. Genet Resource Crop Evol 48:233-238

Ishii T, Mori N, Ogihara Y (2001) Evaluation of allelic diversity at chloroplast microsatellite loci among common wheat and its ancestral species. Theor Appl Genet 103:896-904

Ivandic V, Malyshev V, Korzun V, Graner A, Börner A (1998) Comparative mapping of a gibberelic acid insensitive dwarfing gene (Dwf2) on chromosome 4HS of barley. Theor Appl Genet $98: 728-731$

Iwaki K, Nishida J, Yanagisawa T, Yoshida H, Kato K (2002) Genetic analysis of $V r n-B 1$ for vernalization requirement by using linked dCAPS markers in bread wheat (Triticum aestivum L). Theor Appl Genet 104:571-576

Jahoor A, Eriksen L, Backes G (2004) QTLs and genes for disease resistance in barley and wheat. In: Gupta PK, Varshney RK (eds) Cereal Genomics. Kluwer, Dordrecht, pp 199-252

Jansen RC (2003) Studying complex biological systems using multifactorial perturbation. Nature Rev Genet 4:145-151

Jansen RC, Nap J-P (2001) Genetical genomics: the added value from segregation Trends Genet 17:388-391

Järve K, Peusha HO, Tsymbalova J, Tamm S, Devos KM, Enno TM (2000) Chromosomal location of a Triticum timopheevii-derived powdery mildew resistance gene transferred to common wheat. Genome 43:377-381

Jia J, Devos KM, Chao S, Miller TE, Reader SM, Gale MD (1996) RFLP-based maps of the homoeologous group- 6 chromosomes of wheat and their application in the tagging of Pm12, a powdery mildew resistance gene transferred from Aegilops speltoides to wheat. Theor Appl Genet 92:559-565

Jiang JM, Gill BS (1994) Nonisotopic in-situ hybridization and plant genome mapping - the first 10 years. Genome 37:717725
Joshi CP, Nguyen HT (1993) Application of the random amplified polymorphic DNA technique for the detection of polymorphism among wild and cultivated tetraploid wheats. Genome 36:602-609

Jurman I, Castelluccio MD, Wolf M, Olivieri A, DeAmbrogio E, Morgante M (2003) Construction of an SSR-based linkage map of durum wheat. In: Pogna NE, Romano M, Pogna EA, Galterio G (eds) Proc 10th Int Wheat Genet Symp, Paestum, Italy, pp 968-970

Kantety RV, Rota ML, Matthews DE, Sorrells ME (2002) Data mining for simple sequence repeats in expressed sequence tags from barley, maize, rice, sorghum and wheat. Plant Mol Biol 48:501-510

Kato K, Miura H, Sawada S (1999) Comparative mapping of the wheat $V r n-A 1$ region with the rice $H d-6$ region. Genome 42:204-209

Kato K, Miura H, Sawada S (2000) Mapping QTLs controlling grain yield and its components on chromosome $5 \mathrm{~A}$ of wheat. Theor Appl Genet 101:1114-1121

Kato K, Nakamura W, Tabiki T, Miura H, Sawada S (2001) Detection of loci controlling seed dormancy on group 4 chromosomes of wheat and comparative mapping with rice and barley genomes. Theor Appl Genet 102:980-985

Kato K, Yamashita M, Ishimoto K, Yoshino H, Fujita M (2003) Genetic analysis of two genes for vernalization response, the former Vrn2 and Vrn4, by using PCR-based molecular markers. In: Pogna NE, Romano M, Pogna EA, Galterio G (eds) Proc 10th Int Wheat Genet Symp, Paestum, Italy, pp 971-973

Keller B, Feuillet C (2000) Colinearity and gene density in grass genomes. Trends Plant Sci 5:246-251

Keller M, Karutz C, Schmid JE, Stamp P, Winzeler M, Keller B, Messmer MM (1999a) Quantitative trait loci for lodging resistance in a segregating wheat $\times$ spelt population. Theor Appl Genet 98:1171-1182

Keller M, Keller B, Schachermayr G, Winzeler M, Schmid JE, Stamp P, Messmer MM (1999b) Quantitative trait loci for resistance against powdery mildew in a segregating wheat $\times$ spelt population. Theor Appl Genet 98:903-912

Khan AA, Bergstrom GC, Nelson JC, Sorrells ME (2000a) Identification of RFLP markers for resistance to wheat spindle streak mosaic bymovirus (WSSMV) disease. Genome 43:477-482

Khan IA, Procunier JD, Humphreys DG, Tranquilli G, Schlatter AR, Marcucci-Poltri S, Frohberg R, Dubcovsky J (2000b) Development of PCR-based markers for a high grain protein content gene from Triticum turgidum ssp. dicoccoides transferred to bread wheat. Crop Sci 40:518-524

Khlestkina EK, Than MHM, Pestsova EG, Röder MS, Malyshev SV, Korzun V, Börner A (2004) Mapping of 99 microsatellite loci in rye (Secale cereale $\mathrm{L}$ ) including 39 expressed sequence tags. Theor Appl Genet 109:725-732

Kianian SF, Hossain KG, Riera-Lizarazu O, Kalavacharla V, Vales MI, Maan SS (2003) Radiation hybrid mapping of a species cytoplasm specific $\left(s c s^{a e}\right)$ gene in wheat. In: Pogna NE, Ro- 
mano M, Pogna EA, Galterio G (eds) Proc 10th Int Wheat Genet Symp, Paestum, Italy, pp 595-597

Kim HS, Ward RW (1997) Genetic diversity in Eastern US soft winter wheat (Triticum aestivum $\mathrm{L}$ em Thell) based on RFLPs and coefficients of parentage. Theor Appl Genet 94:472-479

Klein PE, Klein RR, Cartinhour SW, Ulanch PE, Dong J, Obert JA, Morishge DT, Schlueter SD, Childs KL, Ale M et al (2000) A high throughput AFLP based method for constructing integrated genetic and physical maps: progress toward a sorghum genome map. Genome Res 10:789-807

Knox RE, Menzies JG, Howes NK, Clarke JM, Aung T, Penner GA (2002) Genetic analysis of resistance to loose smut and an associated DNA marker in durum wheat doubled haploids. Can J Plant Pathol 24:316-322

Kobiljski B, Quarrie S, Dencic S, Kirby J, Iveges M (2002) Genetic diversity of the Novi Sad Wheat Core Collection revealed by microsatellites. Cell Mol Biol Lett 7:685-694

Koebner RMD (2004) Marker-assisted selection in the cereals: The dream and the reality. In: Gupta PK, Varshney RK (eds) Cereal Genomics. Kluwer, Dordrecht, pp 317-330

Koebner R, Summers R (2003) 21st century wheat breeding: selection in plots or detection in plates? Trends Biotech 21:59-63

Koebner RMD, Powell W, Donini P (2001) The contribution of current and forthcoming DNA molecular marker technologies to wheat and barley genetics and breeding In: Janick J (ed) Plant Breed Rev 21, pp 181-220

Koebner RMD, Donini P, Reeves JC, Cooke RJ, Law JR (2003) Temporal flux in the morphological and molecular diversity of UK barley. Theor Appl Genet 106:550-558

Kojima T, Nagaoka T, Noda K, Ogihara Y (1998) Genetic linkage map of ISSR and RAPD markers in einkorn wheat in relation to that of RFLP markers. Theor Appl Genet 96:37-45

Kojima S, Takahashi Y, Kobayashi Y, Monna L, Sasaki T, Araki T, Yano M (2002) Hd3a, a rice ortholog of the Arabidopsis FT gene, promotes transition to flowering downstream of $\mathrm{Hd} 1$ under short-day conditions. Plant Cell Physiol 43:10961105

Kong LR, Dong YC, Jia JZ (1998) Random amplified polymorphism of DNA analysis in Aegilops tauschii. Acta Bot Sin 40:223-227

Korzun V, Malyshev S, Voylokov A, Börner A (1997a) RFLP based mapping of three mutant loci in rye (Secale cereale $\mathrm{L}$.) and their relation to homoeologous loci within the Gramineae. Theor Appl Genet 95:468-473

Korzun V, Röder M, Worland AJ, Börner A (1997b) Mapping of the dwarfing (Rht12) and vernalisation response (Vrn1) genes in wheat by using RFLP and microsatellite markers. Plant Breed 116:227-232

Korzun V, Röder MS, Ganal MW, Worland AJ, Law CN (1998) Genetic analysis of the dwarfing gene (Rht8) in wheat. Part I: Molecular mapping of Rht8 on the short arm of chromosome 2D of bread wheat (Triticum aestivum $\mathrm{L}$ ). Theor Appl Genet 96:1104-1109
Korzun V, Röder MS, Wendehake K, Pasqualone A, Lotti C, Ganal MW, Blanco A (1999) Integration of dinucleotide microsatellites from hexaploid bread wheat into a genetic linkage map of durum wheat. Theor Appl Genet 98:12021207

Kota RS, Gill KS, Gill BS, Endo TR (1993) A cytogenetically based physical map of chromosome-1B in common wheat. Genome 36:548-554

Kraic J, Silkova S, Hudcovicova, Gregova E, Bartos P (2003) Leaf rust resistant wheat lines developed by marker-assisted selection. In: Pogna NE, Romano M, Pogna EA, Galterio G (eds) Proc 10th Int Wheat Genet Symp, Paestum, Italy, pp 742-745

Kuchel H, Wraner P, Fox RL, Chalmers K, Howes N, Langridge P, Jefferies SP (2003) Whole genome based marker assisted selection strategies in wheat breeding. In: Pogna NE, Romano M, Pogna EA, Galterio G (eds) Proc 10th Int Wheat Genet Symp, Paestum, Italy, pp 144-147

Kulwal P, Singh R, Balyan HS, Gupta PK (2004) Genetic basis of pre-harvest sprouting tolerance using single-locus and two-locus QTL analyses in bread wheat. Funct Integr Genom 4:94-101

Kurata N, Nagamura Y, Yamamoto K, Harushima Y, Sue N, Wu J, Antonio BA, Shomura A, Shimizu T, Lin et al (1994) A 300 kolobase interval genetic map of rice including 883 expressed sequences. Nat Genet 8:365-372

Lage J, Warburton ML, Crossa J, Skovmand B, Andersen SB (2003) Assessment of genetic diversity in synthetic hexaploid wheats and their Triticum dicoccum and Aegilops tauschii parents using AFLPs and agronomic traits. Euphytica 134:305-317

Lagudah ES, Dubcovsky J, Powell W (2001) Wheat genomics. Plant Physiol Biochem 39:335-344

Lamoureux D, Boeuf C, Regad F, Garsmeur O, Charmet G, Sourdille P, Lagoda P, Bernard M (2002) Comparative mapping of the wheat $5 \mathrm{~B}$ short chromosome arm distal region with rice, relative to a crossability locus. Theor Appl Genet 105:759-765

Langridge P, Chalmers K (1998) Techniques for marker development. In: Slinkard AE (ed) Proc 9th Int Wheat Genet Symp, Vol 1. University Extension Press, University of Saskatchewan, Saskatoon, Canada, pp 107-117

Langridge P, Chalmers K (2004) The Principle: Identification and application of molecular markers. In: Lörz H, Wenzel G (eds) Biotechnology in Agriculture and Forestry, Vol 55. Molecular markers systems. Springer, Berlin Heidelberg New York, pp 3-22

Langridge P, Lagudah ES, Holton TA, Appels R, Sharp PJ, Chalmers KJ (2001) Trends in genetic and genome analyses in wheat: a review. Aust J Agric Res 52:1043-1077

Laroche A, Demeke T, Gaudet DA, Puchalski B, Frick M, McKenzie R (2000) Development of a PCR marker for rapid identification of the Bt-10 gene for common bunt resistance in wheat. Genome 43:217-223 
La Rota CM, Sorrells ME (2004) Comparative DNA sequence analysis of mapped wheat ESTs reveals complexity of genome relationships between rice and wheat. Funct Integr Genom 4:34-46

Laubin B, Nicot N, Amiour N, Sourdille P, Branlard G, Leroy $\mathrm{P}$ (2003) In silico mapping and colinearity between the homoeologous group 5 of wheat and the rice genome. In: Pogna NE, Romano M, Pogna EA, Galterio G (eds) Proc 10th Int Wheat Genet Symp, Paestum, Italy, pp 280-283

Law JR, Donini P, Koebner RMD, James CR, Cooke RJ (1998) DNA profiling and plant variety registration. III: The statistical assessment of distinctness in wheat using amplified fragment length polymorphisms. Euphytica 102:335-342

Lazo GR, Chao S, Hummel D, Edwards H, Crosman CC, Lui N, Matthews DE, Carollo VL, Hane DL, You FM et al (2004) Development of an expressed sequence tag (EST) resource for wheat (Triticum aestivum): EST generation, unigene analysis, probe selection and bioinformatics for a 16,000 locus bin-delineated map. Genetics 168:585-593

Leader DJ, Cullup T, Ridley P, van Dodeweerd A-M (2003) Microarray analysis of wheat grain development: applications to trait charcterization in the field. In: Pogna NE, Romano M, Pogna EA, Galterio G (eds) Proc 10th Int Wheat Genet Symp, Paestum, Italy, pp 287-292

Lee M (1995) DNA markers and plant breeding programs. Adv Agron 55:265-344

Leigh F, Lea V, Law J, Wolters P, Powell W, Donini P (2003) Assessment of EST- and genomic microsatellite markers for variety discrimination and genetic diversity studies in wheat. Euphytica 133:359-366

Leister D, Kurth J, Laurie DA, Yano M, Sasaki T, Devos K, Graner A, Schulze-Lefert P (1998) Rapid reorganization of resistance gene homologues in cereal genomes. Proc Natl Acad Sci USA 95:370-375

Li YC, Fahima T, Beiles A, Korol AB, Nevo E (1999) Microclimatic stress and adaptive DNA differentiation in wild emmer wheat, Triticum dicoccoides. Theor Appl Genet 98:873883

Li W, Nelson JC, Chu CY, Shi LH, Huang SH, Liu DJ (2002a) Chromosomal locations and genetic relationships of tiller and spike characters in wheat. Euphytica 125:357-366

Li YC, Röder MS, Fahima T, Kirzhner VM, Beiles A, Korol AB, Nevo E (2002b) Climatic effects on microsatellite diversity in wild emmer wheat (Triticum dicoccoides) at the Yehudiyya microsite, Israel. Heredity 89:127-132

Li C, Ni P, Francki M, Hunter M, Zhang Y, Schibeci D, Li H, Tarr A, Wang J, Cakir M et al. (2004a) Genes controlling seed dormancy and pre-harvest sprouting in a rice-wheatbarley comparison. Funct Integr Genom 4:84-93

Li Z, Huang N, Rampling L, Wang J, Yu J, Morell M, Rahman S (2004b) Detailed comparison between the wheat chromosome group 7 short arms and the rice chromosome arms $6 \mathrm{~S}$ and $8 \mathrm{~L}$ with special reference to genes involved in starch biosynthesis. Funct Integr Genom 4:231-240
Ling H-Q, Zhu Y, Keller B (2003) High-resolution mapping of the leaf rust disease resistance gene $\operatorname{Lr} 1$ in wheat and characterisation of BAC clones from the $\operatorname{Lr} 1$ locus. Theor Appl Genet 3:875-882

Linkiewicz AM, Qi L, Echalier B, Gill BS, Chao S, Lazo G, Anderson OD, Akhunov ED, Dvorak J, Miftahudin et al. (2003) A two thousand loci physical map of wheat homoeologous group 5. In: Pogna NE, Romano M, Pogna EA, Galterio G (eds) Proc 10th Int Wheat Genet Symp, Paestum, Italy, pp 986-988

Linkiewicz AM, Qi LL, Gill BS, Ratnasiri A, Echalier B, Chao S, Lazo G, Hummel DD, Anderson OD, Akhunov ED et al (2004) A 2,500-locus bin map of wheat homoeologous group 5 provides insights on gene distribution and colinearity with rice. Genetics 168:665-676

Liu YG, Tsunewaki K (1991) Restriction fragment length polymorphism (RFLP) analysis in wheat II Linkage maps of the RFLP sites in common wheat. Jpn J Genet 66:617-633

Liu SX, Anderson JA (2003a) Marker assisted evaluation of Fusarium head blight resistant wheat germplasm. Crop Sci 43:760-766

Liu SX, Anderson JA (2003b) Targeted molecular mapping of a major wheat QTL for Fusarium head blight resistance using wheat ESTs and synteny with rice. Genome 46:817823

Liu Z, Sun Q, Ni Z, Yang T (1999a) Development of SCAR markers linked to the Pm21 gene conferring resistance to powdery mildew in common wheat. Plant Breed 118:215-219

Liu ZQ, Pei Y, Pu ZJ (1999b) Relationship between hybrid performance and genetic diversity based on RAPD markers in wheat, Triticum aestivum L. Plant Breed 118:119-123

Liu J, Liu D, Tao W, Li W, Wang S, Chen P, Cheng S, Gao D (2000) Molecular marker-facilitated pyramiding of different genes for powdery mildew resistance in wheat. Plant Breed 119:21-24

Liu SX, Griffey CA, Maroof MAS (2001a) Identification of molecular markers associated with adult plant resistance to powdery mildew in common wheat cultivar Massey. Crop Sci 41:1268-1275

Liu XM, Smith CM, Gill BS, Tolmay V (2001b) Microsatellite markers linked to six Russian wheat aphid resistance genes in wheat. Theor Appl Genet 102:504-510

Liu XM, Smith CM, Gill BS (2002a) Identification of microsatellite markers linked to Russian, wheat aphid resistance genes Dn4 and Dn6. Theor Appl Genet 104:1042-1048

Liu Z, Sun Q, Ni Z, Nevo E, Yang T (2002b) Molecular characterization of a novel powdery mildew resistance gene Pm30 in wheat originating from wild emmer. Euphytica 123:21-29

Liu D, Gao M, Guo X, Zhang A (2003) QTL mapping for kernel weight in multiple environments. In: Pogna NE, Romano M, Pogna EA, Galterio G (eds) Proc 10th Int Wheat Genet Symp, Paestum, Italy, pp 989-993

Lotti C, Salvi S, Pasqualone A, Tuberosa R, Blanco A (2000) Integration of AFLP markers into an RFLP-based map of durum wheat. Plant Breed 119:393-401 
Lubbers EL, Gill KS, Cox TS, Gill BS (1991) Variation of molecular markers among geographically diverse accessions of Triticum tauschii. Genome 34:354-361

Luo M-C, Thomas CS, Deal KR, You FM, Anderson OD, Gu Y-Q, Li W, Kuraparthy V, Gill BS, McGuire PE, Dvorak J (2003) Construction of contigs of Aegilops tauschii genomic DNA fragments cloned in BAC and BiBAC vectors. In: Pogna NE, Romano M, Pogna EA, Galterio G (eds) Proc 10th Int Wheat Genet Symp, Paestum, Italy, pp 293-296

Ma ZQ, Lapitan NLV (1998) A comparison of amplified and restriction fragment length polymorphism in wheat. Cereal Res Commun 26:7-13

Ma ZQ, Sorrells ME, Tanksley SD (1994) RFLP markers linked to powdery mildew resistance genes $P m 1, P m 2, P m 3$ and Pm4 in wheat. Genome 37:871-875

Ma ZQ, Saidi A, Quick JS, Lapitan NLV (1998) Genetic mapping of Russian wheat aphid resistance genes Dn2 and Dn4 in wheat. Genome 41:303-306

Ma JX, Zhou RH, Dong YS, Wang LF, Wang XM, Jia JZ (2001) Molecular mapping and detection of the yellow rust resistance gene Yr26 in wheat transferred from Triticum turgidum L using microsatellite markers. Euphytica 120:219-226

Ma ZQ, Lin F, Kong X, Wu JZ, Zhu HL, Xie SL, Wei JB, Liu DJ (2003) Mapping QTLs associated with FHAB resistance in a Wangshuibai x Nanda2419 population. In: Pogna NE, Romano M, Pogna EA, Galterio G (eds) Proc 10th Int Wheat Genet Symp, Paestum, Italy, pp 372-375

Maccaferri M, Sanguineti MC, Donini P, Tuberosa R (2003) Microsatellite analysis reveals a progressive widening of the genetic basis in the elite durum wheat germplasm. Theor Appl Genet 107:783-797

Mago R, Spielmeyer W, Lawrence GJ, Lagudah ES, Ellis JG, Pryor A (2002) Identification and mapping of molecular markers linked to rust resistance genes located on chromosome $1 \mathrm{RS}$ of rye using wheat rye translocation lines. Theor Appl Genet 104:1317-1324

Malik R, Brown-Guedira GL, Smith CM, Harvey TL, Gill BS (2003) Genetic mapping of wheat curl mite resistance genes Cmc3 and Cmc4 in common wheat. Crop Sci 43:644-650

Manifesto MM, Schlatter AR, Hopp HE, Suarez EY, Dubcovsky J (2001) Quantitative evaluation of genetic diversity in wheat germplasm using molecular markers. Crop Sci 41:682-690

Mares DJ, Mrva K (2001) Mapping quantitative trait loci associated with variation in grain dormancy in Australian wheat. Aust J Agric Res 52:1257-1265

Mares D, Mrva K, Tan MK, Sharp P (2002) Dormancy in whitegrained wheat: Progress towards identification of genes and molecular markers. Euphytica 126:47-53

Marino CL, Nelson JC, Lu YH, Sorrells ME, Leroy P, Tuleen NA, Lopes CR, Hart GE (1996) Molecular genetic maps of the group 6 chromosomes of hexaploid wheat Triticum aestivum $\mathrm{L}$ em Thell). Genome 39:359-366

Masojć P, Myśków B, Milczarski P (2001) Extending a RFLPbased genetic map of rye using random amplified poly- morphic DNA (RAPD) and isozyme markers. Theor Appl Genet 102:1273-1279

Matthews DE, Lazo GR, Carollo V, Anderson OD (2003) Information resources for the wheat genomics In: Pogna NE, Romano M, Pogna EA, Galterio G (eds) Proc 10th Int Wheat Genet Symp, Paestum, Italy, pp 297-300

Matthews DE, Carollo V, Lazo G, Anderson OD (2004) Bioinformatics and Triticeae genomics: resources and future developments. In: Gupta PK, Varshney RK (eds) Cereal Genomics. Kluwer, Dordrecht, pp 425-446

McCartney CA, Brûle-Babel AL, Lamari L, Somers DJ (2003) Chromosomal location of a race-specific gene to $M y$ cosphaerella graminicola in the spring wheat ST6. Theor Appl Genet 107:1181-1186

McLauchlan A, Ogbonnaya FC, Hollingsworth B, Carter M, Gale KR, Henry RJ, Holton TA, Morell MK, Rampling LR, Sharp PJ et al (2001) Development of robust PCRbased DNA markers for each homoeoallele of granulebound starch synthase and their application, in wheat breeding programs. Aust J Agric Res 52:1409-1416

Mesfin A, Frohberg RC, Anderson JA (1999) RFLP markers associated with high grain protein from Triticum turgidum $\mathrm{L}$ var dicoccoides introgressed into hard red spring wheat. Crop Sci 39:508-513

Messmer MM, Keller M, Zanetti S, Keller B (1999) Genetic linkage map of wheat $\times$ spelt cross. Theor Appl Genet 98:1163-1170

Mickelson-Young L, Endo TR, Gill BS (1995) A cytogenetic ladder-map of the wheat homoeologous group-4 chromosomes. Theor Appl Genet 90:1007-1011

Miftahudin, Ross K, Ma X-F, Mahmoud AA, Layton J, Rodriguez Milla MA, Chikmawati T, Ramalingam J, Feril O, Pathan MS et al (2004) Analysis of expressed sequence tag loci on wheat chromosome group 4. Genetics 168:651-663

Milla MAR, Gustafson JP (2001) Genetic and physical characterization of chromosome 4DL in wheat. Genome 44:883-892

Miller CA, Altinkut A, Lapitan NLV (2001) A microsatellite marker for tagging Dn2, a wheat gene conferring resistance to the Russian wheat aphid. Crop Sci 41:1584-1589

Milligan AS, Lopato S, Langridge P (2004) Functional genomics studies of seed development in cereals. In: Gupta PK, Varshney RK (eds) Cereal Genomics. Kluwer, Dordrecht, pp 447482

Mizumoto K, Hirosawa S, Nakamura C, Takumi S (2002) Nuclear and chloroplast genome genetic diversity in the wild einkorn wheat, Triticum urartu, revealed by AFLP and SSLP analyses. Hereditas 137:208-214

Mochida K, Kawaura K, Ogihara Y (2003) SNPs genotyping of hexaploid wheat by the 'Allele-Specific Pyrosequencing'. In: Pogna NE, Romano M, Pogna EA, Galterio G (eds) Proc 10th Int Wheat Genet Symp, Paestum, Italy, pp 1003-1005 Mohammadi SA, Prasanna BM (2003) Analysis of genetic diversity in crop plants - salient statistical tools and considerations. Crop Sci 43:1235-1248 
Mohapatra T, Krishanpal, Singh SS, Swain SC, Sharma RK, Singh NK (2003) STMS-based DNA fingerprints of the new plant type wheat lines. Curr Sci 84:1125-1129

Mohler V, Schwarz G (2004) Genotyping tools in plant breeding: From restriction fragmnet length polymorphisms to single nucleotided polymorphisms. In: Lörz H, Wenzel G (eds) Biotechnology in Agriculture and Forestry 55: Molecular Markers Systems in Plant Breeding and Crop Improvement. Springer, Berlin Heidelberg New York, pp 23-38

Mohler V, Hsam SLK, Zeller FJ, Wenzel G (2001) An STS marker distinguishing the rye-derived powdery mildew resistance alleles at the Pm8/Pm17 locus of common wheat. Plant Breed 120:448-450

Moore G (1995) Cereal Genome evolution-pastoral pursuits with lego genomes. Curr Opin Genet Dev 5:717-724

Moore G, Devos KM, Wang Z, Gale MD (1995a) Cereal genome evolution: grasses, line up and form a circle. Curr Biol 5:737-739

Moore G, Foote T, Helentjaris T, Devos KM, Kurata N, Gale MD (1995b) Was there a single ancestral cereal chromosome? Trends Genet 11:81-82

Mori N, Moriguchi T, Nakamura C (1997) RFLP analysis of nuclear DNA for study of phylogeny and domestication of tetraploid wheat. Genes Genet Syst 72:153-161

Morgante M, Hanafey M, Powell W (2002) Microsatellites are preferentially associated with nonrepetitive DNA in plant genomes. Nat Genet 30:194-200

Munkvold JD, Greene RA, Bermudez-Kandianis CE, La Rota CM, Edwards H, Sorrells SF, Dake T, Benscher D, Kantety $\mathrm{R}$, Linkiewicz AM et al (2004) Group 3 chromosome bin maps of wheat and their relationship to rice chromosome 1 . Genetics $168: 639-650$

Myburg AA, Cawood M, Wingfield BD, Botha AM (1998) Development of RAPD and SCAR markers linked to the Russian wheat aphid resistance gene $D n 2$ in wheat Theor Appl Genet 96:1162-1169

Nachit M, Elouafi I, Pagnotta MA, El Saleh A, Iacono E, Labhili M, Asbati A, Azrak M, Hazzam H, Benscher D et al (2001) Molecular linkage map for an intraspecific recombinant inbred population of durum wheat (Triticum turgidum $\mathrm{L}$ var durum). Theor Appl Genet 102:177-186

Naik S, Gill VS, Rao VSP, Gupta VS, Tamhankar SA, Pujar S, Gill BS, Ranjekar PK (1998) Identification of a STS marker linked to the Aegilops speltoides-derived leaf rust resistance gene Lr28 in wheat. Theor Appl Genet 97:535-540

Namuth DM, Lapitan NLV, Gill KS, Gill BS (1994) Comparative RFLP mapping of Hordeum vulgare and Triticum tauschii. Theor Appl Genet 89:865-872

Nelson JC, Singh RP, Autrique JE, Sorrells ME (1997) Mapping genes conferring and suppressing leaf rust resistance in wheat. Crop Sci 37:1928-1935

Nelson JC, Sorrells ME, Van Deynze AE, Lu YH, Atkinson M, Bernard M, Leroy P, Faris JD, Anderson JA (1995a) Molecular mapping of wheat: major genes and rearrangements in homoeologous groups 4, 5, and 7. Genetics 141:721-731
Nelson JC, Van Deynze AE, Autrique E, Sorrells ME, Lu Y H, Merlino M, Atinkson M, Leroy P (1995b) Molecular mapping of wheat homoeologous group 2. Genome 38:516-524 Nelson JC, Van Deynze AE, Autrique E, Sorrells ME, Lu YH, Negre M, Atinkson M, Leroy P (1995c) Molecular mapping of wheat homoeologous group 3. Genome 38:525-533

Nevo E (2001) Genetic resources of wild emmer, Triticum dicoccoides, for wheat improvement in the third millennium. Israel J Plant Sci 49:S77-S91

Nicot N, Chiquet V, Gandon B, Specel S, Amilhat L, Leroy P, Burr B, Blewitt M, Murigneux A, Chalhoub B et al. (2003a) Genetic mapping of SSR sequences isolated from wheat genomic DNA libraries. In: Pogna NE, Romano M, Pogna EA, Galterio G (eds) Proc 10th Int Wheat Genet Symp, Paestum, Italy, pp 1014-1016

Nicot N, Chiquet V, Gandon B, Specel S, Amilhat L, Leroy P, Legeai F, Foisset N, Dufour P, Bernard M et al. (2003b) SSR marker development from low copy wheat sequences. In: Pogna NE, Romano M, Pogna EA, Galterio G (eds) Proc 10th Int Wheat Genet Symp, Paestum, Italy, pp 1017-1019

Nicot N, Chiquet V, Gandon B, Amilhat L, Legeai F, Leroy P, Bernard M, Sourdille P (2004) Study of simple sequence repeat (SSR) markers from wheat expressed sequence tags (ESTs). Theor Appl Genet 109:800-805

Ogbonnaya FC, Subrahmanyam NC, Moullet O, de Majnik J, Eagles HA, Brown JS, Eastwood RF, Kollmorgen J, Appels R, Lagudah ES (2001) Diagnostic DNA markers for cereal cyst nematode resistance in bread wheat. Aust J Agric Res 52:1367-1374

Ogihara Y (2003) SNPs analysis of homoeologous genes by computing a large scale of expressed sequence tags in the hexaploid wheat. In: Pogna NE, Romano M, Pogna EA, Galterio G (eds) Proc 10th Int Wheat Genet Symp, Paestum, Italy, pp 301-306

Ogihara Y, Hasegawa K, Tsujimoto H (1994) High-resolution cytological mapping of the long arm of chromosome $5 \mathrm{~A}$ in common wheat using a series of deletion lines induced by gametocidal (gc) genes of Aegilops speltoides. Mol Gen Genet 244:253-259

Ogihara Y, Mochida K, Nemoto Y, Murai K, Yamazaki Y, Shin-I T, Kohara Y (2003) Correlated clustering and virtual display of gene expression patterns in the wheat life cycle by largescale statistical analyses of expressed sequence tags. Plant J 33:1001-1011

Otto CD, Kianian SF, Elias EM, Stack RW, Joppa LR (2002) Genetic dissection of a major fusarium head blight QTL in tetraploid wheat. Plant Mol Biol 48:625-632

Ovesna J, Leisova L, Kucera (2003) Evaluation of Czech wheats by DNA markers: possible applet for genetic resources preservation. In: Pogna NE, Romano M, Pogna EA, Galterio G (eds) Proc 10th Int Wheat Genet Symp, Paestum, Italy, pp 503-505

Özkan H, Brandolini A, Schäfer-Pregl R, Salamini F (2002) AFLP analysis of a collection of tetraploid wheats indicates the origin of emmer and hard wheat domestication in south- 
east Turkey. Mol Biol Evol 19:1797-1801

Pagnotta MA, Laghetti G, Mondini L, Codianni P, Volpe N, Riefolo C, Savo Sordaro ML, Perrino P, Fares C (2003) Assessment of genetic diversity and characterization of Italian emmer wheat (Triticum dicoccum Schübler) populations. In: Pogna NE, Romano M, Pogna EA, Galterio G (eds) Proc 10th Int Wheat Genet Symp, Paestum, Italy, pp 506-508

Paillard S, Schnurbusch T, Winzeler M, Messmer M, Sourdille P, Abderhalden O, Keller B, Schachermayr G (2003) An integrative genetic linkage map of winter wheat (Triticum aestivum L). Theor Appl Genet 107:1235-1242

Pallottta MA, Warner P, Fox RL, Kuchel H, Jefferies SJ, Langridge P (2003) Marker-assisted wheat breeding in southern region of Australia. In: Pogna NE, Romano M, Pogna EA, Galterio G (eds) Proc 10th Int Wheat Genet Symp, Paestum, Italy, pp 789-791

Parker GD, Langridge P (2000) Development of a STS marker linked to a major locus controlling flour colour in wheat (Triticum aestivum L). Mol Breed 6:169-174

Parker GD, Chalmers KJ, Rathjen AJ, Langridge P (1998) Mapping loci associated with flour colour in wheat (Triticum aestivum L). Theor Appl Genet 97:238-245

Parker GD, Chalmers KJ, Rathjen AJ, Langridge P (1999) Mapping loci associated with milling yield in wheat (Triticum aestivum $\mathrm{L}$ ). Mol Breed 5:561-568

Parker GD, Fox PN, Langridge P, Chalmers K, Whan B, Ganter PF (2002) Genetic diversity within Australian wheat breeding programs based on molecular and pedigree data. Euphytica 124 (3):293-306

Pasquer F, Stein N, Isidore E, Keller B (2003) Microarray analysis of gene expression in wheat (Triticum aestivum) after fungicide application. In: Pogna NE, Romano M, Pogna EA, Galterio G (eds) Proc 10th Int Wheat Genet Symp, Paestum, Italy, pp 1029-1031

Paterson AH (2004) Comparative genomics in cereals. In: Gupta PK, Varshney RK (eds) Cereal Genomics. Kluwer, Dordrecht, pp 119-134

Paterson AH, Tanksley SD, Sorrells ME (1994) DNA markers in plant breeding. Adv Agron 46:39-90

Paull JG, Pallotta MA, Langridge P (1994) The TT RFLP markers associated with $\mathrm{Sr} 22$ and recombination between chromosome 7A of bread wheat and the diploid species Triticum boeoticum. Theor Appl Genet 89:1039-1045

Paull JG, Chalmers KJ, Karakousis A, Kretschmer JM, Manning S, Langridge P (1998) Genetic diversity in Australian wheat varieties and breeding material based on RFLP data. Theor Appl Genet 96:435-446

Payne PI, Holt LM, Thompson RD, Bartels D, Harberd NP, Harris PA, Law CN (1983) The high molecular weight subunits of glutenin: classical genetics, molecular genetics and the relationship of bread making quality. In: Sakamoto $S$ (ed) Proc 6th Int Wheat Genet Symp, Kyoto, Japan, pp 827-834

Payne PI, Nightingale MA, Krattiger AF, Holt LM (1987) The relationship between HMW glutenin subunit composition and the breadmaking quality of British-grown wheat varieties. J Sci Food Agric 40:51-65

Peng JH, Fahima T, Röder MS, Huang QY, Dahan A, Li YC, Grama A, Nevo E (2000a) Highdensity molecular map of chromosome region harboring striperust resistance genes YrH52 and Yr15 derived from wild emmer wheat, Triticum dicoccoides. Genetica 109:199-210

Peng J, Korol AB, Fahima T, Röder MS, Ronin YI, Li YC, Nevo E (2000b) Molecular genetic maps in wild emmer wheat, Triticum dicoccoides: Genome-wide coverage, massive negative interference, and putative quasi-linkage. Genome Res 10:1509-1531

Peng JH, Zadeh H, Lazo GR, Qi LL, Echalier B, Gill BS, Chao S, Anderson OD, Sandhu D, Gill KS et al (2003) A physical map of expressed sequence tags and functional genomics in the group 1 chromosomes of wheat (Triticum aestivum). In: Pogna NE, Romano M, Pogna EA, Galterio G (eds) Proc 10th Int Wheat Genet Symp, Paestum, Italy, pp 1035-1037

Peng J, Tahir M, Wang H, Lapitan NLV (2004a) Frequency and genomic distribution of functional microsatellites in wheat, Triticum aestivum L. In: Plant Animal Genome XII, Jan 1014, 2004, San Diego, P424

http://www.intl-pag.org/12/abstracts/P5c_PAG12_424.html

Peng JH, Zadeh H, Lazo GR, Gustafson JP, Chao S, Anderson OD, Qi LL, Echalier B, Gill BS, Dilbirgi M et al (2004b) Chromosome bin map of expressed sequence tags in honoeologous group 1 of hexaploid wheat and homoloeolgy with rice and Arabidopsis. Genetics 168:609-623

Penner GA, Zirino M, Kruger S, Townley-Smith F (1998) Accelerated recurrent parent selection in wheat with microsatellite markers. In: Slinkard AE (ed) Proc 9th Int Wheat Genet Symp Vol 1, University of Saskatchewan, Saskatoon, Canada, pp 131-134

Perenzin M, Corbellini M, Accerbi M, Vaccino P, Borghi B (1998) Bread wheat: F-1 hybrid performance and parental diversity estimates using molecular markers. Euphytica 100:273-279

Pester TA, Ward SM, Fenwick AL, Westra P, Nissen SJ (2003) Genetic diversity of jointed goatgrass (Aegilops cylindrica) determined with RAPD and AFLP markers. Weed Sci 51:287293

Pestsova E, Ganal MW, Röder MS (2000) Isolation and mapping of microsatellite markers specific for the D genome of bread wheat. Genome 43:689-697

Phillips RL, Vasil IK (eds) (2001) DNA-Based Markers in Plants, 2nd edn. Kluwer, Dordrecht

Plaschke J, Ganal MW, Röder MS (1995) Detection of genetic diversity in closely-related bread wheat using microsatellite markers. Theor Appl Genet 91:1001-1007

Potokina E, Caspers M, Prasad M, Kota R, Zhang H, Sreenivasulu N, Wang M, Graner A (2004) Functional association between malting quality trait components and cDNA array based expression patterns in barley (Hordeum vulgare L.). Mol Breed 14:153-170 
Powell W, Langridge P (2004) Unfashionable crop species flourish in the 21st century. Genome Biol 5: Art. 233

Prasad M, Varshney RK, Kumar A, Balyan HS, Sharma PC, Edwards KJ, Singh H, Dhaliwal HS, Roy JK, Gupta PK (1999) A microsatellite marker associated with a QTL for grain protein content on chromosome arm 2DL of bread wheat. Theor Appl Genet 99:341-345

Prasad M, Varshney RK, Roy JK, Balyan HS, Gupta PK (2000) The use of microsatellites for detecting DNA polymorphism, genotype identification and genetic diversity in wheat. Theor Appl Genet 100:584-592

Prasad M, Kumar N, Kulwal PL, Röder MS, Balyan HS, Dhaliwal HS, Gupta PK (2003) QTL analysis for grain protein content using SSR markers and validation studies using NILs in bread wheat. Theor Appl Genet 106:659-667

Prins R, Groenewald JZ, Marais GF, Snape JW, Koebner RMD (2001) AFLP and STS tagging of Lr19, a gene conferring resistance to leaf rust in wheat. Theor Appl Genet 103:618624

Pritchard JK, Stephens M, Rosenberg NA, Donnelly P (2000) Association mapping in structured populations. Am J Hum Genet 67:170-181

Procunier JD, Townley-Smith TF, Fox S, Prashar S, Gray M, Kim WK, Czarnecki E, Dyck PL (1995) PCR-based RAPD/DGGE markers linked to leaf rust resistance genes Lr29 and Lr25 in wheat (Triticum aestivum L). J Genet Breed 49:87-92

Pumphrey MO, Anderson JA (2003) QTL validation via systematic development of near-isogenic wheat lines from existing breeding populations. In: Pogna NE, Romano M, Pogna EA, Galterio G (eds) Proc 10th Int Wheat Genet Symp, Paestum, Italy, pp 1227-1229

Qi L-L, Gill BS (2001) High-density physical maps reveal that the dominant male-sterile gene $M s 3$ is located in a genomic region of low recombination in wheat and is not amenable to map-based cloning. Theor Appl Genet 103:998-1006

Qi L, Cao M, Chen P, Li W, Liu D (1996) Identification, mapping, and application of polymorphic DNA associated with resistance gene Pm21 of wheat. Genome 39:191-197

Qi L-L, Echalier B, Friebe B, Gill BS (2003) Molecular characterization of a set of wheat deletion stocks for use in chromosome bin mapping of ESTs. Funct Integr Genom 3:39-55

Qi L-L, Echalier B, Chao S, Lazo GR, Butler GE, Anderson OD, Akhunov ED, Dvorak J, Linkiewicz AM, Ratnasiri et al (2004) A chromosome bin map of 16,000 expressed sequence tag loci and distribution of genes among the three genomes of polyploid wheat. Genetics 168:701-712

Queen RA, Gribbon BM, James C, Jack P, Flavell AJ (2004) Retrotransposon-based molecular markers for linkage and genetic diversity analysis in wheat. Mol Genet Genom 271:91-97

Radovanovic N, Cloutier S (2003) Gene-assisted selection for high molecular weight glutenin subunits in wheat doubled haploid breeding program. Mol Breed 12:51-59
Rafalski A (2002) Applications of single nucleotide polymorphisms in crop genetics. Curr Opin Plant Biol 5:94-100

Rafalski A, Morgante M (2004) Corn and humans: recombination and linkage disequilibrium in two genomes of similar size. Trends Genet 20:103-111

Rampino P, Malatrasi M, Gulli M, Marmiroli N, Perrotta C (2003) Drought stress related sequences in durum wheat. In: Pogna NE, Romano M, Pogna EA, Galterio G (eds) Proc 10th Int Wheat Genet Symp, Paestum, Italy, pp 1233-1235

Randhawa HS, Dilbriligi M, Sidgu D, Erayman M, Sandhu D, Bondareva S, Chao S, Lazo GR, Anderson OD, Miftahudin, Gustafson JP et al (2004) Deletion mapping of homoeologous group 6-specific wheat expressed sequence tags. Genetics 168:677-686

Raupp WJ, Sukhwinder-Singh, Brown-Guedira GL, Gill BS (2001) Cytogenetic and molecular mapping of the leaf rust resistance gene Lr39 in wheat. Theor Appl Genet 102:347352

Rebetzke GJ, Appels R, Morrison AD, Richards RA, McDonald G, Ellis MH, Spielmeyer W, Bonnett DG (2001) Quantitative trait loci on chromosome 4B for coleoptile length and early vigour in wheat (Triticum aestivum L.). Aust J Agric Res 52:1221-1234

Reffo G, Corbellini M, Bruschi G, Brandolini A (2003) Markerassisted introgression of the $P m 13$ powdery mildew resistance gene in Italian bread wheat cultivars. In: Pogna NE, Romano M, Pogna EA, Galterio G (eds) Proc 10th Int Wheat Genet Symp, Paestum, Italy, pp 801-803

Reiter RS, Williams JKG, Feldmann KA, Rafalski JA,Tingey SV, Scolnik PA (1992) Global and local genome mapping in Arabidopsis thaliana by using recombinant inbred lines and random amplified polymorphic DNAs. Proc Natl Acad Sci USA 89:1477-1481

Riley R (1965) Cytogenetics and the evolution of wheat In: Hutchinson JB (ed) Essays on Crop Plant Evolution. Cambridge University Press, Cambridge, pp 103-118

Riley R, Chapman V (1958) Genetic control of the cytologically diploid behaviour of hexaploid wheat. Nature 182:713-715

Robert O, Abelard C, Dedryver F (1999) Identification of molecular markers for the detection of the yellow rust resistance gene Yr17 in wheat. Mol Breed 5:167-175

Rong JK, Millet E, Manisterski J, Feldman M (2000) A new powdery mildew resistance gene: Introgression from wild emmer into common wheat and RFLP-based mapping. Euphytica 115:121-126

Röder MS, Korzun V, Gill BS, Ganal MW (1998a) The physical mapping of microsatellite markers in wheat. Genome 41:278-283

Röder MS, Korzun V, Wendehake K, Plaschke J, Tixier M, Leroy P, Ganal MW (1998b) A microsatellite map of wheat. Genetics 149:2007-2023

Röder MS, Huang X-Q, Börner A, Ganal MW (2003) Wheat microsatellite diversity of a genebank collection in comparison to registered varities. In: Pogna NE, Romano M, 
Pogna EA, Galterio G (eds) Proc 10th Int Wheat Genet Symp, Paestum, Italy, pp 625-627

Röder MS, Huang X-Q, Ganal MW (2004) Wheat microsatellites: Potential and implications. In: Lörz H, Wenzel G (eds) Biotechnology in agriculture and forestry, Vol 55. Molecular marker systems. Springer, Berlin Heidelberg New York, pp 255-266

Rogers WJ, Payne PI, Harinder K (1989) The HMW glutenin subunit and gliadin composition of German-grown wheat varieties and their relationship with breadmaking quality. Plant Breed 103:89-100

Rousset M, Gouis JL, Heumez E (2003) A QTL analysis for spike characteristics and fertility under field conditions in a bread wheat doubled-haploid population. In: Pogna NE, Romano M, Pogna EA, Galterio G (eds) Proc 10th Int Wheat Genet Symp, Paestum, Italy, pp 167-170

Roy JK, Prasad M, Varshney RK, Balyan HS, Blake TK, Dhaliwal HS, Singh H, Edwards KJ, Gupta PK (1999) Identification of a microsatellite on chromosomes $6 \mathrm{~B}$ and a STS on 7D of bread wheat showing an association with preharvest sprouting tolerance. Theor Appl Genet 99:336-340

Roy JK, Balyan HS, Prasad M, Gupta PK (2002) Use of SAMPL for a study of DNA polymorphism, genetic diversity and possible gene tagging in bread wheat. Theor Appl Genet 104:465-472

Roy JK, Lakshmikumaran MS, Balyan HS, Gupta PK (2004) AFLP-based genetic diversity and its comparison with diversity based on SSR, SAMPL, and phenotypic traits in bread wheat. Biochem Genet 42:43-59

Safar J, Bartos J, Janda J, Jaroslav J, Bellec A, Kubalakova M, Valarik M, Pateyron S, Weiserova J, Tuskova R et al (2004) Dissecting large and complex genomes: flow sorting and BAC cloning of individual chromosomes from bread wheat. Plant J 39:960-968

Salina E, Dobrovolskaya O, Efremova T, Leonova I, Röder MS (2003) Microsatellite monitoring of recombination around the Vrn-B1 locus of wheat during early backcross breeding. Plant Breed 122:116-119

Salvo-Garrido H, Laurie DA, Jaffe B, Snape JW (2001) An RFLP map of diploid Hordeum bulbosum $\mathrm{L}$ and comparison with maps of barley (H. vulgare $\mathrm{L}$ ) and wheat (Triticum aestivum L). Theor Appl Genet 103:869-880

Sandhu D, Gill KS (2002a) Gene-containing regions of wheat and the other grass genomes. Plant Physiol 128:803-811

Sandhu D, Gill KS (2002b) Structural and functional organization of the '1S08 gene-rich region' in the Triticeae. Plant Mol Biol 48:791-804

Sandhu D, Sidhu D, Gill KS (2002) Identification of expressed sequence markers for a major gene-rich region of wheat chromosome group 1 using RNA fingerprinting-differential display. Crop Sci 42:1285-1290

Sandhu D, Erayman M, Dilbirligi M, Sidhu D, Gill KS (2003) The gene rich regions of the wheat genome. In: Pogna NE, Romano M, Pogna EA, Galterio G (eds) Proc 10th Int Wheat Genet Symp, Paestum, Italy, pp 308-312
Sarma RN, Gill BS, Sasaki T, Galiba G, Sutka J, Laurie DA, Snape JW (1998) Comparative mapping of the wheat chromosome 5A Vrn-A1 region with rice and its relationship to QTL for flowering time. Theor Appl Genet 97:103-109

Sarma RN, Fish L, Gill BS, Snape JW (2000) Physical characterization of the homoeologous Group 5 chromosomes of wheat in terms of rice linkage blocks, and physical mapping of some important genes. Genome 43:191-198

Sasaki T, Burr B (2000) International rice genome sequencing project: the effort to completely sequence the rice genome. Curr Opin Plant Biol 3:138-141

Sasakuma T, Shindo C (2003) QTLs of heading traits in diploid and hexaploid wheat. In: Pogna NE, Romano M, Pogna EA, Galterio G (eds) Proc 10th Int Wheat Genet Symp, Paestum, Italy, pp 1047-1049

Sax K (1923) The association of size differences with seed-coat pattern and pigmentation in Phaseolus vulgaris. Genetics 8:552-560

Sayed-Tabatabaei BE, Shahnejat-Bushehri AA (2003) Assesment of genetic similarity among wheat cultivars using RAPD and AFLP techniques. In: Pogna NE, Romano M, Pogna EA, Galterio G (eds) Proc 10th Int Wheat Genet Symp, Paestum, Italy, pp 631-633

Schadt EE, Monks SA, Drake TA, Lusis AJ, Che N, Colinayo V, Ruff TG, Milligan SB, Lamb JR, Cavet G et al (2003) Genetics of gene expression surveyed in maize, mouse and man. Nature 422:297-301

Schachermayr G, Feuillet C, Keller B (1997) Molecular markers for the detection of the wheat leaf rust resistance gene Lr10 in diverse genetic backgrounds. Mol Breed 3:65-74

Schmolke M, Zimmermann G, Ebmeyer E, Miedaner T, Schweizer G, Hart L (2003) Molecular mapping of Fusarium head blight resistance QTLs in winter wheat population using AFLP markers. In: Pogna NE, Romano M, Pogna EA, Galterio G (eds) Proc 10th Int Wheat Genet Symp, Paestum, Italy, pp 1245-1247

Schnurbusch Th, Paillard S, Fossati D, Mesmer M, Schachermayr G, Winzeler M, Keller B (2003a) Detection of QTLs for Stagonospora glume blotch resistance in Swiss winter wheat. In: Pogna NE, Romano M, Pogna EA, Galterio G (eds) Proc 10th Int Wheat Genet Symp, Paestum, Italy, pp $1248-1250$

Schnurbusch Th, Paillard S, Schori A, Mesmer M, Schachermayr G, Winzeler M, Keller B (2003b) Dissection of quantitative and durable leaf rust resistance in Swiss winter wheat reveals a major resistance QTL in the Lr34 chromosomal region. In: Pogna NE, Romano M, Pogna EA, Galterio G (eds) Proc 10th Int Wheat Genet Symp, Paestum, Italy, pp $1254-1256$

Schuler GD, Boguski MS, Stewart EA, Stein LD, Gyapay G, Rice K, White RE, Rodriguez-Tome P, Aggarwal A, Bajorek E et al (1996) A gene map of the human genome. Science 274:540-546

Schulman AH, Gupta PK, Varshney RK (2004) Organization of microsatellites and retrotransposons in cereal genomes. 
In: Gupta PK, Varshney RK (eds) Cereal Genomics. Kluwer, Dordrecht, pp 83-118

Schwarz G, Herz M, Huang XQ, Michalek W, Jahoor A, Wenzel G, Mohler V (2000) Application of fluorescence based semiautomated AFLP analysis in barley and wheat. Theor Appl Genet 100:545-551

Schwarzacher T (2003) Meiosis, recombination and chromosomes: a review of gene isolation and fluorescent in situ hybridization data in plants. J Exp Bot 54:11-23

Seah S, Bariana H, Jahier J, Sivasithamparam K, Lagudah ES (2001) The introgressed segment carrying rust resistance genes $\mathrm{Yr} 17, \operatorname{Lr} 37$ and $\mathrm{Sr} 38$ in wheat can be assayed by a cloned disease resistance genelike sequence. Theor Appl Genet 102:600-605

Sears ER (1954) The aneuploids of common wheat. Missouri Agr Expt Sta Res Bull 572:59

Seyfarth R, Feuillet C, Schachermayr G, Winzeler M, Keller B (1999) Development of a molecular marker for the adult plant leaf rust resistance gene Lr35 in wheat. Theor Appl Genet 99:554-560

Shah MM, Gill KS, Baeniziger PS, Yen Y, Kaeppler SM, Ariyarathne HM (1999) Molecular mapping of loci for agronomic traits on chromosome $3 \mathrm{~A}$ of bread wheat. Crop Sci 39:1728-1732

Shan X, Blake TK, Talbert LE (1999) Conversion of AFLP markers to sequence-specific PCR markers in barley and wheat. Theor Appl Genet 98:1072-1078

Shao YT, Niu YC, Zhu LH, Zhai WX, Xu SC, Wu LR (2001) Identification of an AFLP marker linked to the stripe rust resistance gene Yr10 in wheat. Chinese Sci Bull 46:14661469

Shariflou MR, Ghannadha MR, Sharp PJ (2003) Multiplex PCR of microsatellite markers in wheat. In: Pogna NE, Romano M, Pogna EA, Galterio G (eds) Proc 10th Int Wheat Genet Symp, Paestum, Italy, pp 1050-1052

Shen X, Ittu M, Ohm HW (2003a) Quantitative trait loci conditioning resistance to fusarium head blight in wheat line F201R. Crop Sci 43:850-857

Shen X, Zhou M, Lu W, Ohm H (2003b) Detection of fusarium head blight resistance QTL in a wheat population using bulked segregant analysis. Theor Appl Genet 106:10411047

Shi AN, Leath S, Murphy JP (1998) A major gene for powdery mildew resistance transferred to common wheat from wild einkorn wheat. Phytopathology 88:144-147

Shi ZX, Chen XM, Line RF, Leung H, Wellings CR (2001) Development of resistance gene analog polymorphism markers for the Yr9 gene resistance to wheat stripe rust. Genome 44:509-516

Shinbata T, Vrinten P, Iida J, Sato M, Yonemaru J, Saito M, Mitsuse S, Nakamura T (2003) Microarray analysis of gene expression in developing endosperm from different wheat varities. In: Pogna NE, Romano M, Pogna EA, Galterio G (eds) Proc 10th Int Wheat Genet Symp, Paestum, Italy, pp 1053-1055
Sidhu D, Sandhu D, Gill KS (2003) Genes mapping in the functional centromere of the wheat chromosomes In: Pogna NE, Romano M, Pogna EA, Galterio G (eds) Proc 10th Intern Wheat Genet Symp, Paestum, Italy, pp 1056-1058

Siedler H, Messmer MM, Schachermayr GM, Winzeler H, Winzeler M, Keller B (1994) Genetic diversity in European wheat and spelt breeding material based on RFLP data. Theor Appl Genet 88:994-1003

Simons KJ, Gehlhar SB, Maan SS, Kianian SF (2003) Detailed mapping of the species cytoplasm-specific (scs) gene in durum wheat. Genetics 165:2129-2136

Singh S, Grewal TS, Singh H, Sodhi M, Dhaliwal HS (1999) Identification of amplified fragment length polymorphism markers associated with Karnal bunt (Neovossia indica) resistance in bread wheat. Indian J Agric Sci 69:497-501

Singh RP, Nelson JC, Sorrells ME (2000) Mapping Yr28 and other genes for resistance to stripe rust in wheat. Crop Sci 40:1148-1155

Singh H, Prasad M, Varshney RK, Roy JK, Balyan HS, Dhaliwal HS, Gupta PK (2001) STMS markers for grain protein content and their validation using near isogenic lines in bread wheat. Plant Breed 120:273-278

Singh S, Brown-Guedira GL, Grewal TS, Dhaliwal HS, Nelson JC, Singh H, Gill BS (2003) Mapping of a resistance gene effective against Karnal bunt pathogen of wheat. Theor Appl Genet 106:287-292

Singh NK, Raghuvanshi S, Srivastava SK, Gaur A, Pal K, Dalal V, Singh A, Ghazil IA, Bhargav A, Yadav M et al (2004a) Sequence analysis of the long arm of rice chromosome 11 for rice-wheat synteny. Funct Integ Genom 4:102-117

Singh S, Franks CD, Huang L, Brown-Guedira GL, Marshall DS, Gill BS, Fritz A (2004b) Lr41, Lr39, and a leaf rust resistance gene from Aegilops cylindrica may be allelic and are located on wheat chromosome 2DS. Theor Appl Genet 108:586-591

Singrün Ch, Hsam SLK, Hartl L, Zeller FJ, Mohler V (2003) Powdery mildew resistance gene Pm22 in cultivar Virest is a member of the complex Pm1 locus in common wheat (Triticum aestivum L em Thell). Theor Appl Genet 106:1420-1424

Smilde DW, Haluskova J, Sasaki T, Graner A (2001) New evidence for the synteny of rice chromosome 1 and barley chromosome $3 \mathrm{H}$ from rice expressed sequence tags. Genome 44:361-367

Smith PH, Koebner RMD, Boyd LA (2002) The development of a STS marker linked to a yellow rust resistance derived from the wheat cultivar Moro. Theor Appl Genet 104:1278-1282

Soleimani VD, Baum BR, Johnson DA (2002a) AFLP and pedigree-based genetic diversity estimates in modern cultivars of durum wheat [Triticum turgidum L subsp durum (Desf) Husn]. Theor Appl Genet 104:350-357

Soleimani VD, Baum BR, Johnson DA (2002b) Identification of Canadian durum wheat [Triticum turgidum L subsp durum (Desf) Husn] cultivars using AFLP and their STS markers. Can J Plant Sci 82:35-41 
Somers DJ, Fedak G, Savard M (2003a) Molecular mapping of novel genes controlling Fusarium head blight resistance and deoxynivalenol accumulation in spring wheat. Genome 46:555-564

Somers DJ, Kirkpatrick R, Moniwa M, Walsh A (2003b) Mining single nucleotide polymorphisms from hexaploid wheat ESTs. Genome 49:431-437

Somers D, Edwards KJ, Issac P (2004) A high density microsatellite consensus map for bread wheat (Triticum aestivum $\mathrm{L}$ ). Theor Appl Genet 109:1105-1114

Song QJ, Fickus EW, Cregan PB (2002a) Characterization of trinucleotide SSR motifs in wheat. Theor Appl Genet 104:286293

Song QJ, Shi JR, Singh S, Fickus EW, Fernalld R, Gill BS, Cregan PB, Ward R (2002b) Development and mapping of wheat microsatellite markers. In: Plant, Animal and Microbe Genomes X Conf, 12-16 Jan 2002, San Diego. http://www.intl-pag.org/pag/10/abstracts/ PAGX_P371.html

Sorrells ME (2004) Cereal genomics research in post-genomic era. In: Gupta PK, Varshney RK (eds) Cereal Genomics. Kluwer, Dordrecht, pp 559-584

Sorrells ME, La Rota M, Bermudez-Kandianis CE, Greene RA, Kantety R, Munkvold JD, Miftahudin, Mahmoud A, Ma $\mathrm{X}$, Gustafson PJ et al (2003) Comparative DNA sequence analysis of wheat and rice genomes. Genome Res 13:18181827

Sourdille P, Robe P, Tixier M-H, Doussinault G, Pavoine M-T, Bernard M (1999) Location of Pm3g, a powdery mildew resistance allele in wheat, by using a monosomic analysis and by identifying associated molecular markers. Euphytica 110:193-198

Sourdille P, Snape JW, Cadalen T, Charmet G, Nakata N, Bernard S, Bernard M (2000a) Detection of QTLs for heading time and photoperiod response in wheat using a doubledhaploid population. Genome 43:487-494

Sourdille P, Tixier MH, Charmet G, Gay G, Cadalen T, Bernard S, Bernard M (2000b) Location of genes involved in ear compactness in wheat (Triticum aestivum) by means of molecular markers. Mol Breed 6:247-255

Sourdille P, Cadalen T, Gay G, Gill B, Bernard M (2002) Molecular and physical mapping of genes affecting awning in wheat. Plant Breed 121:320-324

Sourdille P, Cadalen T, Guyomarc'h H, Snape JW, Perretant MR, Charmet G, Boeuf C, Bernard S (2003) An update of the Courtot $\times$ Chinese Spring intervarietal molecular marker linkage map for the QTL detection of agronomic traits in wheat. Theor Appl Genet 106:530-538

Sourdille P, Singh S, Cadalen T, Brown-Guedira GL, Gay G, Qi L, Gill BS, Dufour P, Murigneux A, Bernard M (2004) Microsatellite-based delition bin system for the establishment of genetic-physical map relationships in wheat (Triticum aestivum L). Funct Integr Genom 4:12-25
Souza E, Fox PN, Byerlee D, Skovmand B (1994) Spring wheat diversity in irrigated area of 2 developing-countries. Crop Sci 34:774-783

Spielmeyer W, Lagudah ES (2003) Rice genome sequence expedites fine mapping of durable broad spectrum stem rust resistance gene $S r 2$ in wheat (Triticum aestivum). In: Pogna NE, Romano M, Pogna EA, Galterio G (eds) Proc 10th Int Wheat Genet Symp, Paestum, Italy, pp 414-416

Spielmeyer W, Sharp PJ, Lagudah ES (2003) Identification and validation of markers linked to broad spectrum stem rust resistance gene Sr2 in wheat. Crop Sci 43:333-336

Sreenivasulu N, Kavikishor PB, Varshney RK, Altschmied L (2002) Mining functional information from cereal genomes - the utility of expressed sequence tags (ESTs). Curr Sci 83:965-973

Stachel M, Lelley T, Grausgruber H, Vollmann J (2000) Application of microsatellites in wheat (Triticum aestivum $\mathrm{L}$ ) for studying genetic differentiation caused by selection for adaptation and use. Theor Appl Genet 100:242-248

Stam P, Ooijen JW (1995) JoinMap version 2.0: software for the calculation of genetic linkage maps. CPRO-DLO, Wageningen, The Netherlands

Stein N, Graner A (2004) Map-based gene isolation in cereal genomes In: Gupta PK, Varshney RK (eds) Cereal Genomics. Kluwer, Dordrecht, pp 331-360

Stein N, Feuillet C, Wicker T, Schlagenhauf E, Keller B (2000) Subgenome chromosome walking in wheat: A $450-\mathrm{kb}$ physical contig in Triticum monococcum $\mathrm{L}$ spans the $\mathrm{Lr} 10$ resistance locus in hexaploid wheat (Triticum aestivum $\mathrm{L}$ ). Proc Natl Acad Sci USA 97:13436-13441

Steiner B, Griesser M, Lemmens M, Scholz U, Buerstmayr H (2003) Molecular mapping of resistance to Fusarium head blight in the spring wheat cultivar Frontana. In: Pogna NE, Romano M, Pogna EA, Galterio G (eds) Proc 10th Int Wheat Genet Symp, Paestum, Italy, pp 1260-1262

Stephenson P, Bryan G, Kirby J, Collins A, Devos KM, Busso C, Gale MD (1998) Fifty new microsatellite loci for the wheat genetic map. Theor Appl Genet 97:946-949

Stoutjesdijk P, Kammholz SJ, Kleven S, Matsay S, Banks PM, Larkin PJ (2001) PCRbased molecular marker for the Bdv2 Thinopyrum intermedium source of barley yellow dwarf virus resistance in wheat. Aust J Agric Res 52:1383-1388

Suenaga K, Singh RP, Huerta-Espino J, William HM (2003) Microsatellite markers for genes Lr34/Yr18 and other quantitative trait loci for leaf rust and stripe rust resistance in bread wheat. Phytopathology 93:881-890

Sun GL, Fahima T, Korol AB, Turpeinen T, Grama A, Ronin YI, Nevo E (1997) Identification of molecular markers linked to the $\operatorname{Yr} 15$ stripe rust resistance gene of wheat originated in wild emmer wheat, Triticum dicoccoides. Theor Appl Genet 95:622-628

Sun QX, Ni ZF, Liu ZY, Gao JW, Huang TC (1998) Genetic relationships and diversity among Tibetan wheat, common wheat and European spelt wheat revealed by RAPD markers. Euphytica 99:205-211 
Sun Q, Wei Y, Ni Z, Xie C, Yang T (2002) Microsatellite marker for yellow rust resistance gene Yr5 in wheat introgressed from spelt wheat. Plant Breed 121:539-541

Sun G, Bond M, Nass H, Martin R, Dong Z (2003) RAPD polymorphisms in spring wheat cultivars and lines with different level of Fusarium resistance. Theor Appl Genet 106:1059-1067

Sutton T, Whitford R, Baumann U, Dong CM, Able JA, Langridge $\mathrm{P}$ (2003) The Ph2 pairing homoeologous locus of wheat (Triticum aestivum): identification of candidate meiotic genes using a comparative genetics approach. Plant J 36:443-456

Swanepoel E, Lacock L, Myburg AA, Botha AM (2003) A leucinerich homolog to Aegilops tauschii from bread wheat line PI 137739 obtained by subtractive suppression hybridization show linkage to Russian wheat aphid resistance gene Dn1. In: Pogna NE, Romano M, Pogna EA, Galterio G (eds) Proc 10th Int Wheat Genet Symp, Paestum, Italy, pp 1263-1265

TAGI, The Arabidopsis Genome Initiative (2000) The Arabidopsis Genome Initiative Analysis of the genome sequence of the flowering plant Arabidopsis thaliana. Nature 408:796815

Takahashi Y, Shomura A, Sasaki T, Yano M (2001) Hd6, a rice quantitative trait locus involved in photoperiod sensitivity, encodes the alpha subunit of protein kinase CK2. Proc Nat Acad Sci USA 98:7922-7927

Talame V, Ballardini M, Antuono FD, Maccaferri M, Tuberosa R (2003) Evaluation of genetic diversity among Italian 'Farro' (T dicoccum) populations using AFLP markers. In: Pogna NE, Romano M, Pogna EA, Galterio G (eds) Proc 10th Int Wheat Genet Symp, Paestum, Italy, pp 527-529

Talbert LE, Bruckner PL, Smith LY, Sears R, Martin TJ (1996) Development of PCR markers linked to resistance to wheat streak mosaic virus in wheat. Theor Appl Genet 93:463-467

Talbert LE, Smith LY, Blake NK (1998) More than one origin of hexaploid wheat is indicated by sequence comparison of low-copy DNA. Genome 41:402-407

Tanksley SD, McChouch SR (1997) Seed banks and molecular maps: unlocking genetic potential from the wild. Science 277:1063-1066

Tanksley SD, Young ND, Patterson AH, Bonierbale MW (1989) RFLP mapping in plant breeding - new tools for an old science. Bio/Technology 7:257-264

Tanksley SD, Nelson JC (1996) Advanced backcross QTL analysis: a method for the simultaneous discovery and transfer of valuable QTLs from unadapted germplasm into elite breeding lines. Theor Appl Genet 92:191-203

Tanyolac B, Linton E, Ozkan H (2003) Low genetic diversity in wild emmer (T. turgidum L subsp dicoccoides (Korn ex Asch et Graebn) Thell) from South-eastern Turkey revealed by restriction fragment length polymorphism. Genet Resource Crop Evol 50:829-833

Tao W, Liu D, Liu J, Feng Y, Chen P (2000) Genetic mapping of the powdery mildew resistance gene Pm6 in wheat by RFLP analysis. Theor Appl Genet 100:564-568
Thangavelu M, James AB, Bankier A, Bryan GJ, Dear PH, Waugh R (2003) HAPPY mapping in plant genome: reconstruction and analysis of a high-resolution physical map of 19 Mpp region of Arabidopsis thaliana chromosome 4. Plant Biotechnol J 1:23-31

Thiel T, Michalek W, Varshney RK, Graner A (2003) Exploiting EST databases for the developement and characterization of gene-derived SSR-markers in barley (Hordeum vulgare L.). Theor Appl Genet 106:411-422

Thoday JM (1961) Location of polygenes. Nature 191:368-370

Thornsberry JM, Goodman MM, Doebley J, Kresovich S, Nielsen D, Buckler ES (2001) Dwarf8 polymorphisms associate with variation in flowering time. Nat Genet 28:286-289

Tixier MH, Sourdille P, Charmet G, Gay G, Jaby C, Cadalen T, Bernard S, Nicolas P, Bernard M (1998) Detection of QTLs for crossability in wheat using a doubled haploid population. Theor Appl Genet 97:1076-1082

Toubia-Rahme H, Steiner B, Buerstmayr H (2003) Mapping of quantitative trait loci (QTLs) for Stagonospora glume blotch resistance in wheat. In: Pogna NE, Romano M, Pogna EA, Galterio G (eds) Proc 10th Int Wheat Genet Symp, Paestum, Italy, pp 1278-1280

Van Deynze AE, Dubcovsky J, Gill KS, Nelson JC, Sorrells ME, Dvorak J, Gill BS, Lagudah ES, McCouch SR, Appels R (1995a) Molecular-genetic maps for group 1 chromosomes of Triticeae species and their relation to chromosomes in rice and oat. Genome 38:45-59

Van Deynze AE, Nelson JC, Yglesias ES, Harrington SE, Braga DP, McCouch SR, Sorrells ME (1995b) Comparative mapping in gasses - wheat relationships. Mol Gen Genet 248:744-754

Varshney RK, Kumar A, Balyan HS, Roy JK, Prasad M, Gupta PK (2000a) Characterization of microsatellites and development of chromosome specific STMS markers in bread wheat. Plant Mol Biol Rep 18:5-16

Varshney RK, Prasad M, Roy JK, Harjit-Singh NK, Dhaliwal HS, Balyan HS, Gupta PK (2000b) Identification of eight chromosomes and a microsatellite marker on 1AS associated with QTL for grain weight in bread wheat. Theor Appl Genet 100:1290-1294

Varshney RK, Prasad M, Roy JK, Röder MS, Balyan HS, Gupta PK (2001) Integrated physical maps of 2DL, 6BS and 7DL carrying loci for grain protein content and pre-harvest sprouting tolerance in bread wheat. Cereal Res Comm 29:33-40

Varshney RK, Korzun V, Börner A (2004a) Molecular maps in cereals: methodology and progress. In: Gupta PK, Varshney RK (eds) Cereal genomics. Kluwer, Dordrecht, pp 35-82

Varshney RK, Prasad M, Graner A (2004b) Molecular marker maps of barley: a resource for intra- and interspecific genomics. In: Lörz H, Wenzel G (eds) Biotechnology in agriculture and forestry, Vol 55. Molecular markers systems. Springer, Berlin Heidelberg New York, pp 229-245

Varshney RK, Prasad M, Zhang H, Kota R, Sigmund R, Scholz U, Stein N, Graner A (2004c) EST-derived markers and transcript map of barley: a resource for interspecific trans- 
ferability and comparative mapping in cereals. In: Spunar J, Janikova J (eds) Proc 9th Int Barley Genet Symp, Brnno, Czech Republic, pp 332-338

Varshney RK, Graner A, Sorrells ME (2005a) Genic microsatellite markers in plants: features and applications. Trends Biotechnol 23:48-55

Varshney RK, Sigmund R, Korzun V, Boerner A, Stein N, Sorrells M, Langridge P, Graner A (2005b) Interspecific transferability and comparative mapping of barley EST-SSR markers in wheat, rye and rice. Plant Sci 168:195-202

Varshney RK, Thiel T, Stein N, Langridge P, Graner A (2002) In silico analysis on frequency and distribution of microsatellites in ESTs of some cereal species. Cell Mol Biol Lett 7:537546

Velculescu Ve, Zhang L, Vogelstein B, Kinzler KW (1995) Serial analysis of gene expression. Science 270:484-487

Venter E, Botha AM (2000) Development of markers linked to Diuraphis noxia resistance in wheat using a novel PCRRFLP approach. Theor Appl Genet 100:965-970

Verma V, Foulkes MJ, Worland AJ, Sylvester-Bradley R, Caligari PDS, Snape JW (2004) Mapping quantitative trait loci for flag leaf senescence as a yield determinant in winter wheat under optimal and drought-stressed environments. Euphytica 135:255-263

Vierling RA, Nguyen HT (1992) Use of RAPD markers to determine the genetic diversity of diploid, wheat genotypes. Theor Appl Genet 84:835-838

Vikal Y, Chhuneja P, Singh R, Dhaliwal HS (2004) Tagging of an Aegilops speltoides derived leaf rust resistance gene $\mathrm{Lr}$ 28 with a microsatellite marker in wheat. J Plant Biochem Biotechnol 13:47-49

Waldron BL, Moreno-Sevilla B, Anderson JA, Stack RW, Frohberg RC (1999) RFLP mapping of QTL for Fusarium head blight resistance in wheat. Crop Sci 39:805-811

Wang LF, Ma JX, Zhou RH, Wang XM, Jia JZ (2002) Molecular tagging of the yellow rust resistance gene $\mathrm{Yr} 10$ in common wheat, PI178383 (Triticum aestivum L). Euphytica 124:7173

Wang X-E, Zhang Q-P, Wang Y-N, Chen P-D, Chu C-G, Qi Z-J, Zhuang L-F, Liu D-J (2003) Identification and genetic analysis of new germplasms with wheat spindle streak mosaic bymovius (WSMMV) resistance. In: Pogna NE, Romano M, Pogna EA, Galterio G (eds) Proc 10th Int Wheat Genet Symp, Paestum, Italy, pp 1284-1286

Ward RW, Yang ZL, Kim HS, Yen C (1998) Comparative analyses of RFLP diversity in landraces of Triticum aestivum and collections of T-tauschii from China and southwest Asia. Theor Appl Genet 96:312-318

Wardrop J, Snape JW, Powell W, Machray GC (2002) Constructing plant radiation hybrid panels. Plant J 31:223-228

Wardrop J, Fuller J, Powell W, Machray GC (2004) Exploiting plant somatic radiation hybrids for physical mapping of expressed sequence tags. Theor Appl Genet 108:343-348
Waugh R, Dear PH, Powell W, Machray GC (2002) Physical education-new technologies for mapping plant genomes. Trends Plant Sci 7:521-523

Weber D, Helentjaris T (1989) Mapping RFLP loci in maize using B - A translocations. Genetics 121:583-590

Weng Y, Lazar MD (2002a) Amplified fragment length polymorphism and simple sequence, repeatbased molecular tagging and mapping of greenbug resistance gene $G b 3$ in wheat. Plant Breed 121:218-223

Weng Y, Lazar MD (2002b) Comparison of homoeologous group-6 short arm physical maps of wheat and barley reveals a similar distribution of recombinogenic and generich regions. Theor Appl Genet 104:1078-1085

Weng Y, Tuleen NA, Hart GE (2000) Extended physhical map of the homoeologous group- 6 chromosomes of wheat (Triticum aestivum L). Theor Appl Genet 100:519-527

Werner JE, Endo TR, Gill BS (1992) Toward a cytogenetically based physical map of the wheat genome. Proc Natl Acad Sci USA 89:11307-11311

Wicker T, Stein N, Albar L, Feuillet C, Schlagenhauf E, Keller B (2001) Analysis of a contiguous $211 \mathrm{~kb}$ sequence in diploid wheat (Triticum monococcum L) reveals multiple mechanisms of genome evolution. Plant J 26:307-316

William HM, Crosby M, Trethovan R, van Ginkel M, MujeebKazi A, Pfeiffer W, Khairallah M, Hoisington D (2003a) Molecular markers service laboratory at CIMMYT: an interface between the laboratory and the field. In: Pogna NE, Romano M, Pogna EA, Galterio G (eds) Proc 10th Int Wheat Genet Symp, Paestum, Italy, pp 852-854

William HM, Garcia V, Ortiz-Islas S, van Beem J, Worland AJ (2003b) Progress in molecular markers characterization for phasic development genes in wheat. In: Pogna NE, Romano M, Pogna EA, Galterio G (eds) Proc 10th Int Wheat Genet Symp, Paestum, Italy, pp 855-857

William M, Singh RP, Huerta-Espino J, Islas SO, Hoisington D (2003c) Molecular marker mapping of leaf rust resistance gene $L r 46$ and its association with stripe rust resistance gene Yr29 in wheat. Phytopathology 93:153-159

Williams KJ, Taylor SP, Bogacki P, Pallotta M, Bariana HS, Wallwork H (2002) Mapping of the root lesion nematode (Pratylenchus neglectus) resistance gene $R \operatorname{lnn} 1$ in wheat. Theor Appl Genet 104:874-879

Williams CE, Collier CC, Sardesai N, Ohm HW, Cambron SE (2003) Phenotypic assessment and mapped markers for $\mathrm{H} 31$, a new wheat gene conferring resistance to Hessian fly (Diptera: Cecidomyiidae). Theor Appl Genet 107:15161523

Xie DX, Devos KM, Moore G, Gale MD (1993) RFLP-based genetic maps of the homoeologous group 5 chromosomes of bread wheat (Triticum aestivum L). Theor Appl Genet 87:70-74

Xing QH, Ru ZG, Zhou CJ, Xue X, Liang CY, Yang DE, Jin DM, Wang B (2003) Genetic analysis, molecular tagging and mapping of the thermo-sensitive genic male-sterile gene (wtms1) in wheat. Theor Appl Genet 107:1500-1504 
Yahiaoui N, Srichumpa P, Dudler R, Keller B (2003) Genome analysis at different ploidy levels allows cloning of the powdery mildew resistance gene $P m 3 b$ from hexaploid wheat Plant J 37:528-538

Yan GP, Chen XM, Line RF, Wellings CR (2003a) Resistance gene-analog polymorphism markers co-segregating with the Yr5 gene for resistance to wheat stripe rust. Theor Appl Genet 106:636-643

Yan L, Loukoianov A, Tranquilli G, Helguera M, Fahima T, Dubcovsky J (2003b) Positional cloning of the wheat vernalization gene VRN1. Proc Natl Acad Sci USA 100:6263-6268

Yano M, Katayose Y, Ashikari M, Yamanouchi U, Monna L, Fuse T, Baba T, Yamamoto K, Umehara Y, Nagamura Y et al (2000) Hd1, a major photoperiod sensitivity quantitative trait locus in rice, is closely related to the Arabidopsis flowering time gene CONSTANS. Plant Cell 12:2473-2483

Yu J, Hu S, Wang J, Wang G, Li SG, Wong KSG, Liu B, Deng Y, Dai L, Zhou Y, Zhang X et al (2002) A draft sequence of the rice genome (Oryza sativa L ssp. indica). Science 296:79-92

Yu M-Q, Yan NH, Ma XR, Deng GB, Yang XJ, Chen J (2003) Development of SCAR marker for root-knot nematode resistance gene Rkn-mn1 in wheat. In: Pogna NE, Romano M, Pogna EA, Galterio G (eds) Proc 10th Int Wheat Genet Symp, Paestum, Italy, pp 1292-1294

Yu J-K, La Rota M, Kantety RV, Sorrells ME (2004a) EST-derived SSR markers for comparative mapping in wheat and rice. Mol Gen Genom 271:742-751

Yu J-K, Dake TM, Singh S, Benscher D, Li W, Gill BS, Sorrells ME (2004b) Development and mapping of EST-derived simple sequence repeat markers for hexaploid wheat. Genome 47:805-818

Zaharieva M, Santoni S, David J (2001) Use of RFLP markers to study genetic diversity and to build a core-collection of the wild wheat relative Ae-geniculata Roth (= Ae-ovata L). Genet Selec Evol 33:S269-S288

Zanetti S, Winzeler M, Keller M, Keller B, Messmer M (2000) Genetic analysis of pre-harvest sprouting resistance in a wheat $\times$ spelt cross. Crop Sci 40:1406-1417
Zeller FJ, Kong L, Hartl L, Mohler V, Hsam SLK (2002) Chromosomal location of genes for resistance to powdery mildew in common wheat (Triticum aestivum $\mathrm{L}$ em Thell) 7. Gene Pm29 in line Pova. Euphytica 123:187-194

Zhang HN, Nasuda S, Endo TR (2000) Identification of AFLP markers on the satellite region of chromosome $1 \mathrm{BS}$ in wheat. Genome 43:729-735

Zhang XY, Li CW, Wang LF, Wang HM, You GX, Dong YS (2002) An estimation of the minimum number of SSR alleles needed to reveal genetic relationships in wheat varieties. I. Information from large-scale planted varieties and cornerstone breeding parents in Chinese wheat improvement and production. Theor Appl Genet 106:112-117

Zhang L, Sourdille P, Bernard M, Madeore A, Bernard S (2003a) QTL mapping for anther culturability in wheat using a doubled-haploid mapping population. In: Pogna NE, Romano M, Pogna EA, Galterio G (eds) Proc 10th Int Wheat Genet Symp, Paestum, Italy, pp 1078-1080

Zhang XY, You GX, Wang LF (2003b) An estimation of the minimum number of SSR alleles needed to reveal genetic relationships in wheat varieties: information from 96 random accessions with maximized genetic diversity. In: Pogna NE, Romano M, Pogna EA, Galterio G (eds) Proc 10th Int Wheat Genet Symp, Paestum, Italy, pp 545-548

Zhang D, Choi DW, Wanamaker S, Fenton RD, Chin A, Malatrasi M, Turuspekov Y, Walia H, Akhunov ED, Kianain P et al (2004) Construction and evaluation of cDNA libraries for large-scale expressed sequence tag sequencing in wheat (Triticum aestivum L.). Genetics 168:595-608

Zhou WC, Kolb FL, Bai GH, Shaner G, Domier LL (2002) Genetic analysis of scab resistance QTL in wheat with microsatellite and AFLP markers. Genome 45:719-727

Zhou WC, Kolb FL, Bai GH, Domier LL, Boze LK, Smith NJ (2003) Validation of a major QTL for scab resistance with SSR markers and use of marker-assisted selection in wheat. Plant Breed 122:40-46 